\title{
DISCHARGE COEFFICIENTS OF SQUARE-EDGED ORI- FICES FOR MEASURING THE FLOW OF AIR
}

\author{
By H. S. Bean, E. Buckingham, and P. S. Murphy
}

ABSTRACT

1. Air at pressures between 1 and 13 atmospheres was passed through squareedged concentric orifices installed in long, straight pipes of 4,6 , and 8 inches nominal diameter, the three pipes being in series. At each orifice the temperature and static pressure were observed, and the fall of pressure through the orifice was measured between pairs of taps located in each of the three ways commonly adopted in commercial orifice meter practice.

2. The rate of flow was measured by throttling the air nearly to atmospheric pressure and discharging it through a flow nozzle on the end of the line. The design, calibration, and peculiarities of bchavior of the nozzles are described, and the theory of this method of measurement is discussed in two appendixes. Such nozzles appear to be very satisfactory for use as primary standards.

3. The various quantities known as discharge coefficients and used in orifice meter computations are defined.

4. The experimental results are represented by equations connecting the values of the discharge coefficients with the ratio of orifice to pipe diameter and with the ratio of downstream to upstream static pressure. Tables of numerical values of discharge coefficients are also given.

5. The accuracy of the results and the limitations to their general applicability are discussed.

\section{CONTENTS}

I. Introduction

II. General plan of the investigation

III. Orifice plates

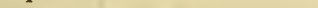

IV. Compressors and test line

V. Orifice stations

VI. Apparatus for measuring the rate of discharge $\ldots \ldots \ldots \ldots 7$

VII. Measurement of the rate of discharge

VIII. Remarks on flow nozzles_._.

IX. Discharge coefficients of orfices for liquids__._. 571

X. Discharge coefficients of orifices for gases____._. 578

XI. Outline of the methods of computation 581

XII. Location of the pressure taps_._. 584

1. Pipe taps._... 584

2. Throat taps._. 585

3. Flange taps_. 585

XIII. Method of analyzing the results

XIV. Results for throat taps..... 588

$\mathrm{XV}$. Comments on the results for throat taps..... 594

XVI. Results for flange taps_._._. 595 
XVII. Comments on the results for flange taps

XVIII. Results for pipe taps.

XIX. Comments on the results for pipe taps.

$\mathrm{XX}$. Comparison of the three sets of results

XXI. Specimens of the experimental results

XXII. Comments on the data in Tables 19 to 22

1. Mean values of $\delta$

2. Scattering of observed points

XXIII. Discussion of the accidental errors

XXIV. The effects of viscosity

XXV. Geometrical similarity and the influence of pipe diameter

XXVI. Equations for use in orifice meter computations.

XXVII. Numerical examples

XXVIII. Remarks on metering other gases.

XXIX. Summary of conclusions

A. Theory of the flow nozzle and the impact tube.-...

B. Discharge coefficients of the nozzles.........

C. Similar orifices

\section{INTRODUCTION}

During the summers of 1922,1923 , and 1924 experiments on the flow of air through orifices of the type commonly used for metering gases were carried out at Edgewood, Md., as a cooperative project between the Chemical Warfare Service of the United States Army and the Bureau of Standards. The authorities of Edgewood Arsenal contributed the use of a bank of large ammonia compressors with their appurtenances, and of much other engineering material, tools, etc.; and, in addition to furnishing the power needed, they facilitated the work in every way possible. The installation of the piping, apparatus, and instruments and the taking of observations were carried out by members of the staff of the Bureau of Standards.

This paper contains a brief description of the apparatus and methods employed and presents a summary of the more important results of the investigation, together with such comments and discussion as seem appropriate. Several matters which required more extended discussion than appeared desirable in the body of the paper have been treated in appendixes.

\section{GENERAL PLAN OF THE INVESTIGATION}

In regard to any one orifice, the object of the experiments is to determine the relation between the rate of discharge of air through the orifice, on the one hand, and the temperature and static pressure of the air and the pressure drop or differential across the orifice, on the other. If this relation has been determined and expressed in simple form, the rate of discharge may thereafter be found, by computation or graphically, from observations of the temperature, 
static pressure, and differential, and the orifice may thus be utilized as a flow meter for air.

The purpose of the investigation was to obtain experimental data from orifices of various sizes and proportions, working over a wide range of static pressures and rates of flow, so as to get as much systematic general information regarding the properties and behavior of such orifices as was practicable with the facilities and in the time at our disposal.

The circumstances which permitted of using large volumes of air and high static pressures, so as to cover a wide range of working conditions, entailed the disadvantage - which attaches to most large scale as contrasted with laboratory experiments-of making it impossible to secure high precision in the individual experiments. To offset this, the methods adopted made it practicable to work rapidly and make a large number of separate experiments so as, in some degree, to average out the accidental errors.

The principle of the experiments is very simple. A steady stream of compressed air is sent along the pipe in which the orifice to be tested is installed; the temperature, static pressure, and differential are observed by means of instruments near the orifice; and at the same time the rate at which air is flowing along the pipe and through the orifice is measured by some independent means, either ahead of the orifice or farther along the line.

The most obvious method of measurement is to discharge the air into a gas holder and measure the rate of rise, but since no holder of sufficient size was available the rate of discharge was determined by means of flow nozzles, as will be explained later. If the flow of air is not perfectly steady, the capacity between the orifice and the flow nozzle on the end of the line introduces a time lag, so that, though the measurement of the rate of discharge from the nozzle may be accurate, it does not correspond exactly in time to the observations made simultaneously at the orifice. Accidental errors of this sort were unavoidable because the power supply to the compressors was not perfectly steady, and the speed of the compressors could not be held entirely constant.

\section{ORIFICE PLATES}

The orifices to be reported on here were all of the most familiar type-round, concentric with the pipe, and square-edged at the upstream face of the plate. They were adapted for use in pipes of 8,6 , and 4 inches nominal diameter, and the list in Table 1 gives some of their important dimensions.

gilt to gribsed and it 
TABLE 1.- List of orifice plates

$D=$ inside diameter of pipe in inches.

$d=$ diameter of orifice in inches.

e. $w .=$ width of cylindrical edge of orifice in inches.

$d / D=\beta=$ diameter ratio.

-e. $w . / d=$ edge-width ratio.

[Letters in column 5 denote the owners of the borrowed plates, as follows: $B$, Bachrach Instrument Co.; $C$, Chemical Warfare Service; $F$, Foxboro Co.; $H$, Hope Natural Gas Co.; $M$, Metric Metal Works]

\begin{tabular}{|c|c|c|c|c|}
\hline Diameter of pipe $D$ (inches.) & $\begin{array}{l}\text { Serial } \\
\text { number- } \\
\text { of plate }\end{array}$ & $\begin{array}{c}\begin{array}{c}\text { Diameter } \\
\text { ratio }\end{array} \\
\quad \frac{d}{D}=\beta\end{array}$ & $\begin{array}{l}\text { Edge- } \\
\text { width } \\
\text { ratio } \\
\frac{e . w}{d}\end{array}$ & $\begin{array}{l}\text { Owner } \\
\text { of plate }\end{array}$ \\
\hline 1 & 2 & 3 & 4 & 5 \\
\hline 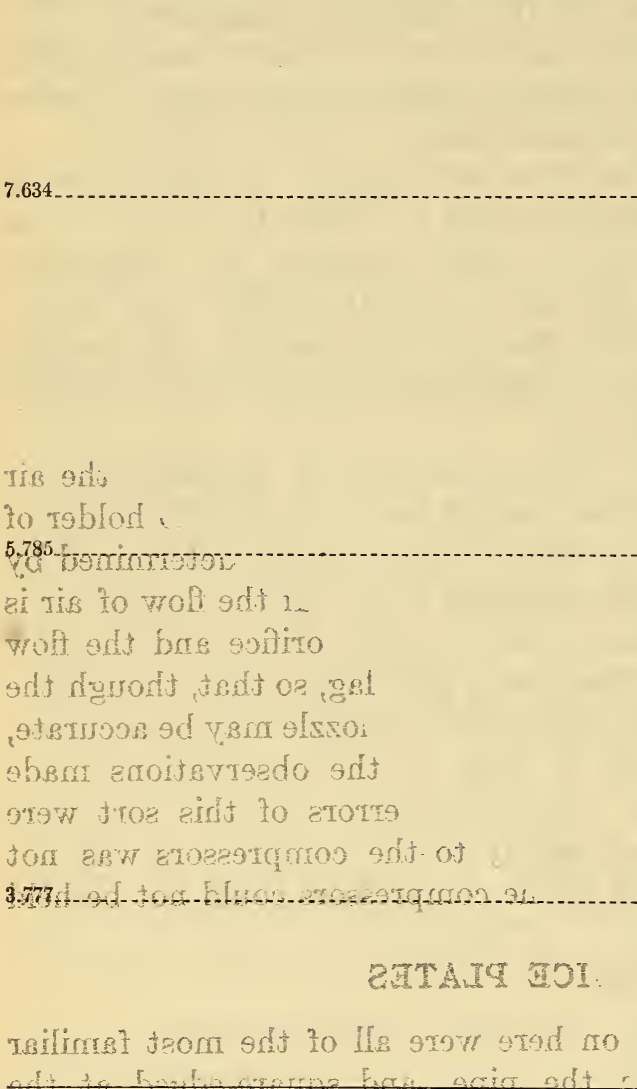 & $\begin{array}{r}1-8 \\
2-8 \\
3-8 \\
4-8 \\
5-8 \\
6-8 \\
7-8 \\
8-8 \\
9-8 \\
10-8 \\
11-8 \\
12-8 \\
13-8 \\
14-8 \\
15-8 \\
16-8 \\
17-8 \\
1-6 \\
12-6 \\
2-6 \\
3-6 \\
4-6 \\
5-6 \\
6-6 \\
7-6 \\
8-6 \\
9-6 \\
10-6 \\
11-6 \\
12-6 \\
13-6 \\
14-6 \\
15-6 \\
1-4 \\
12-4 \\
3-4 \\
4-4 \\
5-4 \\
6-4 \\
7-4 \\
8-4 \\
9-4 \\
10-4 \\
11-4 \\
12-4 \\
13-4 \\
14-4 \\
15-4 \\
16-4\end{array}$ & $\begin{array}{l}0.1308 \\
.1961 \\
.2050 \\
.2613 \\
.2778 \\
.3931 \\
.3936 \\
.3960 \\
.4015 \\
.4996 \\
.5245 \\
.5254 \\
.5580 \\
.5980 \\
.7042 \\
.7847 \\
.8023 \\
.1080 \\
.192 \\
.2636 \\
.3026 \\
.3453 \\
.411 \\
.497 \\
.5180 \\
.5190 \\
.562 \\
.605 \\
.630 \\
.6094 \\
.780 \\
.801 \\
.1992 \\
.2642 \\
.2651 \\
.2651 \\
.3256 \\
.3977 \\
.3982 \\
.5295 \\
.5305 \\
.5944 \\
.6125 \\
.6624 \\
.6651 \\
.8277 \\
.8578\end{array}$ & $\begin{array}{l}0.128 \\
.085 \\
.090 \\
.064 \\
.061 \\
.043 \\
.010 \\
.042 \\
.046 \\
.031 \\
.008 \\
.032 \\
.030 \\
.028 \\
.024 \\
.021 \\
.021 \\
.212 \\
.123 \\
.084 \\
.067 \\
.065 \\
.048 \\
.047 \\
.043 \\
.042 \\
.039 \\
.037 \\
.009 \\
.033 \\
.032 \\
.007 \\
.186 \\
.084 \\
.067 \\
.124 \\
.036 \\
.105 \\
.093 \\
.021 \\
.129 \\
.036 \\
.058 \\
.056 \\
.012 \\
.049 \\
.038 \\
.040\end{array}$ & $\begin{array}{c}\text { M. } \\
\text { H. } \\
\text { M. } \\
\text { H. }\end{array}$ \\
\hline
\end{tabular}

10 Of these 48 plates, 22 were made at the Bureau of Standards, while the others were loaned to us by the five organizations named in the heading of the table, to all of whom we wish to express our thanks.

The bureau plates were made with great care, and the inclusion of the commercial plates increased the interest of the results by show- 
ing that, as a general rule, the behavior of the commercial plates did not differ appreciably from that of similar plates made at the bureau.

The plates were all in good condition, with the corner between the flat upstream face of the plate and the cylindrical edge of the orifice approximately square and smooth. Microscopic examination showed in many cases that this entrance corner was by no means perfect, but with few exceptions the experiments failed to reveal differences of behavior that could be traced to these visible imperfections of finish.

The 12 plates loaned by the Metric Metal Works were $1 / 4$ inch thick and were chamfered on the downstream side so as to leave the cylindrical edge of the orifice only $1 / 8$ inch wide. Of the 4 plates loaned by the Hope Natural Gas Co., the two larger were $3 / 4$ inch

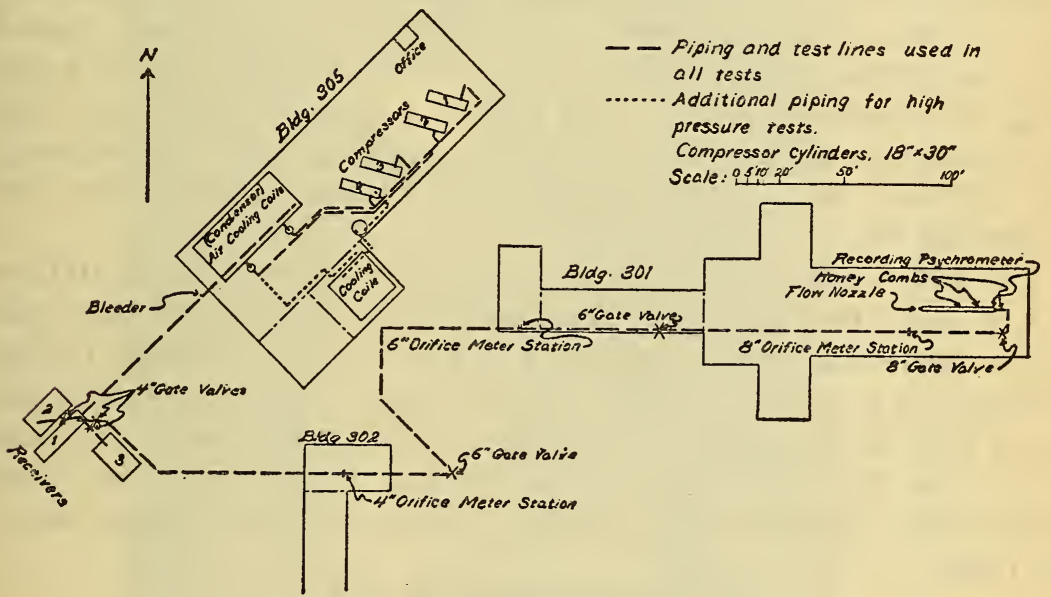

FIG. 1.-Arrangement of piping for orifice meter tests

Located in part of $155 \mathrm{~mm}$ gas shell filling plant of Edgewood Arsenal, Md.

thick and the two smaller $1 / 4$ inch. All 4 were chamfered so as to leave the cylindrical edge of the orifice about $\frac{1}{32}$ inch wide. All the other plates were flat on both sides with the hole bored straight through, the thicknesses of the plates being $\frac{5}{32}$ inch or less.

\section{COMPRESSORS AND TEST LINE}

The general arrangement and approximate dimensions of the experimental installation are shown in Figure 1.

Air was supplied by one or more of a set of four 18 by 30 inch ammonia compressors which had a maximum combined output of about 30 cubic feet of free air per second. In most cases the gauge pressure in the test line was limited to $75 \mathrm{lbs} . / \mathrm{in} .{ }^{2}$ at the first orifice, but a number of runs were also made at pressures up to $275 \mathrm{lbs} . / \mathrm{in} .^{2}$ 
For these high-pressure runs the compressors were compounded, so that three working in parallel discharged through an intercooler to the fourth, acting as a second stage.

From the compressors to the first, or 4-inch orifice station, the air passed successively through: (a) Two oil traps of 60 cubic feet capacity, (b) a bank of ammonia condenser coils, (c) 100 feet of 4-inch pipe, (d) a receiver of 450 cubic feet capacity, and (e) 130 feet more of 4-inch pipe. This pipe, as well as the following 6 and 8 inch sections of the line, was "extra heavy." The lengths and volumes stated above are, of course, only approximate.

Any desired number of the 48 sections of the condenser coils could be cut out so as to change the resistance, and by this means, together with adjustment of a valve at the outlet from the receiver, a pressure drop of from 10 to $15 \mathrm{lbs}$./in. ${ }^{2}$ was maintained between the compressor outlet and the first orifice station. This resistance, in conjunction with the capacities mentioned, was sufficient to prevent any appreciable compressor pulsations from reaching the orifices. In the beginning, two further receivers with a total volume of 2,300 cubic feet were connected to the smaller receiver as additional steadying capacity, but they were found to be unnecessary and were shut off to save time in starting up.

The 4-inch orifice station was followed by somewhat over 400 feet of 4,6 , and 8 inch pipe, with the 6 and 8 inch stations and three gate valves, located as shown in Figure 1. The terminal section of the line consisted of a 30 -foot length of 36-inch pipe, and on the end of this was a flow nozzle through which the air finally escaped. The parts of the line which were not under cover were shielded from direct sunshine by semicylindrical sections of cork insulation laid on top of the pipe.

\section{ORIFICE STATIONS}

Except for the difference of pipe diameter all three orifice stations were much alike. Figure 2 is a view of the 8 -inch station. The 4 and 8 inch flanges for holding the orifice plates were kindly loaned to us by the Hope Natural Gas Co., and the 6-inch pair was made at the Bureau of Standards.

The side holes for pressure connections, provided at various distances from the orifice plate, were tapped with $1 / 8$-inch standard threads, and after the internal burr had been removed, brass connectors were screwed in, care being taken that they did not project beyond the inner surface of the pipe. All the upstream holes were connected to a single header through $\frac{5}{16}$-inch copper tubing, each lead including a valve so that any one hole could be used by itself. The downstream holes were similarly connected to a second header, the two headers were connected to the differential gauge, and either header could be connected to the static pressure gauge. 





B. S. Journal of Research, RP49

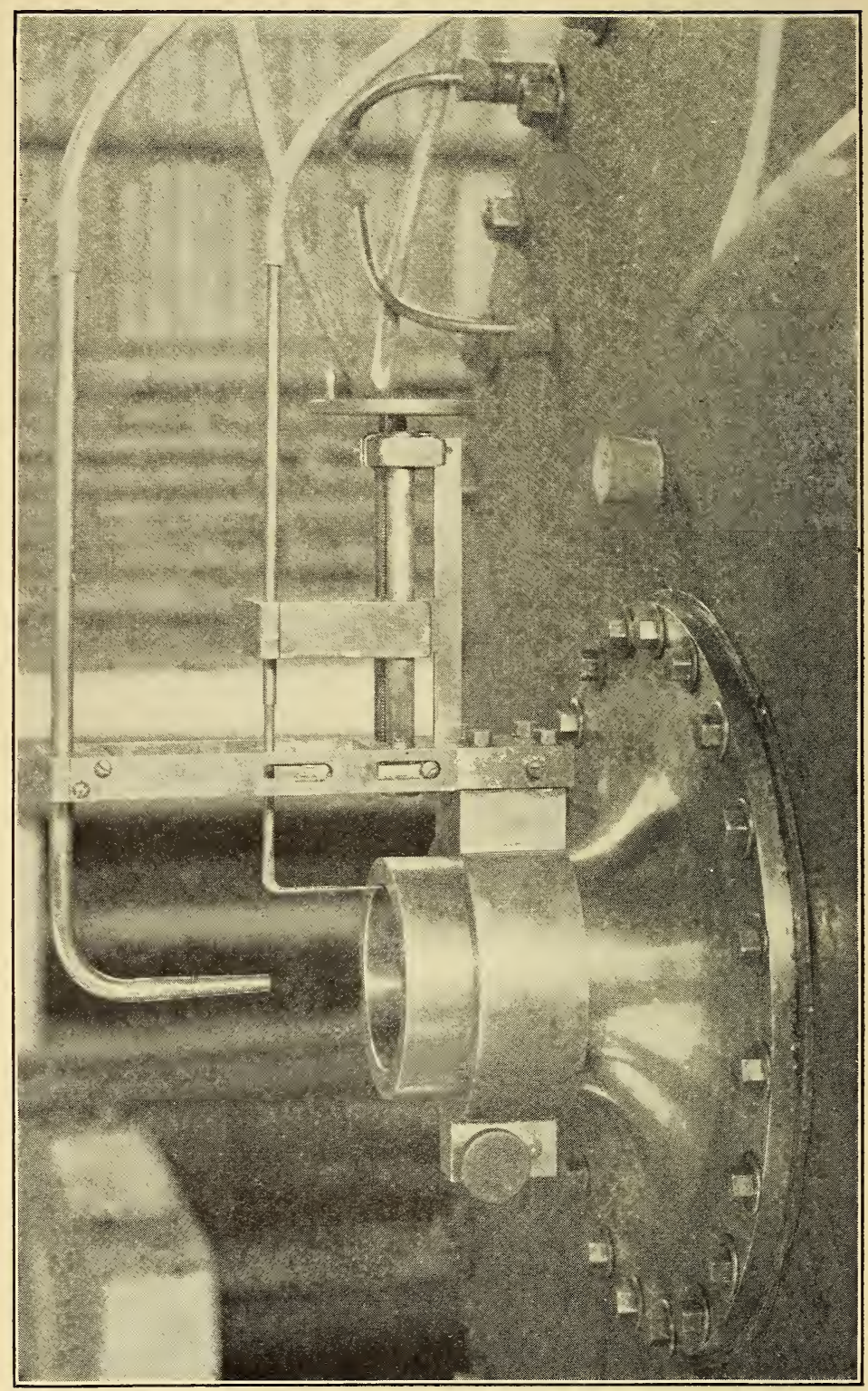

FIG. 3.-Discharge nozzle and impact tips 
The distance from the center of each side hole to the face of the nearer flange was measured, once for all. A punch mark was made on the flange, and its distance from the face was also measured, the marks on the two flanges being on a line parallel to the axis of the pipe. After a plate of known thickness had been inserted and the bolts drawn up, a measurement of the distance between the two punch marks gave the combined thickness of the two gaskets; and on the permissible assumption that the gaskets were of sensibly equal thickness, the distance of any hole from the upstream face of the orifice plate could be computed.

Static pressures above 100 inches of mercury were read on standardized Bourbon gauges and lower pressures on mercury $U$-tube manometers. Differentials were read on U-tube manometers containing water, carbon tetrachloride, or mercury.

Wells containing mercurial thermometers were located about 12 pipe diameters upstream and downstream from the orifice plate. They had fins to increase the surface in contact with the air flowing along the pipe.

Thermometers were hung in suitable places for giving the approximate temperatures of the manometer columns, so that temperature corrections could be applied when needed.

\section{APPARATUS FOR MEASURING THE RATE OF DISCHARGE}

The rate of flow of air along the line was measured by means of a nozzle and impact tube, according to the method described by S. A. Moss. ${ }^{1} \quad$ Figure 1 shows the position of the 36-inch pipe or discharge trunk in relation to the test line, and Figure 3 shows the end of the trunk with a nozzle and impact tubes in place.

Inside the trunk a mercurial thermometer gave the temperature of the air approaching the nozzle, and a recording psychrometer near the entrance end furnished data for finding the humidity. Two honeycombs were used to straighten and regularize the flow along the trunk toward the nozzle.

The large impact tip shown in Figure 3 was $1 / 4$ inch in diameter and was fixed on the axis of the jet about $2 \frac{1}{2}$ inches out from the end of the nozzle. It was connected to one leg of an open, vertical manometer containing water or oil which served to measure the impact pressure at the center of the jet, and it could also be connected to one leg of an inclined manometer which was employed during calibration.

The small impact tip, about 0.02 inch in diameter, was mounted on a radial cross slide and could be traversed along any radius of the jet, just clearing the end of the nozzle. A scale and vernier permitted of determining its distance from the axis of the nozzle. This small

1 Trans. Am. Soc. Mech. Engs., 38, p. 761; 1916. 
tip was used only for calibrating the nozzle, and during this operation it was connected to the other leg of the inclined manometer mentioned above. By traversing the small impact tip along various radii of the jet and taking readings of the inclined manometer, while the impact pressure at the large fixed tip remained constant, the distribution of impact pressure over the area of the mouth of the nozzle could be determined.

A mercurial barometer was provided for reducing observed gauge pressures to absolute pressures when necessary.

Nine nozzles were prepared for the investigation and were calibrated, but most of the observations on rates of discharge were made

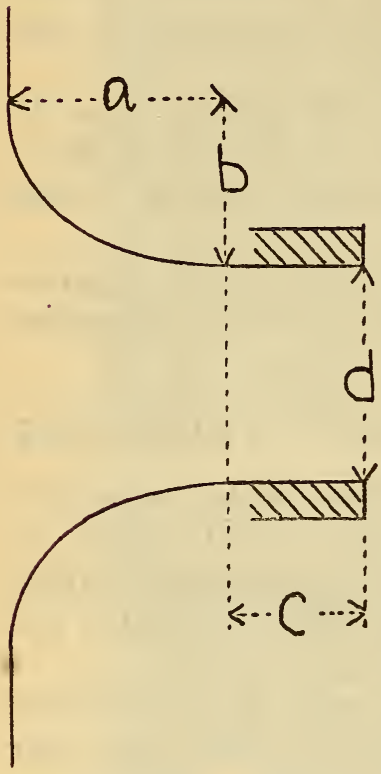

Fig. 4.-Proportions of with only four of them. They were of cast bronze smoothly finished and polished inside. The entrance curve leading to the cylindrical throat was a quarter-ellipse with a diameter ratio of 2 to 3 , except in one case, where it was a quarter-circle. Table 2 contains a list of the nozzles, with their throat diameters and the approximate ratios of their other dimensions to the throat diameters, the notation being given in Figure 4 .

TABLE 2.-Dimensions of flow nozzles

\begin{tabular}{|c|c|c|c|c|}
\hline Nozzle & $d$ & $\frac{c}{d}$ & $\frac{a}{d}$ & $\frac{b}{d}$ \\
\hline 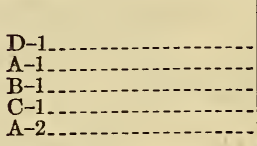 & $\begin{array}{c}\text { Inches } \\
1.764 \\
3.255 \\
4.206 \\
5.006 \\
3.262\end{array}$ & $\begin{array}{l}1 \\
1 \\
1 \\
1 \\
1 / 2\end{array}$ & $\begin{array}{l}1 \\
1 \\
1 \\
1 \\
1\end{array}$ & $\begin{array}{l}2 / 3 \\
2 / 3 \\
2 / 3 \\
2 / 3 \\
2 / 3\end{array}$ \\
\hline $\begin{array}{l}\mathrm{B}-2 \\
\mathrm{C}-2 \\
\mathrm{~A}-3 \\
\mathrm{~A}-4\end{array}$ & $\begin{array}{l}\text { 4. } 521 \\
\text { 5. } 003 \\
\text { 3. } 272 \\
\text { 3. } 258\end{array}$ & $\begin{array}{l}1 / 2 \\
1 / 2 \\
1 \\
1\end{array}$ & $\begin{array}{l}1 \\
1 \\
1 \\
2 / 3\end{array}$ & $\begin{array}{l}\frac{2 / 3}{2 / 3} \\
1^{2 / 3}\end{array}$ \\
\hline
\end{tabular}

\section{MEASUREMENT OF THE RATE OF DISCHARGE}

Air from the test line entered the discharge trunk and after passing through the two honeycombs it approached the nozzle in a slow, regular stream at a speed of not over $4.2 \mathrm{ft}$./ $/ \mathrm{sec}$. It then expanded to the outside barometric pressure and issued from the parallel-sided mouth of the nozzle as a cylindrical jet at a speed between fifty and four hundred times the speed of approach.

In such a jet the impact pressure is uniform all over the middle part. Near the wall of the nozzle skin friction retards the motion and the impact pressure falls off; but this influence of the wall does 
not reach far into the jet because with a short nozzle and high air speed there is no time for it to do so, and the uniform central core of the jet is not affected by it.

From the uniformity of the impact pressure we may conclude that the fall of pressure and the increase of speed have taken place in the same way for all filaments of the core, and that since these filaments have not been affected by proximity to the wall of the nozzle the flow in them has been unresisted and adiabatic; that is, isentropic. The ideal conditions presupposed in the familiar thermodynamic theory of the formation of jets of gas are therefore satisfied, in the core, to a high degree of approximation, and the theoretical equations may be relied upon for computing the rate of discharge per square inch of cross section of the core as is discussed in Appendix A.

The observational data needed for this are theoutside barometric pressure, the pressure drop or differential through the nozzle, and the temperature and humidity of the air approaching along the trunk.

The pressure drop through the nozzle is obtained from the central impact tip. If this tip is connected to one leg of the vertical water manometer while the other leg is connected to a static side hole in the wall of the trunk, the manometer shows no difference of pressure. Strictly speaking, it gives the impact pressure of the air moving along the trunk, but this was never more than about 0.004 inch of water and was inappreciable. This relation holds quite accurately-certainly to better than 1 part in 1,000-up to the speed of sound or the critical pressure ratio, though not beyond.

It follows from the foregoing that the pressure in the central impact tip is equal to the pressure of the air ahead of the nozzle in the trunk, so that its excess over the outside barometric pressure, as read on the open manometer, is the same thing as the pressure drop which is driving the air through the nozzle.

The theoretical equation gives the rate of discharge per square inch of section of the core, and if there were no skin friction and the uniform core filled the whole section of the mouth of the nozzle, the total rate of discharge could be found by multiplying the rate per square inch in the core by the measured area of the nozzle mouth, expressed in square inches. The actual rate of discharge is, of course, somewhat less than this because the core does not fill the whole nozzle but is surrounded by a nonuniform sheath in which the speed falls off toward the wall. The actual total rate of discharge is therefore the product of the theoretical rate by a discharge coefficient which is slightly less than unity and the value of which is determined by calibration.

Observations with the small, movable impact tip serve to determine how the speed falls off toward the wall, and when the distribution of 
speed in the nonuniform sheath is known, the discharge coefficient can be computed. The process will be further discussed in Appen$\operatorname{dix} B$.

\section{REMARKS ON FLOW NOZZLES}

The smoother the internal surface of the nozzle the less will be the tangential retarding drag of skin friction and the nearer will the discharge coefficient be to unity. With a given quality of surface, a large nozzle is relatively smoother than a small one; hence it is to be expected that if the surfaces are finished with equal care, large nozzles will, in general, have higher discharge coefficients than smaller ones of the same shape. This rule may, however, be subject to frequent exceptions, for smoothness of finish is difficult to reproduce at all exactly, and rather small variations in the internal finish of a nozzle may have an appreciable effect on the discharge coefficient.

If the linear speed of the air is increased, each individual particle of air takes less time to pass through the nozzle, and there is less time for the retarding effect of the drag at the wall to be propagated inward toward the center of the jet. The diameter of the uniform core therefore increases, and the discharge coefficient of the nozzle increases with the linear speed of the jet; that is, with the rate of discharge or with the impact pressure in the core.

This variation with speed is quite appreciable, especially at low speeds, and the discharge coefficients of such flow nozzles as were used in this investigation can not be treated as constants except over short ranges of speed. The results of the calibration experiments were represented by curves showing the relation of the discharge coefficient to the central impact pressure, and each time that a nozzle was used to measure the rate of flow of air along the test line, the value of the discharge coefficient to be used in the computations was read from the curve for this nozzle, at the impact pressure observed in the large central impact tip.

An idea of the magnitude of the above-mentioned variations of the discharge coefficient with diameter and impact pressure may be obtained from Table 3 . This table contains values of the discharge coefficient read from the calibration curves of the four nozzles which were used in most of the orifice tests, at impact pressures of $h=1,2$, 5,12 , and 30 inches of water, corresponding to linear speeds of about $66,94,150,230$, and $360 \mathrm{ft}$./sec.

TABLE 3.-Discharge coefficients of nozzles

\begin{tabular}{|c|c|c|c|c|c|c|}
\hline \multirow{2}{*}{ Nozzle } & \multirow{2}{*}{$\begin{array}{l}\text { Throat } \\
\text { diameter } \\
\text { (inches) }\end{array}$} & \multicolumn{5}{|c|}{ Discharge coefficient at- } \\
\hline & & $h=1 \mathrm{inch}$ & $h=2$ inches & $h=5$ inches & $h=12$ inches & $h=30$ inches \\
\hline 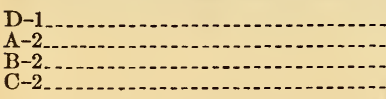 & $\begin{array}{l}\text { 1. } 764 \\
\text { 3. } 262 \\
\text { 4. } 521 \\
\text { 5. } 003\end{array}$ & $\begin{array}{r}0.980 \\
.983 \\
.989 \\
.991\end{array}$ & $\begin{array}{l}0.983 \\
.985 \\
.992 \\
.992\end{array}$ & $\begin{array}{r}0.986 \\
.988 \\
.994 \\
.994\end{array}$ & $\begin{array}{r}0.989 \\
.991 \\
.995 \\
.995\end{array}$ & $\begin{array}{r}0.991 \\
.994 \\
\\
\hdashline\end{array}$ \\
\hline
\end{tabular}


The expectation that for similarly finished nozzles the discharge coefficient will increase with the diameter is seen to be confirmed for these nozzles. The values in the table also conform to the rule that the discharge coefficient of a nozzle increases with the rate of discharge, and this gradual increase of the discharge coefficient, as the uniform core of the jet fills a larger and larger fraction of the cross section of the mouth of the nozzle, may be regarded as the normal course of affairs for a nozzle which is suitably designed for the rates of discharge which it is intended to measure; but exceptions to this normal behavior may occur if the approach to the cylindrical throat is too sharply curved. At the entrance end of the nozzle, where the cross section is large and the speed low, the degree of curvature is of little importance; but upon approaching the throat the speed increases and the permissible curvature becomes less.

The curvature of the path of the particles of fluid near the wall of the nozzle gives rise to a centrifugal force directed inward and causes a decrease of pressure near the wall. In the case of a liquid, this may result in a detachment of the jet from the wall, so that the jet contracts and no longer fills the nozzle; and in the case of air, the result is to decrease the diameter of the uniform core at the mouth of the nozzle and so decrease the discharge coefficient.

Since the centrifugal force directed away from the curved wall toward the axis of the nozzle depends on both the curvature of the path and the linear speed along it, both of these are of importance. With a given nozzle, the discharge coefficient may increase with the rate of discharge up to a certain point; but then, if the rate of discharge is increased still more, the effect of too great curvature of the wall may begin to make itself evident by a decrease of the discharge coefficient.

This is what was observed with nozzles A-3 and A-4. With A-3 the earlier part of the calibration curve was of normal shape and very like the curves for the other nozzles, but when the impact pressure had reached about 8 inches of water the discharge coefficient began to fall slowly instead of continuing to increase. With nozzle A-4, in which the curvature near the beginning of the cylindrical throat was considerably sharper, this effect was much more marked and began earlier-when the impact pressure or the drop through the nozzle was only 5 or 6 inches of water.

Calibration curves for all the flow nozzles are given in Appendix B, Figure 12 .

\section{DISCHARGE COEFFICIENTS OF ORIFICES FOR LIQUIDS}

The most generally useful method of describing the results of such experiments as those now in question is to state the numerical values of the discharge coefficients obtained, and that plan is adopted here. 
But a discharge coefficient may be defined in various ways, and the value obtained from a given set of observations depends on how the coefficient is defined; hence, unless this is clearly understood, a table of discharge coefficients has no precise meaning and is useless. It is, therefore, advisable to discuss the meaning of the term "discharge coefficient" somewhat fully.

The differential set up by a fluid flowing through an orifice depends on the density of the fluid as well as on the rate of flow. The density of an ordinary liquid is so little affected by changes of pressure that it may be treated as constant, but the density of a gas depends on the temperature and static pressure in the pipe and, furthermore, it decreases as the gas passes through the orifice from a higher to a lower pressure. For this reason the behavior of gases is somewhat less simple than that of liquids, and it seems well to discuss liquids first.

Let it be supposed that we have means for making a liquid of known density, such as water, flow steadily along a pipe and through an orifice installed in it; and that a pair of pressure taps and a differential gauge are provided for measuring the pressure drop, or differential, from the upstream to the downstream side of the orifice plate. Weighing or measuring tanks are also to be provided, so that the rate of discharge can be determined simultaneously with observations of the differential, and the relation between the two determined by experiments at various rates of flow, with various liquids and various orifices.

The result of such experiments on round, concentric, square-edged orifices has been to show that under most ordinary conditions: (a) The rate of discharge $M$ of a given liquid through a particular orifice is nearly proportional to the square root of the differential $\Delta$, or $M \propto \sqrt{\Delta}$, nearly; (b) if a given orifice is tested with liquids of different densities, the rate of discharge needed to set up a given differential is nearly proportional to the square root of the density $\rho$, or $M \propto \sqrt{\rho}$, nearly; $(c)$ if a larger or smaller orifice is substituted for the one first used, and if the pipe diameter $D$ and the distances of the pressure taps from the orifice plate are also increased or decreased in the same ratio as the orifice diameter $d$, the rate of discharge of any one liquid, at a given differential is nearly proportional to the area of the orifice, that is, to the square of its diameter $d$, or $M \propto d^{2}$, nearly.

These three conclusions from experiment may be summed up by the statement that if we write

$$
B=\frac{M}{d^{2} \sqrt{\rho \Delta}} \text { or } M=B d^{2} \sqrt{\rho \Delta}
$$


the value of $B$ is nearly the same for all rates of flow, for all liquids, and for all round, concentric, square-edged orifices of the same diameter ratio $d / D$, so long as the pressure taps are always placed in the same relative positions with respect to the orifice.

If the experiments are made on orifices of some other diameter ratio, a relation of the same form is obtained, but the value of $B$ is somewhat different, depending on the value of $d / D$; and if the location of the pressure taps is altered, the value of $B$ is again nearly constant but different from the previous value.

If $B$ were strictly constant under all circumstances, the result of the whole investigation could be stated by giving the one value found for $B$, and the rate of discharge in any future case could be found by substituting this value in (1), together with the known values of $d$ and $\rho$, and the observed differential $\Delta$. For an orifice of measured diameter, employed for metering a liquid of known density, the quantity

$$
B d^{2} \sqrt{\rho}=K
$$

would be a known constant, and the computation of the rate of discharge from the observed differential by means of the formula

$$
M=K \sqrt{\Delta}
$$

would be a very simple operation.

In reality, the three experimental relations stated above are not exact and $B$ is not always quite constant, even for a given diameter ratio and with given relative positions of the pressure taps. It may vary slightly with the absolute size of the orifice, the linear speed of flow, and the density and viscosity of the liquid; but under most conditions of ordinary orifice meter practice these variations are small, and for any one diameter ratio and a given location of the pressure taps $B$ may be treated as a constant.

It is evident from the foregoing that the results of an experimental study of the flow of liquids through any type of orifice, such as the square-edged orifice in a thin plate, might be made conveniently available for application to orifice meter calculations by means of tables or curves giving the values found for $B$, from which the value to be used in equation (1) in any particular case might be read off, either directly or by interpolation. This is, in substance, the method actually adopted, although the conventional presentation of the subject gives it a slightly different appearance and seems to attach more importance to an obviously very imperfect theory than is at all necessary. The conventional treatment runs about as follows:

The flow of a liquid through an orifice is a mechanical phenomenon and is, of course, subject to the general laws of mechanics; but the motion is so complicated that it is impossible to construct a 
complete mathematical theory for describing or accounting for all the details of what happens. Instead of attempting this, we limit ourselves to considering an ideal state of motion which bears some resemblance to the reality, though not a very close one, and which is simple enough that the rate of flow under the ideal conditions can be computed exactly from mechanical principles.

The ideal simplified state of motion is specified as one in which the following conditions are satisfied: (a) At the section where the upstream pressure tap is situated, the velocity is uniform and parallel to the axis of the pipe, and the static pressure is also uniform all over the section and equal to the pressure indicated by a gauge connected to the tap; $(b)$ at the smallest section of the orifice the velocity of the liquid is perpendicular to the plane of this section-that is, parallel to the axis of the pipe-and both the velocity and the static pressure are uniform all over the section; $(c)$ the pressure in the downstream pressure tap is equal to the uniform static pressure in the plane of the orifice; and $(d)$ there are no energy losses by turbulence, viscosity, or skin friction.

In the actual motion of a liquid through, an orifice installed in a pipe, conditions $a$ and $d$ are usually nearly fulfilled, and in these respects the ideal state of affairs does not differ very much from what really happens. Conditions $b$ and $c$ may also be nearly satisfied in practice, if the orifice has a well-rounded entrance or is in the form of a flow nozzle, and if the pressure taps are suitably placed. For such an orifice, the conditions presupposed in the theoretical reasoning are approximately satisfied, and the rate of discharge deduced for the ideal case is fairly close to the true rate found by experiment.

But with a square-edged orifice condition $b$ is far from satisfied. In the plane of the orifice the flow is convergent, and neither the velocity nor the static pressure is uniform; the jet is trumpet shaped, with its narrowest section or vena contracta considerably smaller than the orifice and some distance downstream, and the velocity and pressure are nearly uniform at the vena contracta instead of at the orifice. Condition $c$ loses its meaning when $b$ is not satisfied. The downstream pressure tap may be so placed as to give the pressure in the vena contracta; but it need not be, and often is not, so placed, and the pressure it gives depends to a considerable extent on where it is.

On the whole, it may be said that the ideal state of motion for which the theoretical deductions are exactly true, while it may be nearly realized for well-shaped flow nozzles, is not a good representation of the facts for square-edged orifices. It is therefore not surprising that the "theoretical" rate of discharge turns out to be 
quite different from the true rate in the case of square-edged orifices.

Turning, now, to the consideration of the ideal case, let-

$D$ [ins.] = the inside diameter of the pipe;

$d$ [ins.] = the diameter of the orifice;

$\beta=\frac{d}{D}=$ the diameter ratio of the orifice;

$\rho\left[\mathrm{lb} . / \mathrm{ft} .{ }^{3}\right]=$ the density of the liquid;

$\Delta\left[\mathrm{lb} . / \mathrm{in} .{ }^{2}\right]=$ the differential;

$S_{1}[\mathrm{ft} . / \mathrm{sec}]=$. the linear speed at the upstream tap;

$S_{2}[\mathrm{ft} . / \mathrm{sec}]=$. the linear speed through the orifice;

$M_{\mathrm{t}}[\mathrm{lb} . / \mathrm{sec}]=$. the theoretical rate of discharge;

$M[\mathrm{lb} . / \mathrm{sec}]=$. the actually observed rate;

$C=M / M_{\mathrm{t}}=$ the discharge coefficient of the orifice.

Since the rate of flow is the same past the upstream tap as through the orifice and the speed is uniform over each of these sections (conditions $a$ and $b$ ), we have

$$
M_{\mathrm{t}}=\frac{\pi}{4}\left(\frac{D}{12}\right)^{2} \rho S_{1}=\frac{\pi}{4}\left(\frac{d}{12}\right)^{2} \rho S_{2}
$$

whence

$$
S_{1}=\frac{d^{2}}{D^{2}} S_{2}=\beta^{2} S_{2}
$$

Since there are no energy losses (condition $d$ ), the increase of kinetic energy of each cubic foot of the liquid, as its speed increases from $S_{1}$ at the upstream tap to $S_{2}$ at the plane of the orifice, is equal to the work done on it by the pressure drop $\Delta$. Hence, measuring work and kinetic energy in standard foot pounds, we have

$$
\frac{\rho\left(S_{2}{ }^{2}-S_{1}{ }^{2}\right)}{2 \times 32.174}=144 \Delta
$$

or after eliminating $S_{1}$ by means of (5) and solving for $S_{2}$,

$$
S_{2}=96.261 \sqrt{\frac{\Delta}{\left(1-\beta^{4}\right) \rho}}
$$

Upon substituting this value of $S_{2}$ in (4), we have as the expression for the theoretical rate of discharge through the orifice

$$
M_{\mathrm{t}}=\frac{0.5250}{\sqrt{1-\beta^{4}}} d^{2} \sqrt{\rho \Delta}
$$


where $M_{\mathrm{t}}=\mathrm{lb} . / \mathrm{sec} . ; d=$ ins.; $\rho=\mathrm{lb} . / \mathrm{ft} .{ }^{3} ;$ and $\Delta=\mathrm{lb} / \mathrm{in}^{2}$.

The factor

$$
\frac{0.5250}{\sqrt{1-\beta^{4}}}
$$

is independent of the absolute size of the orifice and is a constant for all orifices of any one diameter ratio, so long as the units specified above are retained. A change of units would, in general, require a change in the figure 0.525 .

In some unusual circumstances the effects of the departures of the actual from the ideal motion of the liquid may offset one another in such a way that the theoretical rate of discharge computed from (9) agrees with the rate actually observed; but, in general, the two rates are different, often considerably different. The ratio of the two, or

$$
C=\frac{M}{M_{\mathrm{t}}}
$$

is known as the "discharge coefficient" of the orifice for the given liquid at the differential $\Delta$; and if (12) is written in the form

$$
M=C M_{\mathrm{t}}=C \frac{0.5250}{\sqrt{1-\beta^{4}}} d^{2} \sqrt{\rho \Delta}
$$

it states that when the discharge coefficient $C$ is known the true rate of discharge may be found by multiplying the theoretical rate by the discharge coefficient.

Upon comparing (13) with (1), we find that

$$
B=\frac{0.5250}{\sqrt{1-\beta^{4}}} C
$$

and $B$ differs from $C$ only by a constant factor, the value of which is determined by the units and the diameter ratio. Hence, what was said earlier regarding the approximate constancy of $B$ and the convenience of representing experimental results by tables of values of $B$ is equally applicable to the discharge coefficient $C$. Tables of either quantity may be transformed into tables of the other by means of (14) without further experiment.

The statement of results in terms of $C$ is the method most commonly adopted, and it has the advantage that $C$ is a pure ratio and therefore independent of the units in which rates of discharge are expressed, so long as the same unit is used for both $M$ and $M_{\mathrm{t}}$. On the other hand, the constant in (14) does depend on what units are used for $M, d, \rho$, and $\Delta$, and the same is therefore true of $B$. Accordingly, results stated in terms of $B$ would be directly applicable only to computations made in terms of a particular set of units, whereas a statement in terms of $C$ is applicable, whatever the units used. A further advantage of stating results in terms of the discharge coeffi- 
cient $C$ is that it conforms to established practice and so facilitates the comparison of new experimental results with data which may already have been published.

In leading up to the conception of the discharge coefficient, the first step was to specify an ideal state of motion of the liquid which was simple enough to be treated rigorously by the principles of mechanics. This led to equation (9) for the theoretical rate of discharge and to the definition of $C$ by (12). The result is satisfactory because, for a given liquid flowing through a given orifice, the discharge coefficient thus defined is nearly constant, so that equation (13) reduces to the very simple approximate form

$$
M=K \sqrt{\Delta}
$$

where $K$ is a known constant, to the same order of accuracy as $C$ itself is a known constant.

But there was no necessity of specifying the ideal motion in the particular way adopted, for any other ideal state of motion that was simple enough to be treated rigorously by theoretical principles might equally well have been selected. A different choice would have led to a different expression for the theoretical rate of discharge $M_{\mathrm{t}}$; and the discharge coefficient defined by (12), in conjunction with the equation for $M_{\mathrm{t}}$, would have had a different value. It is therefore evident that the discharge coefficient might be defined in various ways, and that the term "discharge coefficient" has no definite significance unless accompanied by a statement of how the "theoretical " rate of discharge is to be computed.

Since the procedure followed above leads to a satisfactorily simple result, there is no object in making a change unless it either simplifies the computation of $M_{\mathrm{t}}$ or leads to more nearly constant values of the discharge coefficient; and in practice, only one other definition of the discharge coefficient is in common use. It is arrived at by adding to the conditions already imposed on the ideal state of motion the further condition that the diameter of the pipe shall be treated as if very much larger than the diameter of the orifice, regardless of what the ratio of the two really is, thus departing still further from the actual state of motion.

Imposing this condition is equivalent to setting $\beta=0$ in the equations already obtained, without changing anything else, and we get the equations

$$
\begin{gathered}
M^{\prime}{ }_{\mathrm{t}}=0.5250 d^{2} \sqrt{\rho \Delta} \\
C^{\prime}=\frac{M}{M^{\prime}} \\
M=C^{\prime} M^{\prime}{ }_{\mathrm{t}}=C^{\prime} \times 0.5250 d^{2} \sqrt{\rho \Delta}
\end{gathered}
$$

in place of $(9,12,13)$. 
The quantity $C^{\prime}$ defined by $(16,17)$ may be called "the discharge coefficient with approach factor included," to distinguish it from $C$, which is "the discharge coefficient with approach factor not included." When the term "discharge coefficient" is used without qualification, it usually means $C$ and not $C^{\prime}$. Comparison of (18) with (13) shows that

$$
C=C^{\prime} \sqrt{1-\beta^{4}}
$$

so that either form of the discharge coefficient may readily be transformed into the other and a table of one is equivalent to tables of both.

When the diameter ratio $d / D=\beta$ is small, $C$ and $C^{\prime}$ are nearly equal, and it is unnecessary to distinguish them. For example, if $d=0.2 D, C=0.9992 C^{\prime}$. But if $d=0.5 D, C=0.9682 C^{\prime}$, and mistaking one for the other would result in an error of over 3 per cent.

\section{DISCHARGE COEFFICIENTS OF ORIFICES FOR GASES}

The subject of discharge coefficients may be discussed in the same general way for gases as for liquids. By specifying an ideal state of motion that.is simple enough for exact treatment on theoretical principles we find the rate at which the gas would flow through the orifice if the ideal conditions could be realized, and we then express the ratio of the actual to the theoretical rate as a discharge coefficient. If the orifice meter is to be a commercial and not merely a laboratory instrument, the computations must be simple, and the discharge coefficient must not vary too much with the rate of discharge; but, aside from these two requirements, the question whether the imaginary ideal motion bears any close resemblance to reality is of no importance whatever.

We start by imposing the same conditions as for liquids, regarding the distribution of velocity and pressure in the vicinity of the orifice and the absence of energy losses. But since the density of a gas depends on its pressure and temperature and changes as the gas flows through the orifice, the ideal state of motion requires further specification, either by making assumptions as to how the gas behaves or by imposing conditions as to how it shall behave in the ideal case.

The most obvious conditions to impose are that the gas shall follow the ideal gas equation $p v=R T$ exactly, and that it shall not gain or lose any heat by contact with the orifice plate or the walls of the pipe. These supplementary conditions, with those previously adopted for liquids, lead to the so-called "adiabatic equation" for the theoretical rate of discharge and to a corresponding definition of the discharge coefficient. This equation is important and useful for some purposes, but it is much too complicated to be used in ordinary practice and it need not be discussed here, though it will be referred to again later. 
For the sake of obtaining a simpler result we adopt a condition which makes the ideal state of motion to be treated by theoretical principles much more unlike what really happens, and this condition is that the density of the gas shall remain constant during the flow through the orifice instead of decreasing, as it does, in fact. But imposing this condition is merely saying that the gas shall act like a liquid, and therefore the reasoning to be gone through is an exact repetition of what has already been given for liquids, and the resulting equations are precisely the same in form.

Only one more point remains to be specified. Having said that the density shall be constant, we are still at liberty to say what the constant value shall be and to select any value that is most convenient. In practice, the choice is usually made in one of the two following ways.

Let

$p_{1}\left[\mathrm{lb} . / \mathrm{in} .{ }^{2}\right]=$ the absolute static pressure at the upstream pressure tap;

$p_{2}\left[\mathrm{lb} . / \mathrm{in} .{ }^{2}\right]=$ the absolute static pressure at the downstream pressure tap;

$t\left[^{\circ} \mathrm{F}.\right]=$ the temperature of the gas ahead of the orifice, just before the flow starts to converge;

$\rho_{1}\left[\mathrm{lb} . / \mathrm{ft} .{ }^{3}\right]=$ the density of the gas at $p_{1}, t$;

$\rho_{2}\left[\mathrm{lb} . / \mathrm{ft} .{ }^{3}\right]=$ the density it would have at $p_{2}, t$.

Then, in practice either $\rho_{1}$ or $\rho_{2}$ is taken as the density to be used in the equations; that is, the gas is treated as a liquid of density either $\rho_{1}$ or $\rho_{2}$. Introducing these specifications of the density into the equations already obtained for liquids gives us from (13)

$$
M=C_{1} \frac{0.5250}{\sqrt{1-\beta^{4}}} d^{2} \sqrt{\rho_{1} \Delta}
$$

or

$$
M=C_{2} \frac{0.5250}{\sqrt{1-\beta^{4}}} d^{2} \sqrt{\rho_{2} \Delta}
$$

and from (18)

or

$$
M=C_{1}{ }^{\prime} \times 0.5250 d^{2} \sqrt{\rho_{1} \Delta}
$$

$$
M=C_{2}{ }^{\prime} \times 0.5250 d^{2} \sqrt{\rho_{2} \Delta}
$$

We thus have four slightly different equations for computing the true rate of flow $M$ from the observed differential $\Delta$, each of which contains and defines one of the four coefficients $C_{1}, C_{2}, C_{1}{ }^{\prime}$, and $C_{2}{ }^{\prime}$.

It is convenient to have descriptive names for these discharge coefficients, and, to start with, they may all be called "hydraulic" coefficients, to indicate that they are obtained by treating the gas as 
a liquid, and to distinguish them from the "adiabatic" discharge coefficient which results from using the adiabatic equation mentioned above. The following designations may now be adopted:

$C_{1}$ is "the hydraulic discharge coefficient based on the upstream static pressure, with the approach factor not included";

$C_{2}$ is "the hydraulic discharge coefficient based on the downstream static pressure, with the approach factor not included;"

$C_{1}^{\prime}$ is "the hydraulic discharge coefficient based on the upstream static pressure, with the approach factor included"; and

$C_{2}^{\prime}$ is "the hydraulic discharge coefficient based on the downstream static pressure, with the approach factor included."

These four kinds of discharge coefficients are evidently not independent but connected by relations. which permit of computing the value of any one from that of any other. For example, we have from (20) the relations

$$
\begin{aligned}
C_{2} & =C_{1} \sqrt{\frac{\rho_{1}}{\rho_{2}}} \\
C_{1}^{\prime} & =C_{1} / \sqrt{1-\beta^{4}} \\
C_{2}{ }^{\prime} & =C_{1} \sqrt{\frac{\rho_{1}}{\rho_{2}}} / \sqrt{1-\beta^{4}}
\end{aligned}
$$

This is merely another way of saying that the same set of experimental results may equally well be expressed in any one of the four ways, that is, by tables or curves giving values of any one of the four discharge coefficients.

In the foregoing discussion of the meaning and definition of discharge coefficients, the theoretical rate of discharge $M_{\mathrm{t}}$ and the true rate $M$ have been expressed in pounds per second, because when the rates are expressed as mass per unit time the equations have a particularly simple form; but any other units might equally well have been used without changing the values of the $C^{\prime} s$, because these values are pure ratios and therefore independent of what units may be used for measuring the two rates of discharge.

If other units were adopted, such as gallons per minute for liquids or cubic feet per hour at standard pressure and temperature for gases, equations (20) would have a somewhat different appearance. And, similarly, measuring diameters in feet or centimeters instead of in inches, or measuring differentials in inches of water or mercury instead of in pounds per square inch, would change the value of the numerical factor 0.5250 . But no such changes in the units have any effect on the values of the discharge coefficients.

Some of these other forms of equation, equivalent to (20), will be given later with illustrative examples, but that may be postponed until the results of the present experimental investigation have been set forth and discussed. 


\section{OUTLINE OF THE METHODS OF COMPUTATION}

Of the four kinds of discharge coefficients defined by equations (20), only $C_{1}$ was computed directly from the observations, the values of the other three being found subsequently by means of (21). To find the value of $C_{1}$, equation (20a) is put into the form

$$
C_{1}=\frac{\sqrt{1-\beta^{4}}}{0.525 d^{2}} \cdot \frac{M}{\sqrt{\rho_{1} \Delta}}
$$

and the values of $d, \beta, M, \Delta$, and $\rho_{1}$, are substituted.

The internal diameter $D$ of each of the three sizes of pipe at its orifice station, and the diameter $d$ of each of the orifices, were measured by ordinary methods which need not be described. The values of the factor $\left(\sqrt{1-\beta^{4}} / 0.525 d^{2}\right)$, which is a constant for each orifice, were then computed once for all.

The values of $\Delta, M$, and $\rho_{1}$ varied from one experiment to another and had to be determined from the observations in each case. The differential $\Delta$ was read in inches of water, carbon tetrachloride, or mercury and after reduction to pounds per square inch it was ready for substitution in (22); but the values of $M$ and $\rho_{1}$ required some preliminary computation.

Since the flow was kept as nearly as possible steady during each experiment, the rate of flow through any orifice inserted in the line was the same as the rate of discharge from the flow nozzle on the end of the discharge trunk and was to be determined from observations there. The quantities required were: (a) The outside barometric pressure, (b) the impact pressure at the center of the jet, (c) the temperature of the air in the discharge trunk ahead of the nozzle, and $(d)$ the wet bulb depression read from the chart of the recording psychrometer in the trunk. The calibration curve of the nozzle having been determined by separate experiments, the value of $M$ could be computed from the observations just mentioned.

The remaining quantity needed for substitution in (22) is the density $\rho_{1}$, which is, by definition, to be computed for the upstream static pressure $p_{1}$ and the temperature $t$ of the air just ahead of the orifice. Since the air was not dry but contained a small admixture of water vapor, the humidity had to be known so that allowance might be made for the effect of the vapor.

Thep ressure $p_{1}$ is the sum of the static gauge pressure at the upstream tap and the outside barometric pressure. The static gauge was usually connected to the upstream tap and the pressure there observed directly, although since the differential was always observed at the same time, the static gauge might equally well have been connected to the downstream tap.

The temperature $t$ was taken to be the mean of the temperatures $t_{1}$ and $t_{2}$ read at the upstream and downstream thermometer wells, 
each about 12 pipe diameters distant from the orifice plate. An error of $1^{\circ} \mathrm{F}$. in the value of $t$ causes an error of $1 / 1,000$ or less in the value of $C_{1}$, and since this was small in comparison with the other accidental errors of the experiments, an accuracy of \pm 1 degree was sufficient.

When the outside air was much hotter or colder than the air in the pipe, the resulting heat leakage was sometimes enough to make $t_{1}$ and $t_{2}$ differ by $2^{\circ}$ or more, but in most of the experiments the difference was much less than this, and either $t_{1}$ or $t_{2}$ could be used in place of the mean value without causing any significant change in $C_{1}$. In runs where this was found to be the case, further readings of one of the thermometers were usually dispensed with.

In addition to the values of $p_{1}$ and $t$, which would have sufficed if the air had been perfectly dry, it was necessary to know what fraction of the mixture consisted of water vapor. After the air entered the test line it had no opportunity to take up more water, and the vapor content could not increase. On the other hand, the pressure was continually falling, while the temperature remained nearly constant, so that the vapor in the expanding mixture was becoming more dilute and further from saturation and there was no tendency for water to be precipitated. Hence, the composition of the moist air remained unchanged along the line and was the same at each orifice as in the discharge trunk where the psychrometer was situated.

A sufficiently accurate measure of the vapor content of the air is provided by the value of the ratio $\pi / p$, where $p$ is the total pressure of the mixture and $\pi$ is the partial pressure of the water vapor in it. The value of $\pi / p$ was found for the air in the discharge trunk from the observed pressure, temperature, and wet bulb depression. The hygrometric tables in the "Smithsonian Meteorological Tables" were used for this purpose. The value of $\pi / p$ thus found was applicable to the air at higher pressures upstream, for reasons stated above.

The values of $p_{1}, t$, and $\pi / p$ being known, it was possible to compute the value of $\rho_{1}$ from known data on the properties of dry air and water vapor. The following values were used:

The density of dry air containing the normal amount of carbon dioxide, at $32^{\circ} \mathrm{F}$., and at the pressure of 1 atmosphere or 14.696 lbs./in. ${ }^{2}$, was taken to be $0.08072 \mathrm{lb} . / \mathrm{ft}^{3}{ }^{3}$ The coefficient of expansion at the constant pressure of 1 atmosphere was taken to be $1 / 490$ of the volume at $32^{\circ}$, per degree. This is very close to the mean value over the range $32^{\circ}$ to $122^{\circ}$. Values of the $(p v)$ product, needed in determining the correction factor which allows for the departure from Boyle's law, were taken from the "Wärmetabellen" issued by the Physikalisch-Technische Reichsanstalt. The specific gravity of water vapor, referred to dry air at the same pressure and temperature, was assumed to be $18 / 29$. 
On the basis of the foregoing data, if air followed Boyle's law exactly, the density of dry air at $t^{\circ} \mathrm{F}$. and $p_{1} \mathrm{lb} . / \mathrm{in} .^{2}$ would be

$$
0.08072 \times \frac{p_{1}}{14.696} \times \frac{490}{458+t}=2.6914 \frac{p_{1}}{458+t} \mathrm{lb} . / \mathrm{ft}^{3}
$$

Within the range of pressure and temperature covered in these experiments, the value of the $(p v)$ product at any one temperature is not quite constant but decreases slightly as the pressure is raised. Hence, the density at any pressure $p_{1}$ is greater than the Boyle's law value given by (23) in the ratio

$$
\frac{(p v) \text { at } t^{\circ} \text { and } 14.7 \mathrm{lb} . / \mathrm{in}^{2}}{(p v) \text { at } t^{\circ} \text { and } p_{1} \mathrm{lb} . / \mathrm{in}^{2}}=Y
$$

Since the air is not dry but contains water vapor at the partial pressure $\pi_{1}$, the partial pressure of the dry air in the mixture is only $\left(p_{1}-\pi_{1}\right)$. This substitution of water vapor for a part of the dry air, without changing the total pressure, has the same effect on the density as if a fraction $\pi_{1} / p_{1}$ of the dry air had been made lighter in the ratio $18 / 29$; or as if the fraction $\pi_{1} / p_{1}$ of the whole number of molecules of air had been removed and replaced by the same number of water molecules, which are only $18 / 29$ as heavy. The density as computed for dry air at $p_{1}, t$ must, therefore, be multiplied by the correction factor

$$
\frac{p_{1}-\pi_{1}+\frac{18}{29} \pi_{1}}{p_{1}}=1-0.38 \frac{\pi_{1}}{p_{1}}
$$

The equation finally obtained from $(23,24,25)$ is

$$
\rho_{1}=2.6914 \frac{p_{1}}{458+t} Y\left(1-0.38 \frac{\pi_{1}}{p_{1}}\right)
$$

and this was used for computing the values of $\rho_{1}$ to be substituted in (22) for computing the value of $C_{1}$.

To facilitate the work of computation, curves giving the values of $\log Y$ in terms of $p_{1}$ were drawn for each $10^{\circ}$ from $32^{\circ}$ to $112^{\circ}$. The value of $\log Y$ for any values of $p_{1}$ and $t$ could then be obtained by interpolation from this set of curves.

Within the range of conditions covered by these experiments the departure of air from Boyle's law increases with rising pressure or falling temperature, but it is never large, and $Y$ remains between 1.00 and 1.01. For example, if $p_{1}=295 \mathrm{lbs}$. $/$ in. $^{2}$ and $t=42^{\circ}$, the correction factor is $Y=1.0092$. Hence if $Y$ were omitted from (26) the value computed for $\rho_{1}$ would be somowhat less than 1 per cent low and the resulting value of $C_{1}$, one-half per cent high. But this represents an extreme case, for the pressure was usually much less than $295 \mathrm{lbs} . /$ in. $^{2}$ and the temperature was seldom or never as low 
as $42^{\circ}$. Hence, in the great majority of instances the effect of the departure from Boyle's law was insignificant and $Y$ could be omitted from (26) without affecting $C_{1}$ by as much as 1 in 1,000 .

It may be remarked here, however, that in some natural gases the departures from Boyle's law are so much greater than in air that when such a gas is to be metered through an orifice at high pressure, failure to allow for these departures when interpreting the meter readings may result in errors of several per cent.

The humidity correction was also always small. If the air were completely saturated at as high a temperature as $90^{\circ}$, and its absolute pressure were as low as $20 \mathrm{lbs}$./in. ${ }^{2}$, the value of the humidity factor would be $1-0.38 \pi_{1} / p_{1}=0.9868$, so that the correction to $C_{1}$ would be nearly 0.7 per cent. But at lower temperatures or higher pressures the possible concentration of water vapor is relatively less and the correction is smaller. In many of the experiments it was negligible.

In computing the value of the correction term $\left(0.38 \pi_{1} / p_{1}\right)$, it is assumed that the air and the water vapor exert their partial pressures independently, each as if the other were not present, and that each of them follows the ordinary gas equation $p v=R T$. These assumptions are, of course, only approximately true; but when the water content is low and the correction small, as it always was, they are quite adequate to the purpose.

\section{LOCATION OF THE PRESSURE TAPS}

In addition to the abrupt fall of pressure from the upstream to the downstream side of the orifice plate, there are other variations of pressure along the wall of the pipe near the orifice, particularly on the downstream side, so that the differential observed at any given rate of discharge depends on the distances of the pressure taps from the orifice plate and the observations have no precise meaning unless these distances are specified. This may be done most satisfactorily in terms of the diameter of the pipe as the unit, by stating the values of $l_{1} / D$ and $l_{2} / D$, where $l_{1}$ and $l_{2}$ are the distances from the upstream face of the orifice plate to the centers of the upstream and downstream taps, and $D$ is the inside diameter of the pipe.

Since there is nothing in the definitions of the discharge coefficients by equations (20) to fix the positions of the pressure taps, any pair of distances might be adopted; but in American practice three particular arrangements have become more or less standard, to the exclusion of others. They may be designated and described as follows.

\section{PIPE TAPS}

The standard distances, expressed in pipe diameters, are $l_{1} / D=2.5$ and $l_{2} / D=8$, but these distances need not be at all exact because in both these regions the pressure varies slowly along the wall of the 
pipe and the tap may be displaced some distance from the standard position without any appreciable effect on the discharge coefficient. To the accuracy now attainable in the commercial use of orifice meters, and so long as the diameter ratio of the orifice is not greater than $\beta=0.6$, a tolerance of at least \pm 1 pipe diameter is permissible in the distances of the taps from the orifice plate.

\section{THROAT TAPS ${ }^{2}$}

The standard distances are $l_{1} / D=1$ and $l_{2} / D=0.5$.

\section{FLANGE TAPS}

The standard positions for the pressure holes are 1 inch from the nearer face of the orifice plate, regardless of the thickness of the plate or the diameter of the pipe, so that there are no standard values of $l_{1} / D$ and $l_{2} / D$.

For orifices of diameter ratios up to $\beta=0.6$, installed in 6 -inch or larger pipes, it seems probable that holes at any smaller distances from the plate would give sensibly the same differential, and that 1 inch is merely a safe upper limit. ${ }^{3}$ But for orifices of larger diameter ratio, or for much smaller pipes, this would no longer be true and the positions of the pressure holes would need to be more accurately specified. It would also be desirable to adopt a standard upper limit to the thickness of the orifice plate, expressed as a fraction of the pipe diameter.

There would be some advantages in abandoning this arrangement in favor of one in which the pressures were taken off right in the corner at the face of the plate through a narrow circumferential slit left between the plate and the end of the pipe, as recommended by Hodgson. ${ }^{4}$

In the present investigation each orifice was tested with three combinations of pressure taps which corresponded, roughly, to those mentioned above; and in each experiment the differentials were read between the three pairs of taps, as nearly as practicable at the same time and under the same conditions of flow. Auxiliary experiments on the longitudinal distribution of pressure for orifices of various diameter ratios made it possible to reduce the values obtained for $C_{1}$ to what they would have been with the taps in the standard locations. The

2 This designation is used here for lack of a better short term. Such appropriateness as it can claim consists in the fact that on the downstream side of orifices of medium diameter ratio the lowest static pressure is usually found at about one-half pipe diameter from the orifice plate, so that this section corresponds in some measure to the throat of a Venturi. The term "Venturi taps" might, perhaps, be an acceptable alternative.

${ }^{3}$ See Holbrook Gaskell, jr., Proc. Inst. Civ. Eng., 197, p. 250; 1913-14. Horace Judd, Trans. A. S. M. E., 38, p. 331; 1916. J. M. Spitzglass, Trans. A. S. M. E., 44, p. 919; 1922.

J. L. Hodgson, The Orifice as a Basis of Flow-Measurement, Inst. Civ. Eng., Selected Engineering Papers, No. 31; 1025. 
necessary corrections were usually quite negligible, but they were applied when they were as large as 1 in 1,000. The discharge coefficients to be given are therefore to be regarded as referring to the three standard combinations of pressure taps described above.

\section{METHOD OF ANALYZING THE RESULTS}

The three sets of results, each comprising about 360 separate values of the coefficient $C_{1}$, were examined separately but treated in the same general manner. Orifice plates of about the same diameter ratio were grouped together, and the values of $C_{1}$ obtained for each group were plotted as ordinates against the values of the pressure ratio $p_{2} / p_{1}=r$ as abscissas. A smooth curve was drawn to represent the general run of the points, and the result was a set of curves representing, approximately, the relation

$$
C_{1}=f(r) \quad(\beta \text { constant })
$$

for each of the mean values of $\beta$ pertaining to the several groups of orifices.

Values of $C_{1}$ were then read from these smooth curves at $r=1.00$, $0.95,0.90, \ldots$ etc., and the values for each $r$ were plotted against the values of the diameter ratio $\beta$. If the original curves had been consistent with one another, the points of this second or cross plotting would have fallen on a set of smooth curves

$$
C_{1}=f_{1}(\beta) \quad(r \text { constant })
$$

but in reality they were somewhat scattered, showing that the first set of curves required some modifications. By gradual readjustment two consistent sets of smooth curves were obtained, which appeared to represent the aggregate of all the values of $C_{1}$ as well as could be done.

Since such a process involves a good deal of judgment on the part of the operator, it was carried through on the throat tap values several times by each of two persons, at considerable intervals of time, and the results were tabulated and compared. For diameter ratios up to $\beta=0.5$, the different independent estimates of the most representative mean value of $C_{1}$, at any given value of the pressure ratio $r$, seldom differed by as much as 0.5 per cent and were usually closer together than that. But for the higher diameter ratios, where the possible range of pressure ratios was short, on account of the limited air supply, and where there were fewer observations, the different estimates sometimes differed by as much as 1.5 per cent.

After a good deal of study it was found that if the results obtained in the 4-inch pipe were set aside for separate discussion, the values 
of $C_{1}$ for the 6 and 8 inch pipes could be represented satisfactorily by empirical equations of the general form

$$
C_{1}=\varphi(r, \beta)
$$

the particular forms of the equation being different for the different combinations of pressure taps.

In deciding on the form to be adopted for (29), two conditions had to be satisfied. The first was that at any given pressure ratio $r$ the limiting value of $C_{1}$ as $\beta$ approaches zero must be the same for all three pairs of pressure taps. This is evident from the consideration that when $\beta$ is very small the flow is merely a discharge from one large space into another, with the fluid in each of the spaces so nearly at rest that, aside from gravity, its pressure is sensibly the same on all parts of the wall, and the location of the pressure taps is immaterial. The empirical equations (29) for the three combinations had, therefore, to become identical for $\beta=0$.

The second condition arises from the fact that when the percentage differential is very small and the pressure ratio $p_{2} / p_{1}=r$ approaches unity, the effects of compressibility vanish and air behaves like a liquid of the same kinematic viscosity. ${ }^{5}$ This means that if the influence of viscosity is negligible, as it was in all or nearly all of our experiments, the value of $C_{1}$ for a given orifice and for very low percentage differentials must be the same as the discharge coefficient of the orifice for water.

This familiar experimental fact would have provided a desirable check on our limiting values of $C_{1}$ for $r=1$, if accurate values of $C$ as a function of $\beta$ had been available for water. We did not find any such values for orifices installed in pipes, which appeared to be more trustworthy than an extrapolation from our own values for air, but there is one particular value which seems pretty well fixed.

If the percentage differential is very small, and if the diameter ratio is also very small, the value of $C_{1}$ for air must become identical with the value for a submerged jet of water issuing from a round, square-edged orifice in the wall of a large tank. This quantity has been the subject of a great many measurements, and the best determinations ${ }^{6}$ show that when the Reynolds number ${ }^{7}$ is high enough that viscosity no longer has any appreciable influence, the value is close to 0.597 . This agrees well with a natural extrapolation from our observed points to $r=1$ and $\beta=0$, and also with the experiments of Bachmann ${ }^{8}$ on air. We therefore adopted this figure as a fundamental value to which $C_{1}$ must converge when $r=1$ and $\beta=0$.

5 See Section XXIV.

6 See for example, Hamilton Smith's "Hydraulics," Chap. XI.

7 See Section XXIV and Appendix C.

8 H. Bachmann, Dissertation, Darmstadt; 1911. 
The results obtained for 8 and 6 inch pipes did not show any systematic differences greater than the accidental differences between ostensibly similar orifices of the same size; but the coefficients for the 4-inch pipe were, on the whole, distinctly higher. The tables of discharge coefficients presently to be given are therefore to be understood as representing our average results from 6 and 8 inch plates only.

\section{RESULTS FOR THROAT TAPS}

Throat taps are, by definition, located one pipe diameter upstream and one-half pipe diameter downstream from the upstream face of the orifice plate. The definitions of the four familiar forms of discharge coefficient, $C_{1}, C_{2}, C^{\prime}{ }_{1}$, and $C^{\prime}{ }_{2}$, are given by equations (20) in Section $X$, above, and the relations between them are given by equations (21).

Our average results for orifices in the 6 and 8 inch pipes are represented by the equation

$$
C_{1}=0.5970+0.09 \beta^{4}-0.115\left(x+x^{2}\right)\left(1+1.5 \beta^{4}\right)
$$

in which

$$
x=\frac{p_{1}-p_{2}}{p_{1}}=1-r
$$

that is, $x$ is the differential, expressed as a fraction of the upstream static pressure.

Values of $C_{1}$ computed from (30) are given in Table 4.

TABLE 4.-Throat taps

[Values of $C_{1}$, the hydraulic discharge coefficient based on the upstream static pressure, with the approach factor not included]

\begin{tabular}{|c|c|c|c|c|c|c|c|}
\hline$\beta=$ & 0.0 & 0.2 & 0.3 & 0.4 & 0.5 & 0.55 & 0.6 \\
\hline $\begin{array}{r}r= \\
1.00 \\
.95 \\
.90\end{array}$ & $\begin{array}{r}0.597 \\
.591 \\
.584\end{array}$ & $\begin{array}{r}0.597 \\
.591 \\
.584\end{array}$ & $\begin{array}{r}0.598 \\
.592 \\
.585\end{array}$ & $\begin{array}{r}0.599 \\
.593 \\
.586\end{array}$ & $\begin{array}{r}0.602 \\
.596 \\
.589\end{array}$ & $\begin{array}{r}0.605 \\
.598 \\
.591\end{array}$ & $\begin{array}{r}0.609 \\
.601 \\
.593\end{array}$ \\
\hline $\begin{array}{l}.85 \\
.80 \\
.75 \\
.70\end{array}$ & $\begin{array}{l}.577 \\
.569 \\
.561 \\
.552\end{array}$ & $\begin{array}{l}.577 \\
.569 \\
.561 \\
.552\end{array}$ & $\begin{array}{l}.578 \\
.570 \\
.561 \\
.552\end{array}$ & $\begin{array}{l}.579 \\
.571 \\
.562 \\
.553\end{array}$ & $\begin{array}{r}.581 \\
.572 \\
.563\end{array}$ & $\begin{array}{l}.583 \\
.574\end{array}$ & .585 \\
\hline $\begin{array}{l}.65 \\
.60\end{array}$ & $\begin{array}{r}.543 \\
.533\end{array}$ & $\begin{array}{r}.543 \\
.533\end{array}$ & $\begin{array}{r}.543 \\
.533\end{array}$ & .543 & & & \\
\hline $\begin{array}{l}.55 \\
.50\end{array}$ & $\begin{array}{l}.522 \\
.511\end{array}$ & $\begin{array}{l}.522 \\
.511\end{array}$ & &  & & & 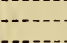 \\
\hline & & & & & & & \\
\hline
\end{tabular}

$C_{1}=0.5970+0.09 \beta^{4}-0.115\left(x+x^{2}\right)\left(1+1.5 \beta^{4}\right)$

The shortening of the later columns is due to the limited compressor capacity, which made it impossible to attain high differentials with the larger orifices.

Equation (30) is purely empirical and should not be relied on outside the limits shown by the table. We had some observations on the smaller orifices at pressure ratios as low as $r=0.3$, and the equation appears to fit these points within the experimental errors, but 
there were relatively few of these observations, and we prefer not to trust the equation for pressure ratios lower than shown in the table.

As regards higher values of $\beta$, our observations were not satisfactory. Even for the smaller diameter ratios, the accidental errors were large and the resulting points much scattered, when the percentage differential was low; and in no case would the observations at pressure ratios greater than $r=0.95$ have sufficed, by themselves, to determine a curve $C_{1}=f(r)$. At higher percentage differentials the observations were more consistent and for the plates of small or medium diameter ratios, which could be tested over a large range of values of $r$, a fairly good determination of the mean curve was possible. But with large diameter ratios the possible range of $r$ was narrower and the scattering worse.

For example, with two orifices for which $\beta=0.6904$ and $0.7042,13$ values of $C_{1}$ obtained at pressure ratios greater than $r=0.956$ were distributed irregularly between 0.598 and 0.643 . In another case with four orifices, of diameter ratios from 0.780 to $0.802,15$ values of $C_{1}$ obtained with pressure ratios down to $r=0.967$, were scattered between 0.610 and 0.664 , with one additional value at 0.713 .

In both these instances the mean value of $C_{1}$ was within one-fourth per cent of the value computed from equation (30) for the mean values of $x$ and $\beta$, and it seems probable that, for low percentage differentials, the equation gives a fairly good representation of the facts for 6 and 8 inch pipes up to $\beta=0.8$; but we do not recommend it for use when the diameter ratio of the orifice is greater than $\beta=0.6$, the limit shown in the table.

After the values of $C_{1}$ had been obtained those of $C_{2}, C^{\prime}{ }_{1}$, and $C^{\prime}{ }_{2}$, defined in Section $\mathrm{X}$, were found from them by means of equations $(21)$, and the results corresponding to Table 4 are given in Tables 5,6 , and 7 .

\section{TABLE 5.-Throat taps}

[Values of $C_{2}$, the hydraulic discharge coefficient based on the downstream static pressure, with the approach factor not included]

$$
C_{2}=C_{1} \sqrt{\frac{1}{1-x}}
$$

\begin{tabular}{|c|c|c|c|c|c|c|c|}
\hline$\beta=$ & 0.0 & 0.2 & 0.3 & 0.4 & 0.5 & 0.55 & 0.6 \\
\hline $\begin{array}{l}r= \\
1.00\end{array}$ & 0.597 & & & & 0.603 & & \\
\hline .95 & .606 & $\begin{array}{l}.606 \\
.606\end{array}$ & .607 & .608 & .611 & .614 & .617 \\
\hline .90 & .616 & .616 & .617 & .618 & .621 & .623 & .626 \\
\hline .85 & .626 & .626 & .627 & .628 & .630 & .632 & .634 \\
\hline .80 & . 637 & .637 & .637 & . 638 & .640 & .642 & \\
\hline .75 & .648 & .648 & .648 & .649 & . 650 & & \\
\hline .65 & .673 & $\begin{array}{l}.000 \\
.673\end{array}$ & .673 & .673 & & & \\
\hline .60 & . 688 & .688 & .688 & & & & \\
\hline $\begin{array}{l}.55 \\
.50\end{array}$ & $\begin{array}{l}.704 \\
.722\end{array}$ & .704 & & & & & \\
\hline & & & & & & & \\
\hline
\end{tabular}




\section{TABLE 6.-Throat taps}

[Values of $C_{1}^{\prime}$, the hydraulic discharge coefficient based on the upstream static pressure, with the approach factor included]

$C^{\prime}=C_{1} / \sqrt{1-\beta^{4}}$

\begin{tabular}{|c|c|c|c|c|c|c|c|}
\hline$\beta=$ & 0.0 & 0.2 & 0.3 & 0.4 & 0.5 & 0.55 & 0.6 \\
\hline$r=$ & & & & & & & \\
\hline $\begin{array}{r}1.00 \\
.95 \\
.90 \\
.85\end{array}$ & $\begin{array}{r}0.597 \\
.591 \\
.584 \\
.577\end{array}$ & $\begin{array}{r}0.598 \\
.592 \\
.585 \\
.578\end{array}$ & $\begin{array}{r}0.600 \\
.594 \\
.587 \\
.580\end{array}$ & $\begin{array}{r}0.607 \\
.601 \\
.594 \\
.586\end{array}$ & $\begin{array}{r}0.622 \\
.616 \\
.608 \\
.600\end{array}$ & $\begin{array}{r}0.635 \\
.628 \\
.620 \\
.611\end{array}$ & $\begin{array}{r}0.652 \\
.645 \\
.636 \\
.627\end{array}$ \\
\hline $\begin{array}{l}.80 \\
.75 \\
.70 \\
.65\end{array}$ & $\begin{array}{l}.569 \\
.561 \\
.552 \\
.543\end{array}$ & $\begin{array}{l}.570 \\
.562 \\
.553 \\
.543\end{array}$ & $\begin{array}{l}.572 \\
.564 \\
.555 \\
.545\end{array}$ & $\begin{array}{r}.578 \\
.569 \\
.560 \\
.550\end{array}$ & $\begin{array}{r}591 \\
.582 \\
\end{array}$ & 602 & \\
\hline $\begin{array}{l}.60 \\
.55 \\
.50\end{array}$ & $\begin{array}{r}.533 \\
.522 \\
.511\end{array}$ & $\begin{array}{l}.533 \\
.522 \\
.511\end{array}$ & .535 & & & & \\
\hline
\end{tabular}

TABLE 7.-Throat taps

[Values of $\mathrm{C}_{2}^{\prime}$, "the hydraulic discharge coefficient based on the downstream static pressure, with the approach factor included]

$$
C^{\prime}{ }_{2}=C_{2} / \sqrt{1-\beta^{4}}
$$

\begin{tabular}{|c|c|c|c|c|c|c|c|}
\hline$\beta=$ & 0.0 & 0.2 & 0.3 & 0.4 & 0.5 & 0.55 & 0.6 \\
\hline$r=x$ & & & & & & & \\
\hline $\begin{array}{r}1.00 \\
.95 \\
.90 \\
.85\end{array}$ & $\begin{array}{r}0.597 \\
.606 \\
.616 \\
.626\end{array}$ & $\begin{array}{r}0.598 \\
.607 \\
.617 \\
.627\end{array}$ & $\begin{array}{r}0.600 \\
.609 \\
.619 \\
.629\end{array}$ & $\begin{array}{r}0.607 \\
.616 \\
.626 \\
.636\end{array}$ & $\begin{array}{r}0.622 \\
.631 \\
.641 \\
.651\end{array}$ & $\begin{array}{r}0.635 \\
.644 \\
.653 \\
.663\end{array}$ & $\begin{array}{r}0.652 \\
.661 \\
.671 \\
.680\end{array}$ \\
\hline $\begin{array}{l}.80 \\
.75 \\
.70 \\
.65\end{array}$ & $\begin{array}{l}.637 \\
.648 \\
.660 \\
.673\end{array}$ & $\begin{array}{l}.637 \\
.648 \\
.661 \\
.674\end{array}$ & $\begin{array}{l}.640 \\
.651 \\
.663 \\
.676\end{array}$ & $\begin{array}{l}.646 \\
.657 \\
.669 \\
.682\end{array}$ & $\begin{array}{r}661 \\
.672 \\
\end{array}$ & 673 & \\
\hline $\begin{array}{l}.60 \\
.55 \\
.50\end{array}$ & $\begin{array}{l}.688 \\
.704 \\
.722\end{array}$ & $\begin{array}{r}.688 \\
.704 \\
.723\end{array}$ & 690 & & & & \\
\hline
\end{tabular}

Table 8 contains values of a fifth discharge coefficient $C_{\mathrm{m}}$, defined in analogy with (20) by writing

$$
M=C_{\mathrm{m}} \frac{0.5250}{\sqrt{1-\beta^{4}}} d^{2} \sqrt{\rho_{\mathrm{m}} \Delta}
$$

in which $\rho_{\mathrm{m}}$ is the density of the air at $t^{\circ} \mathrm{F}$. and at the mean pressure

$$
p_{\mathrm{m}}=\frac{p_{1}+p_{2}}{2}
$$

It is connected with $C_{1}$ by the equation

$$
C_{\mathrm{m}}=C_{1} \sqrt{\frac{2}{2-x}}
$$

and might be designated as "the mean hydraulic discharge coefficient with approach factor not included." 
The corresponding quantity

$$
C^{\prime}{ }_{\mathrm{m}}=C_{\mathrm{m}} / \sqrt{1-\beta^{4}}
$$

might then be called "the mean hydraulic discharge coefficient with approach factor included."

TABLE 8.-Throat taps

[Values of $C_{\mathrm{m}}$, the mean hydraulic discharge coefficient, with the approach factor not included]

$$
C_{\mathrm{m}}=C_{1} \sqrt{\frac{2}{2-x}}
$$

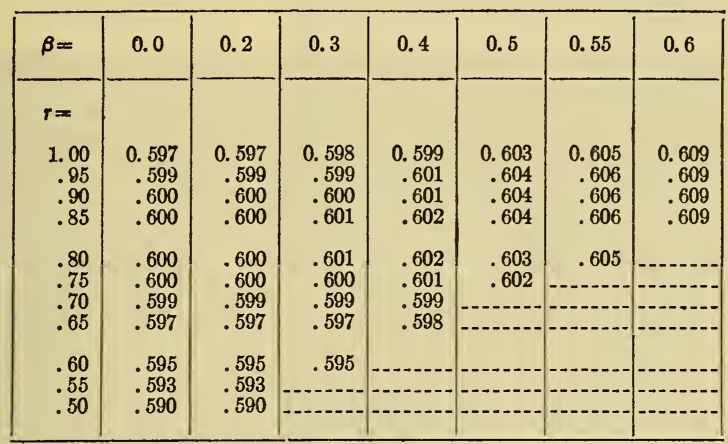

Table 9 contains values of the "adiabatic" discharge coefficient $C_{\mathrm{a}}$ found from those of $C_{1}$ by means of the relation

$$
C_{\mathrm{a}}=C_{1}\left[\frac{2(1-r)\left(1-\beta^{4} r^{r^{2}}\right)}{7\left(r^{10}-r^{12}\right)\left(1-\beta^{4}\right)}\right]^{\frac{1}{2}}
$$

Readers who are interested in this quantity may be assumed to be already familiar with the theoretical considerations on which the definition of $C_{\mathrm{a}}$ is based. They are usually set forth in works on technical thermodynamics and are similar to those involved in the theory of the flow nozzle discussed in Appendix A to the present paper.

\begin{tabular}{|c|c|c|c|c|c|c|c|}
\hline$\beta=$ & 0.0 & 0.2 & 0.3 & 0.4 & 0.5 & 0.55 & 0.6 \\
\hline$r=$ & & & & & & & \\
\hline $\begin{array}{r}1.00 \\
.95 \\
.90 \\
.85 \\
.80\end{array}$ & $\begin{array}{r}0.597 \\
.608 \\
.618 \\
.630 \\
.642\end{array}$ & $\begin{array}{r}0.597 \\
.608 \\
.619 \\
.630 \\
.643\end{array}$ & $\begin{array}{r}0.598 \\
.608 \\
.619 \\
.631 \\
.643\end{array}$ & $\begin{array}{r}0.599 \\
.610 \\
.622 \\
.633 \\
.646\end{array}$ & $\begin{array}{r}0.603 \\
.614 \\
.626 \\
.638 \\
.652\end{array}$ & $\begin{array}{r}0.605 \\
.617 \\
.630 \\
.643 \\
.656\end{array}$ & $\begin{array}{r}0.609 \\
.621 \\
.635 \\
.648\end{array}$ \\
\hline $\begin{array}{l}.75 \\
.70 \\
.65 \\
.60 \\
.55\end{array}$ & $\begin{array}{r}.656 \\
.670 \\
.686 \\
.704 \\
704\end{array}$ & $\begin{array}{l}.656 \\
.670 \\
.686 \\
.704 \\
724\end{array}$ & $\begin{array}{l}.657 \\
.671 \\
.687 \\
.705\end{array}$ & $\begin{array}{l}.660 \\
.674 \\
.690\end{array}$ & .666 & & \\
\hline & .724 & .74 & & & & & \\
\hline
\end{tabular}

TABLE 9.-Throat taps

[Values of $C_{\mathrm{a}}$, the adiabatic discharge coefficient] 
The relations of the various discharge coefficients to one another and to the pressure ratio and diameter ratio may be exhibited most clearly by curves drawn from the tabulated values, either with $r$ as abscissa for constant $\beta$, or with $\beta$ as abscissa for constant $r$. A few such diagrams may be given.

Figure 5 shows curves drawn with $r$ as abscissa for the limiting diameter ratio $\beta=0$; that is, for a small orifice between two large spaces. Since the differential is independent of the positions of the pressure taps, when $\beta$ is sufficiently small, these curves are applicable

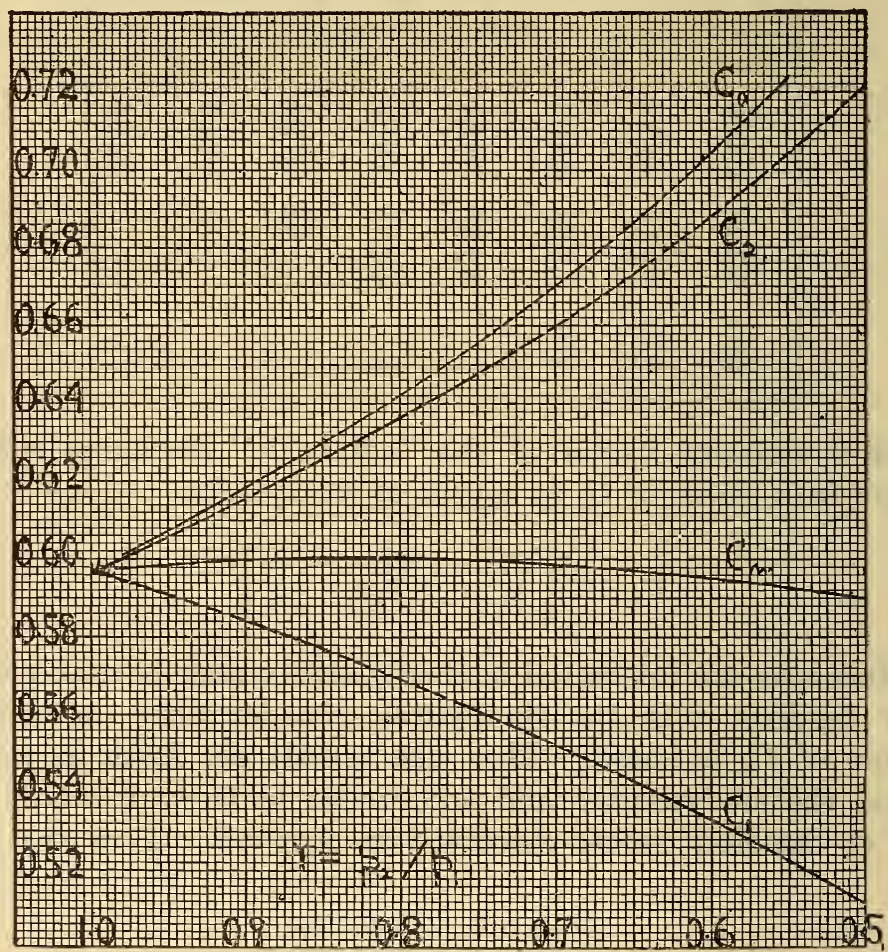

FIG. 5.-Variation of discharge coefficients with pressure ratio, for small diameter ratios (Tables 4, 5, 8, and 9)

to all three types of pressure connection. Moreover, when $\beta$ is very small, the curves for $C^{\prime}{ }_{1}, C^{\prime}{ }_{2}$, and $C_{\mathrm{m}}{ }^{\prime}$ become identical with those for $C_{1}, C_{2}$, and $C_{\mathrm{m}}$, respectively.

The following points may be noted:

(a) As $r$ decreases and the differential becomes a larger and larger fraction of the upstream static pressure, $C_{1}$ decreases only about twothirds as fast as $C_{2}$ increases. In other words, the discharge coefficient $C_{1}$, based on the density at the upstream pressure, is somewhat less affected by changes of the pressure ratio than is the coefficient $C_{2}$, based on the downstream pressure. 
(b) The values of $C_{2}$ are not greatly different from those of the "adiabatic" coefficient $C_{\mathrm{a}}$.

(c) The mean coefficient $C_{\mathrm{m}}$, defined by (34), is nearly constant over a wide range of pressure ratios. If the indicating and recording mechanism of an orifice meter were so designed as to be actuated by the mean of the two static pressures, the meter could be used without any correction for change of coefficient with pressure ratio, over a much wider range than when only one of the two static pressures is employed. By using a pressure somewhat nearer the lower of the two, the first part of the curve for $C_{\mathrm{m}}$ might be made very close to a horizontal straight line.

When the diameter ratio is not very small and the differentials measured between

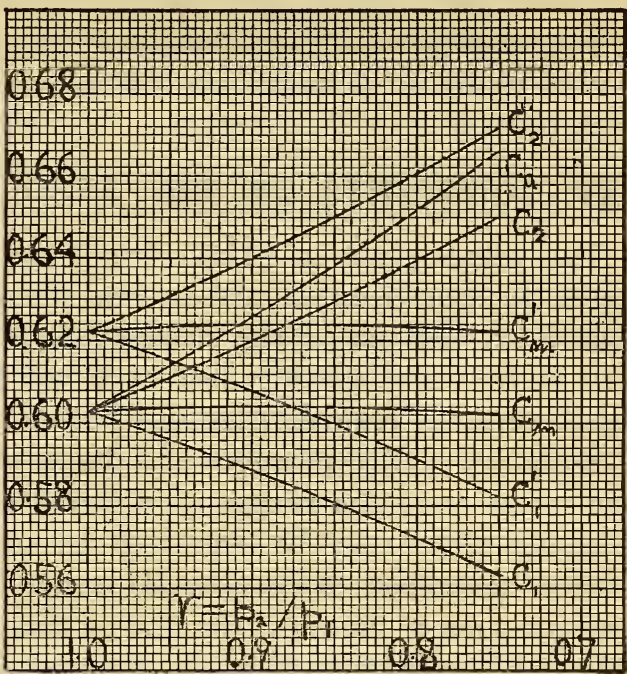

Fig. 6.-Discharge coefficients for $\beta=0.5$ and for throat taps (Tables 4 to 9 )

the different pairs of taps are appreciably different, the diagrams will be different for the three pairs, and the curves for $C^{\prime}{ }_{1}, C^{\prime}{ }_{2}$, and $C^{\prime}{ }_{\mathrm{m}}$ will not coincide with those for $C_{1}, C_{2}$, and $C_{\mathrm{m}}$. The curves for throat taps and for the diameter ratio $\beta=0.5$ are given in Figure 6.



FIg. 7.-Variation of $C_{1}$ and $C_{2}$ with area ratio for throat taps

Another mode of representation is illustrated in Figure 7, in which the abscissa is $\beta^{2}$, or the ratio of the area of the orifice to the cross section of the pipe, and each curve refers to a constant pressure ratio instead of to a constant diameter ratio as in Figures 5 and 6. 
The middle curve gives the limiting values of both $C_{1}$ and $C_{2}$ for vanishingly small differentials, on the supposition that the effects of viscosity are negligible. The two lower curves give the values of $C_{1}$ for differentials of 5 and 10 per cent of the unstream pressure, and the two upper curves give the corresponding values of $C_{2}$.

Since equation (30) is linear in $\beta^{4}$ for any fixed value of $x$, all these curves would be straight lines if $\beta^{4}$ were used as abscissa instead of the area ratio $\beta^{2}$.

\section{COMMENTS ON THE RESULTS FOR THROAT TAPS}

The values given in Tables 4 to 9 are rounded off from values coniputed to four decimal places, and since they have not been further smoothed, the run of the differences is sometimes irregular by one unit in the third place. But even the third figure has little general significance as regards absolute values.

Equation (30) represents the mean of our results for the 6 and 8 inch pipes over the ranges of $r$ and $\beta$ covered by the tables, and it indicates what may be expected, on the average, from such orifices as were described in Section III when $(a)$ they are installed in long straight runs of pipe, $(b)$ the flow is steady, and $(c)$ the product of the differential in inches of water, the mean static pressure in pounds per square inch, and the square of the orifice diameter in inches is not less than $10 .^{9}$ But the values of $C_{1}$ for individual orifices showed systematic departures of as much as 1 per cent, and occasionally more, from the average represented by equation (30).

These individual pecularities were most marked among the smaller orifices, in which a given degree of imperfection of the upstream corner of the orifice is relatively more important than for larger orifices. It was thought, at first, that these unexpectedly large differences of behavior between orifice plates of the same diameter ratio could be referred to differences in the ratio of the width of the cylindrical edge to the diameter of the orifice, but this explanation was found to be inadequate. For experiments on a series of cylindrical orifices in flat plates of various thicknesses showed that so long as the thickness was less than one-fourth of the diameter of the hole its value was unimportant. This result agreed perfectly with the results obtained by S. J. G. Thomas ${ }^{10}$ for much smaller orifices.

We are left with the impression that it is a difficult matter to produce a number of duplicate plates which will all give the same discharge coefficient within \pm 0.3 per cent.

The 4-inch plates gave higher values of $C_{1}$ than the 6 and 8 inch plates and for any given diameter ratio the mean curve $C_{1}=f(x)$

- See Section XXIV and Appendix C.

10 Phil. Mag., 44, p. 969; November, 1922. 
for the 4-inch plates would lie about 1.5 per cent higher than the mean curve for the 6 and 8 inch plates, represented by (30).

The values of $C_{1}$ for individual 4-inch plates differed from their mean by amounts up to \pm 1.5 per cent; that is, they were from nothing up to 3 per cent higher than values computed from (30). One 4-inch plate gave values of $C_{1}$ low enough to agree very well with (30). It had been noted, after microscopic examination, as having a "poor edge, rough and ridged," and this imperfection doubtless accounted for its departing so far from the mean of the 4 -inch plates. This was one of the bureau plates, of diameter ratio $\beta=0.3295$.

The range of variation of the values of $C_{1}$ for the 4-inch plates from their mean, or \pm 1.5 per cent, was somewhat greater than the similar range for the 6 and 8 inch plates about their mean, represented by (30). Moreover, with the 6 and 8 inch plates the departures from the mean were most pronounced for the small values of $\beta$; that is, on the whole, for small absolute diameters. Both these facts point to the necessity of greater perfection of workmanship for small than for large orifices, if any standard table of discharge coefficients is to be relied upon.

Possible reasons for the high values of $C_{1}$ obtained from the 4-inch plates will be suggested in Section XXV.

\section{RESULTS FOR FLANGE TAPS}

The pair of flanges for holding the 8-inch orifice plates was one loaned to us by the Hope Natural Gas Co., and the holes for the pressure connections were approximately at the standard distances of 1 inch from the nearer face of the plate. In the 6-inch flanges, which were made at the Bureau of Standards, these distances were about three-fourths inch, so that for the 8 and 6 inch pipes the pressure taps were not equally distant from the plate, but at distances proportional to the diameter of the pipe. With pipes as large as 6 inches in diameter, such small variations have no appreciable effect on the differential, or on the discharge coefficient computed from it, unless the diameter ratio is considerably higher than $\beta=0.6$.

Our average results for orifices in the 6 and 8 inch pipes are represented by the equation

$$
C_{1}=0.5970+0.12 \beta^{4}-0.6 \beta^{12}-0.115\left(x+x^{2}\right)\left(1+1.5 \beta^{4}\right)
$$

in which, as before,

$$
x=\frac{p_{1}-p_{2}}{p_{1}}=1-r
$$

Values of $C_{1}$ computed from (37) are shown in Table 10 and the corresponding values of $C_{2}, C^{\prime}{ }_{1}, C^{\prime}{ }_{2}$, and $C_{\mathrm{m}}$ in Tables 11 to 14 . 


\section{TABLE 10.-Flange taps}

[Values of $C_{1}$, the hydraulic discharge coefficient based on the upstream static pressure, with the approach factor not included]

$C_{1}=0.5970+0.12 \beta^{4}-0.6 \beta^{12}-0.115\left(x+x^{2}\right)\left(1+1.5 \beta^{4}\right)$

\begin{tabular}{|c|c|c|c|c|c|c|c|}
\hline$\beta=$ & 0.0 & 0.2 & 0.3 & 0.4 & 0.5 & 0.55 & 0.6 \\
\hline \multicolumn{8}{|l|}{$r=$} \\
\hline $\begin{array}{r}1.00 \\
.95 \\
.90 \\
.85\end{array}$ & $\begin{array}{r}0.597 \\
.591 \\
.584 \\
.577\end{array}$ & $\begin{array}{r}0.597 \\
.591 \\
.585 \\
.577\end{array}$ & $\begin{array}{r}0.598 \\
.592 \\
.585 \\
.578\end{array}$ & $\begin{array}{r}0.600 \\
.594 \\
.587 \\
.579\end{array}$ & $\begin{array}{r}0.604 \\
.598 \\
.591 \\
.583\end{array}$ & $\begin{array}{r}0.608 \\
.601 \\
.593 \\
.585\end{array}$ & $\begin{array}{r}0.611 \\
.604 \\
.596 \\
.588\end{array}$ \\
\hline $\begin{array}{l}.80 \\
.75 \\
.70 \\
.65\end{array}$ & $\begin{array}{l}.569 \\
.561 \\
.552 \\
.543\end{array}$ & $\begin{array}{r}.570 \\
.561 \\
.552 \\
543\end{array}$ & $\begin{array}{l}.570 \\
.562 \\
.553 \\
.543\end{array}$ & $\begin{array}{l}.571 \\
.563 \\
.553 \\
.543\end{array}$ & $\begin{array}{r}574 \\
.565 \\
\end{array}$ & .576 & \\
\hline $\begin{array}{l}.60 \\
.55 \\
.50\end{array}$ & $\begin{array}{r}.533 \\
.522 \\
.511\end{array}$ & $\begin{array}{l}.533 \\
.522 \\
.511\end{array}$ & .533 & & - & &.- \\
\hline
\end{tabular}

TABLE 11.-Flange taps

[Values of $C_{2}$, the hydraulic discharge coefficient based on the downstream static pressure, with the approach factor not included]

$$
C_{2}=C_{1} \sqrt{\frac{1}{1-x}}
$$

\begin{tabular}{|c|c|c|c|c|c|c|c|}
\hline$\beta=$ & 0.0 & 0.2 & 0.3 & 0.4 & 0.5 & 0.55 & 0.6 \\
\hline$r=$ & & & & & & & \\
\hline $\begin{array}{r}1.00 \\
.95 \\
.90 \\
.85\end{array}$ & $\begin{array}{r}0.597 \\
.606 \\
.616 \\
.626\end{array}$ & $\begin{array}{r}0.597 \\
.606 \\
.616 \\
.626\end{array}$ & $\begin{array}{r}0.598 \\
.607 \\
.617 \\
.627\end{array}$ & $\begin{array}{r}0.600 \\
.609 \\
.619 \\
.629\end{array}$ & $\begin{array}{r}0.604 \\
.613 \\
.622 \\
.632\end{array}$ & $\begin{array}{r}0.608 \\
.616 \\
.625 \\
.634\end{array}$ & $\begin{array}{r}0.611 \\
.620 \\
.628 \\
.637\end{array}$ \\
\hline $\begin{array}{l}.80 \\
.75 \\
.70 \\
.65\end{array}$ & $\begin{array}{l}.637 \\
.648 \\
.660 \\
.673\end{array}$ & $\begin{array}{l}.637 \\
.648 \\
.660 \\
.673\end{array}$ & $\begin{array}{l}.637 \\
.648 \\
.660 \\
.673\end{array}$ & $\begin{array}{l}.639 \\
.650 \\
.661 \\
.674\end{array}$ & $\begin{array}{r}.642 \\
.653 \\
\end{array}$ & .644 & \\
\hline $\begin{array}{l}.60 \\
.55 \\
.50\end{array}$ & $\begin{array}{l}.688 \\
.704 \\
.722\end{array}$ & $\begin{array}{l}.688 \\
.704 \\
.722\end{array}$ & . 688 & & & & \\
\hline
\end{tabular}

\section{TABLE 12.-Flange taps}

[Values of $C^{\prime}{ }_{1}$, the hydraulic discharge coefficient based on the upstream static pressure, with the approach factor included]

$$
C^{\prime}{ }_{1}=C_{1} / \sqrt{1-\beta^{4}}
$$

\begin{tabular}{|c|c|c|c|c|c|c|c|}
\hline$\beta=$ & 0.0 & 0.2 & 0.3 & 0.4 & 0.5 & 0.55 & 0.6 \\
\hline$r=$ & & & & & & & \\
\hline $\begin{array}{r}1.00 \\
.95 \\
.90 \\
.85\end{array}$ & $\begin{array}{r}0.597 \\
.591 \\
.584 \\
.577\end{array}$ & $\begin{array}{r}0.598 \\
.592 \\
.585 \\
.578\end{array}$ & $\begin{array}{r}0.600 \\
.594 \\
.587 \\
.580\end{array}$ & $\begin{array}{r}0.608 \\
.602 \\
.595 \\
.587\end{array}$ & $\begin{array}{r}0.624 \\
.617 \\
.610 \\
.602\end{array}$ & $\begin{array}{r}0.637 \\
.630 \\
.622 \\
.614\end{array}$ & $\begin{array}{r}0.655 \\
.647 \\
.639 \\
.630\end{array}$ \\
\hline $\begin{array}{l}.80 \\
.75 \\
.70 \\
.65\end{array}$ & $\begin{array}{l}.569 \\
.561 \\
.552 \\
.543\end{array}$ & $\begin{array}{l}.570 \\
.562 \\
.553 \\
.543\end{array}$ & $\begin{array}{l}.572 \\
.564 \\
.555 \\
.545\end{array}$ & $\begin{array}{r}.579 \\
.570 \\
.561 \\
.551\end{array}$ & $\begin{array}{l}.593 \\
.584\end{array}$ & .604 & \\
\hline $\begin{array}{l}.60 \\
.55 \\
.50\end{array}$ & $\begin{array}{l}533 \\
.522 \\
.511\end{array}$ & $\begin{array}{l}.533 \\
.522 \\
.511\end{array}$ & .535 & & & & \\
\hline
\end{tabular}


TABLE 13.-Flange taps

[Values of $C^{\prime}$, the hydraulic discharge coefficient based on the downstream static pressure, with the approach factor included]

$C^{\prime}{ }_{2}=C_{2} / \sqrt{1-\beta^{4}}$

\begin{tabular}{|c|c|c|c|c|c|c|c|}
\hline$\beta=$ & 0.0 & 0.2 & 0.3 & 0.4 & 0.5 & 0.55 & 0.6 \\
\hline$r=$ & & & & & & & \\
\hline $\begin{array}{r}1.00 \\
.95 \\
.90 \\
.85\end{array}$ & $\begin{array}{c}0.597 \\
.606 \\
.616 \\
.626\end{array}$ & $\begin{array}{r}0.598 \\
.607 \\
.617 \\
.627\end{array}$ & $\begin{array}{r}0.600 \\
.610 \\
.619 \\
.629\end{array}$ & $\begin{array}{r}0.608 \\
.617 \\
.627 \\
.637\end{array}$ & $\begin{array}{r}0.624 \\
.633 \\
.643 \\
.658\end{array}$ & $\begin{array}{r}0.637 \\
.647 \\
.656 \\
.666\end{array}$ & $\begin{array}{r}0.655 \\
.684 \\
.674 \\
.683\end{array}$ \\
\hline $\begin{array}{l}.80 \\
.75\end{array}$ & $\begin{array}{l}.637 \\
.648\end{array}$ & .637 & $\begin{array}{r}.640 \\
.651\end{array}$ & .647 & .863 & .676 & \\
\hline $\begin{array}{l}.70 \\
.65\end{array}$ & $\begin{array}{l}.660 \\
.673\end{array}$ & .661 & $\begin{array}{r}.663 \\
.676\end{array}$ & $\begin{array}{r}.670 \\
.683\end{array}$ & & & \\
\hline 60 & . 688 & .688 & . 691 & & & & \\
\hline & $\begin{array}{r}.704 \\
.722\end{array}$ & $\begin{array}{l}.704 \\
.723\end{array}$ & & & & & \\
\hline
\end{tabular}

TABLE 14.-Flange taps

[Values of $C_{m}$, the mean hydraulic discharge coeftcient, with the approach factor not included]

$$
C_{\mathrm{n}}=C_{1} \sqrt{\frac{2}{2-x}}
$$

\begin{tabular}{|c|c|c|c|c|c|c|c|}
\hline$\beta=$ & 0.0 & 0.2 & 0.3 & 0.4 & 0.5 & 0.55 & 0.60 \\
\hline$r=$ & & & & & & & \\
\hline $\begin{array}{r}1.00 \\
.95 \\
.90 \\
.85\end{array}$ & $\begin{array}{r}\text { 0. } 597 \\
.599 \\
.600 \\
.600\end{array}$ & $\begin{array}{r}0.597 \\
.599 \\
.600 \\
.600\end{array}$ & $\begin{array}{r}0.598 \\
.599 \\
.600 \\
.601\end{array}$ & $\begin{array}{r}0.600 \\
.601 \\
.602 \\
.602\end{array}$ & $\begin{array}{r}0.604 \\
.605 \\
.606 \\
.606\end{array}$ & $\begin{array}{r}0.607 \\
.608 \\
.609 \\
.608\end{array}$ & $\begin{array}{c}0.611 \\
.612 \\
.612 \\
.611\end{array}$ \\
\hline $\begin{array}{l}.80 \\
.75\end{array}$ & $\begin{array}{l}.600 \\
.600\end{array}$ & $\begin{array}{l}.600 \\
.600\end{array}$ & $\begin{array}{l}.601 \\
.600\end{array}$ & $\begin{array}{l}.602 \\
.602\end{array}$ & $\begin{array}{l}.605 \\
.604\end{array}$ & .607 & \\
\hline $\begin{array}{l}.70 \\
.65\end{array}$ & $\begin{array}{l}.599 \\
.597\end{array}$ & $\begin{array}{r}.599 \\
.598\end{array}$ & $\begin{array}{l}.589 \\
.598\end{array}$ & $\begin{array}{l}.6000 \\
.598\end{array}$ & & & \\
\hline .60 & .595 & .595 & .596 & & & & \\
\hline $\begin{array}{l}.55 \\
.50\end{array}$ & $\begin{array}{l}593 \\
.590\end{array}$ & $\begin{array}{l}.593 \\
.590\end{array}$ & & & & & \\
\hline
\end{tabular}

Tables of $C^{\prime}{ }_{\mathrm{m}}$ and $C_{\mathrm{a}}$ may readily be computed by means of equations $(37,34,35,36)$, but since these two forms of the coefficient are not in common use they may be omitted. The table for $C_{\mathrm{m}}$ is given in order to call attention again to the advantage of this quantity. Values of $C^{\prime}{ }_{m}$ would have the same property of approximate independence of the pressure ratio for orifices of any one diameter ratio.

Equation (37) satisfies the condition of reducing to identity with (30) when $\beta=0$. Like (30), it is a purely empirical representation of the observed facts, and it does not lay claim to validity outside the limits shown by the tables, although it does, in fact, represent such observations as were made outside these limits with about the same accuracy as equation (30) for the throat tap combination.

Figure 5 , for $\beta=0$, is applicable to flange taps, as already remarked. The curves for $\beta=0.5$ would be very like those of Figure 6 , and since the information they would convey is all contained in the tables it seems unnecessary to give them. 


\section{COMMENTS ON THE RESULTS FOR FLANGE TAPS}

Much the same comments may be made here as in Section XV with regard to throat taps. Equation (37) represents the average results obtained from orifices installed in the 6 and 8 inch pipes, but the values of $C_{1}$ for individual orifices departed from the mean in the same way and by about the same amounts as when the differentials were measured between the throat taps.

The 4-inch plates likewise behaved as described in Section XV. One of them agreed with the equation, but the others gave values of $C_{1}$ from 0.3 to 3.2 per cent higher than computed from (37), the average excess being about 1.3 per cent.

In one respect the results for flange taps differ from those for throat taps. This difference is shown by Figure 8 , in which $F$ is the limiting curve $C_{1}=f\left(\beta^{2}\right)$ for $x=0$ and for flange taps, while $T$, repeated from Figure 7 , is the corresponding curve for throat taps.

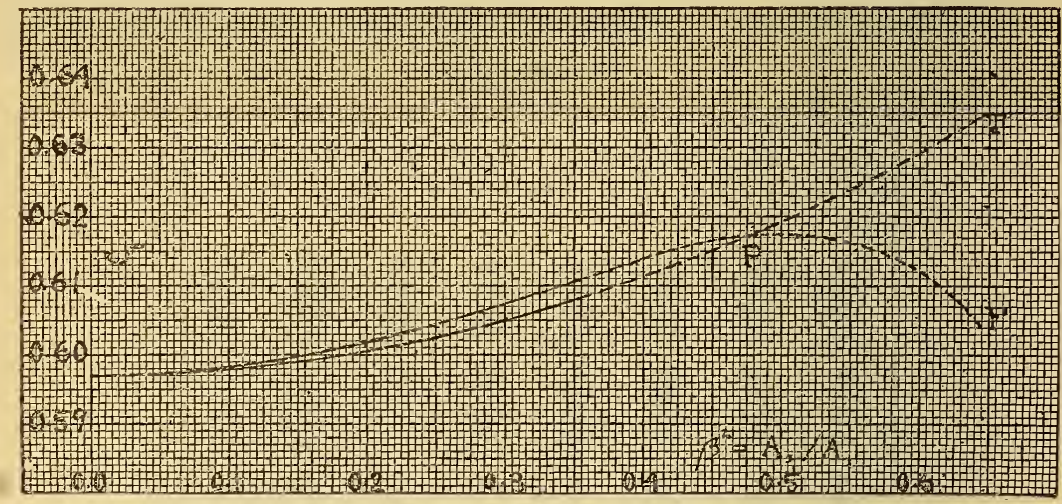

Fra. 8. - Limiting values of $C_{1}$ at low differentials for throat taps $(T)$ and flange taps (F)

As $\beta$ increases from very small values, where both arrangements of taps give the same differential, $C_{1}$ increases more rapidly for flange than for throat taps, as indicated by the term $0.12 \beta^{4}$ in (37) compared with $0.09 \beta^{4}$ in (30). The pressure is a little higher near the plate than it is one-half pipe diameter downstream, so that the differential is lower and the discharge coefficient higher, and this difference increases with $\beta$, up to about $\beta=0.6$ or $\beta^{2}=0.36$.

But as $\beta$ increases, the downstream minimum of pressure moves up toward the plate and the pressure at the flange tap falls, relatively to that at the throat tap. The effect of this is that as $\beta$ continues to increase, the difference between the differentials measured in the two ways increases less rapidly, reaches a maximum, and then falls off, the two values of $C_{1}$ approaching each other. At some point, 
indicated by $P$ in Figure 8 , the curves cross, and thereafter the discharge coefficient is lower for flange than for throat taps.

Assuming that the equations (30) and (37) from which the curves are drawn remain valid for $\beta>0.6$, and that the dotted portions of the curves are approximately correct, the crossing occurs at about $\beta^{2}=0.475$ or $\beta=0.69$. For still higher diameter ratios, the value of $C_{1}$ for the flange taps decreases and, as shown by our experiments, it is lower at $\beta=0.79$ than at $\beta=0.70$, and still lower at $\beta=0.83$.

These peculiarities of the curve for flange taps are sufficiently well represented by the inclusion of the term $-0.6 \beta^{12}$ in (37). More extensive and more accurate experiments would doubtless permit of improving the empirical equations for both flange and throat taps, but the present forms of (30) and (37) seem to be as good as the observations they purport to represent.

\section{RESULTS FOR PIPE TAPS}

Pipe taps are, by definition, placed 2.5 pipe diameters upstream and 8 pipe diameters downstream from the orifice plate.

Our average results for orifices in the 6 and 8 inch pipes may be represented by the equation

$$
C_{1}=0.5970+0.006 \beta+0.54 \beta^{2.3}+\beta^{3} x^{2}-0.115\left(x+x^{2}\right)\left(1+11 \beta^{3}\right)
$$

in which

$$
x=\frac{p_{1}-p_{2}}{p_{1}}=1-r
$$

Values of $C_{1}$ computed from (39) are given in Table 15 and the corresponding values of $C_{2}, C^{\prime}{ }_{1}$, and ${C^{\prime}}_{2}$ in Tables 16,17 , and 18 .

TABLE 15.-Pipe laps

[Values of $C_{1}$, the hydraulic discharge coefficient based on the upstream static pressure, with the approach factor not included.]

\begin{tabular}{|c|c|c|c|c|c|c|c|c|c|c|}
\hline$\beta=$ & 0.0 & 0.1 & 0.2 & 0.3 & 0.35 & 0.4 & 0.45 & 0.5 & 0.55 & 0.6 \\
\hline$r=$ & & & & & & & & & & \\
\hline $\begin{array}{r}1.00 \\
.95 \\
.90 \\
.85\end{array}$ & $\begin{array}{r}0.597 \\
.591 \\
.584 \\
.577\end{array}$ & $\begin{array}{r}0.600 \\
.594 \\
.588 \\
.580\end{array}$ & $\begin{array}{r}0.612 \\
.605 \\
.598 \\
.590\end{array}$ & $\begin{array}{r}0.633 \\
.625 \\
.617 \\
.608\end{array}$ & $\begin{array}{r}0.647 \\
.639 \\
.629 \\
.619\end{array}$ & $\begin{array}{r}0.665 \\
.655 \\
.645 \\
.633\end{array}$ & $\begin{array}{r}0.686 \\
.674 \\
.661 \\
.648\end{array}$ & $\begin{array}{r}0.710 \\
.696 \\
.681 \\
.665\end{array}$ & $\begin{array}{r}0.737 \\
.720 \\
.703 \\
.684\end{array}$ & $\begin{array}{r}0.767 \\
.748 \\
.727\end{array}$ \\
\hline $\begin{array}{l}.80 \\
.75 \\
.70 \\
.65\end{array}$ & $\begin{array}{r}.569 \\
.561 \\
.552 \\
.543\end{array}$ & $\begin{array}{l}.572 \\
.564 \\
.555 \\
.545\end{array}$ & $\begin{array}{r}.582 \\
.573 \\
.563 \\
.553\end{array}$ & $\begin{array}{r}.598 \\
.5888 \\
.577 \\
.565\end{array}$ & $\begin{array}{r}.608 \\
.597 \\
.585 \\
.573\end{array}$ & $\begin{array}{l}.621 \\
.608 \\
.594 \\
.580\end{array}$ & $\begin{array}{l}.634 \\
.619 \\
.604\end{array}$ & $\begin{array}{r}.649 \\
.632\end{array}$ & .665 & \\
\hline $\begin{array}{l}.60 \\
.55\end{array}$ & $\begin{array}{r}.533 \\
.522 \\
\end{array}$ & $\begin{array}{r}.535 \\
.525\end{array}$ & $\begin{array}{r}.543 \\
.532\end{array}$ & $\begin{array}{r}.553 \\
.541\end{array}$ & .559 & & & & & 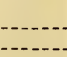 \\
\hline .50 & .511 & . 513 & .520 & & & & & & & \\
\hline
\end{tabular}

$C_{1}=0.5970+0.006 \beta+0.54 \beta^{2,3}+\beta^{3} x^{2}-0.115\left(x+x^{2}\right)\left(1+11 \beta^{3}\right)$ 


\section{TABLE 16.-Pipe taps}

[Values of $C_{2}$, the hydraulic discharge coefficient based on the downstream static pressure, with the approach factor not included]

$$
C_{2}=C_{1} \sqrt{\frac{1}{1-x}}
$$

\begin{tabular}{|c|c|c|c|c|c|c|c|c|c|c|}
\hline$\beta=$ & 0.0 & 0.1 & 0.2 & 0.3 & 0.35 & 0.4 & 0.45 & 0.5 & 0.55 & 0.6 \\
\hline$r=$ & & & & & & & & & & \\
\hline $\begin{array}{r}1.00 \\
.95 \\
.90 \\
.85\end{array}$ & $\begin{array}{r}0.597 \\
.606 \\
.616 \\
.626\end{array}$ & $\begin{array}{r}0.600 \\
.610 \\
.619 \\
.620\end{array}$ & $\begin{array}{r}0.612 \\
.621 \\
.630 \\
.640\end{array}$ & $\begin{array}{r}0.633 \\
.641 \\
.650 \\
.659\end{array}$ & $\begin{array}{r}0.647 \\
.655 \\
.663 \\
.672\end{array}$ & $\begin{array}{r}0.665 \\
.672 \\
.679 \\
.686\end{array}$ & $\begin{array}{r}0.686 \\
.691 \\
.697 \\
.703\end{array}$ & $\begin{array}{r}0.710 \\
.714 \\
.718 \\
.722\end{array}$ & $\begin{array}{r}0.737 \\
.739 \\
.741 \\
.743\end{array}$ & $\begin{array}{r}0.767 \\
.767 \\
.766\end{array}$ \\
\hline $\begin{array}{l}.80 \\
.75 \\
.70 \\
.85\end{array}$ & $\begin{array}{l}.637 \\
.648 \\
.660 \\
.673\end{array}$ & $\begin{array}{l}.640 \\
.651 \\
.663 \\
.677\end{array}$ & $\begin{array}{l}.650 \\
.662 \\
.674 \\
.686\end{array}$ & $\begin{array}{l}.669 \\
.670 \\
.690 \\
.701\end{array}$ & $\begin{array}{l}.680 \\
.690 \\
.700 \\
.710\end{array}$ & $\begin{array}{r}.694 \\
.702 \\
.710 \\
.720\end{array}$ & $\begin{array}{r}.709 \\
.715 \\
.722\end{array}$ & .720 & .744 & \\
\hline $\begin{array}{l}.60 \\
.55 \\
.50\end{array}$ & $\begin{array}{r}.688 \\
.704 \\
.722\end{array}$ & $\begin{array}{r}.691 \\
.707 \\
.726\end{array}$ & $\begin{array}{l}.701 \\
.717 \\
.735\end{array}$ & $\begin{array}{r}.715 \\
.729\end{array}$ & .722 & & & & & \\
\hline
\end{tabular}

TABLE 17.-Pipe taps

[Values of $C^{\prime}{ }_{1}$, the hydraulic discharge coefficient based on the upstream static pressure, with the approach factor included]

$$
C_{1}^{\prime}=C_{1} / \sqrt{1-\beta^{4}}
$$

\begin{tabular}{|c|c|c|c|c|c|c|c|c|c|c|}
\hline$\beta=$ & 0.0 & 0.1 & 0.2 & 0.3 & 0.35 & 0.4 & 0.45 & 0.5 & 0.55 & 0.6 \\
\hline$r \infty$ & & & & & & & & & & \\
\hline $\begin{array}{r}1.00 \\
.95 \\
.90 \\
.85\end{array}$ & $\begin{array}{r}0.597 \\
.591 \\
.584 \\
.577\end{array}$ & $\begin{array}{r}0.600 \\
.594 \\
.588 \\
.580\end{array}$ & $\begin{array}{r}0.612 \\
.605 \\
.598 \\
.591\end{array}$ & $\begin{array}{r}0.635 \\
.627 \\
.619 \\
.610\end{array}$ & $\begin{array}{r}0.652 \\
.643 \\
.634 \\
.624\end{array}$ & $\begin{array}{r}0.674 \\
.663 \\
.653 \\
.641\end{array}$ & $\begin{array}{r}0.700 \\
.688 \\
.675 \\
.662\end{array}$ & $\begin{array}{r}0.733 \\
.718 \\
.703 \\
.687\end{array}$ & $\begin{array}{r}0.765 \\
.748 \\
.730 \\
.711\end{array}$ & $\begin{array}{r}0.822 \\
.801 \\
.779 \\
. .2 .\end{array}$ \\
\hline $\begin{array}{l}.80 \\
.70 \\
.70 \\
.65\end{array}$ & $\begin{array}{l}.569 \\
.561 \\
.552 \\
.543\end{array}$ & $\begin{array}{l}.572 \\
.564 \\
.555 \\
.546\end{array}$ & $\begin{array}{l}.582 \\
.573 \\
.564 \\
.554\end{array}$ & $\begin{array}{l}.600 \\
.590 \\
.579 \\
.568\end{array}$ & $\begin{array}{l}.613 \\
.602 \\
.590 \\
.577\end{array}$ & $\begin{array}{l}.629 \\
.616 \\
.602 \\
.588\end{array}$ & $\begin{array}{r}.648 \\
.633 \\
.617 \\
\end{array}$ & $\begin{array}{r}.670 \\
.653 \\
. . .-\end{array}$ & .691 & \\
\hline $\begin{array}{l}.60 \\
.55 \\
.50\end{array}$ & $\begin{array}{r}.533 \\
.522 \\
.511\end{array}$ & $\begin{array}{r}.535 \\
.525 \\
.513\end{array}$ & $\begin{array}{r}.543 \\
.532 \\
.520\end{array}$ & $\begin{array}{r}.556 \\
.543 \\
\end{array}$ & .564 & & & & & \\
\hline
\end{tabular}

TABLE 18.-Pipe taps

[Values of $C^{\prime}{ }_{2}$, the hydraulic discharge coefficient based on the downstream static pressure, with the approach factor included]

\begin{tabular}{|c|c|c|c|c|c|c|c|c|c|c|}
\hline$\beta=$ & 0.0 & 0.1 & 0.2 & 0.3 & 0.35 & 0.4 & 0.45 & 0.5 & 0,55 & 0.6 \\
\hline \multicolumn{11}{|l|}{$r=$} \\
\hline $\begin{array}{r}1.00 \\
.95 \\
.90 \\
.85\end{array}$ & $\begin{array}{r}0.597 \\
.606 \\
.616 \\
.626\end{array}$ & $\begin{array}{r}0.600 \\
.610 \\
.619 \\
.629\end{array}$ & $\begin{array}{r}0.612 \\
.621 \\
.631 \\
.641\end{array}$ & $\begin{array}{r}0.635 \\
.644 \\
.653 \\
.662\end{array}$ & $\begin{array}{r}0.652 \\
.660 \\
.668 \\
.677\end{array}$ & $\begin{array}{r}0.674 \\
.681 \\
.688 \\
.695\end{array}$ & $\begin{array}{r}0.700 \\
.706 \\
.712 \\
.718\end{array}$ & $\begin{array}{r}0.733 \\
.737 \\
.741 \\
.745\end{array}$ & $\begin{array}{r}0.765 \\
.767 \\
.769 \\
.771\end{array}$ & $\begin{array}{r}0.822 \\
.822 \\
.821 \\
\end{array}$ \\
\hline $\begin{array}{l}.80 \\
.75 \\
.70 \\
.65\end{array}$ & $\begin{array}{l}.637 \\
.648 \\
.660 \\
.673\end{array}$ & $\begin{array}{l}.640 \\
.651 \\
.663 \\
.677\end{array}$ & $\begin{array}{l}.651 \\
.662 \\
.674 \\
.687\end{array}$ & $\begin{array}{l}.671 \\
.681 \\
.692 \\
.704\end{array}$ & $\begin{array}{l}.685 \\
.695 \\
.705 \\
.716\end{array}$ & $\begin{array}{l}.703 \\
.711 \\
.720 \\
.729\end{array}$ & $\begin{array}{r}.724 \\
.730 \\
.737\end{array}$ & $\begin{array}{r}.749 \\
.754 \\
.-. .\end{array}$ & .773 & \\
\hline $\begin{array}{l}.60 \\
.55 \\
.50\end{array}$ & $\begin{array}{l}.688 \\
.704 \\
.722\end{array}$ & $\begin{array}{r}.681 \\
.707 \\
.726\end{array}$ & $\begin{array}{l}.701 \\
.717 \\
.736\end{array}$ & $\begin{array}{r}.717 \\
.732\end{array}$ & .728 & & & & & \\
\hline
\end{tabular}

$$
C^{\prime}{ }_{2}=C_{2} / \sqrt{1-\beta^{4}}
$$


Like equations (30) and (37), equation (39) is not to be regarded as valid beyond the limits of $r$ and $\beta$ for which values are given in the tables.

\section{COMMENTS ON THE RESULTS FOR PIPE TAPS}

Over the range of $r$ and $\beta$ covered by the tables, the values of $C_{1}$ for individual plates of the 6 and 8 inch sizes departed from the mean values, represented by the empirical equation (39), in the same way as was found to occur with throat and flange taps, though the departures were, if anything, not quite so large.

With the exception already noted, the 4 -inch plates gave systematically higher values of $C_{1}$ than those computed from (39).

If we exclude from consideration two further plates on which only a very few observations were made, there remain nine of the 4-inch plates having diameter ratios from 0.1992 to 0.6125 . For these plates the excess of $C_{1}$ over the value computed from (39) ranged from 0.4 per cent to 1.9 per cent, with a mean of 1.1 per cent. For the same set of plates the corresponding figures for throat taps are 0.5 to 2.7 , mean 1.4; and for flange taps they are 0.3 to 2.3, mean 1.1.

The figure for any one plate is, of course, an average from the separate values obtained with that plate; and since the observations were seldom numerous enough to determine a curve for a single plate with any great precision, the figures just given for the individual plates must be regarded as uncertain by at least \pm 0.3 per cent.

\section{COMPARISON OF THE THREE SETS OF RESULTS}

Since the equations which have been devised for representing our results are purely empirical, they might, of course, be somewhat varied, or possibly replaced by others of quite different appearance. But such other equations would have to represent the same facts by giving approximately the same numerical values of $C_{1}$ over the specified ranges of $r$ and $\beta$, and the equations as they stand provide adequate means for comparing the three kinds of result.

For convenience of comparison, the equations may be reproduced here in the following forms:

For throat taps (30)

$$
C_{1}=0.5970+0.09 \beta^{4}\left[-0.115\left(x+x^{2}\right)\left(1+1.5 \beta^{4}\right)\right]
$$

For flange taps (37)

$$
C_{1}=0.5970+0.09 \beta^{4}+0.03 \beta^{4}-0.6 \beta^{12}\left[-0.115\left(x+x^{2}\right)\left(1+1.5 \beta^{4}\right)\right]
$$

For pipe taps (39)

$$
C_{1}=0.5970+0.006 \beta+0.54 \beta^{2.3}\left[-0.115\left(x+x^{2}\right)\left(1+11 \beta^{3}\right)+\beta^{3} x^{2}\right]
$$


In each case the terms involving $x$ have been placed within the square brackets [ ], and since these terms vanish when $x=0$, the earlier terms alone give the limiting form of the equation for very low percentage differentials.

The terms within the [ ] represent the changes of $C_{1}$, with increasing $x$, for any fixed value of $\beta$. Their presence is necessitated by the fact that the air expands as its pressure falls. If there were no such expansion, these terms would be absent, and the earlier terms therefore, represent, according to an extrapolation from our experimental results, what is to be expected for water-always on the supposition that the effects of viscosity do not become appreciable.

In the limiting case of very small diameter ratios, and therefore negligible speed of flow at all points not close to the orifice, the three equations degenerate into the single form

$$
C_{1}=0.5970-0.115\left(x+x^{2}\right)
$$

thus satisfying the conditions mentioned in Section XIII.

Equations (41) and (42) are much alike. Of the two additional terms $+0.03 \beta^{4}$ and $-0.6 \beta^{12}$, which appear in (43), the first represents the fact that as $\beta$ increases from very small values the differential between the flange taps is, at first, less than between the throat taps. The second term, which ultimately more than offsets the first, represents the effect of the displacement of the downstream pressure minimum toward the orifice. This displacement is slow and of little importance, so long as $\beta$ is small, but has a marked influence later on, as was illustrated in Figure 8.

In contrast with (41) and (42), equation (43) is of a very different and more complicated form. This difference reflects the different physical nature and greater complexity of the phenomena which determine the differential when the region in question extends far enough downstream to include the zone of maximum restoration of pressure, instead of stopping at a section 0.5 pipe diameter from the orifice, or approximately at the minimum of static pressure.

In defining the discharge coefficient of an orifice for a liquid we make use, first, of the conception of a "theoretical" jet speed which would occur if the whole observed fall of pressure were due to, or were used up in producing, acceleration of the fluid. In practice, there is very little dissipative resistance, as far as the vena contracta, and the speed of the jet there is nearly equal to the theoretical speed which would be computed from the fall of pressure between the undisturbed stream ahead of the orifice and the vena contracta.

If the theoretical rate of discharge could then be computed from the cross section of the vena contracta, it would agree very closely with the actual discharge, and the discharge coefficient would be nearly unity, as it is for a well-made flow nozzle or Venturi. In practice, the computation has to be made with the area of the orifice 
because the cross section of the vena contracta is unknown, and the computed rate of discharge is correspondingly increased. And if the differential used in the computation is the true fall of static pressure from the undisturbed stream ahead of the orifice to the vena contracta, the discharge coefficient obtained will be very nearly identical with the contraction coefficient, defined as the ratio of the cross sectional area of the jet at the vena contracta to the area of the orifice.

In a cylindrical jet the static pressure must be uniform over any section and equal to the pressure just outside. So long as the diameter ratio is not large and the vena contracta is still at some distance from the orifice, the profile of the jet in the vicinity of the vena contracta is not sharply curved, and the relation just mentioned must be approximately true.

In practice, the downstream static pressure is observed at the wall of the pipe and not in, or just outside, the vena contracta. But visual observations with glass pipes ${ }^{11}$ have shown that the minimum of pressure at the wall occurs at the same section of the pipe as the vena contracta, and it has commonly been assumed that this minimum pressure is equal to the static pressure in the vena contracta. While this can hardly be very accurately true, it seems probable that it is nearly so for diameter ratios not greater than $\beta=0.6$; and in the absence of further evidence the assumption may be accepted as nearly true.

From this it follows that if the downstream tap is placed at the point of minimum pressure or maximum differential the discharge coefficient obtained is very nearly equal to the contraction coefficient. And since the minimum pressure is sensibly the same as the pressure at the downstream throat tap, so long as $\beta<0.6$, we may regard the discharge coefficient with approach factor not included, obtained from observations with throat taps, as a fairly accurate representation of the contraction coefficient.

Except for the disturbing effects of viscosity, which are usually small in practice, the profile of a jet of liquid from a round, squareedged orifice is independent of the speed; the contraction coefficient remains constant; and the discharge coefficient is independent of the magnitude of the differential. But with a gas the phenomena are somewhat different.

Since the static pressure of the jet does not fall to its lowest value until the vena contracta is reached, it is higher in the converging part of the jet between the orifice and the vena contracta than the pressure in the surrounding space. This transverse gradient of pressure causes the gas to expand laterally, as well as forward, with

11 Experiments by E. G. Bailey, Report of the Special Research Committee on Fluid Meters of the American Society of Mechanical Engineers, 2d ed., pp. 34, 35; 1927. 
the result that the section of the vena contracta is larger than it would be for a nonexpanding liquid, and the difference increases as the percentage differential increases.

The effect of this change in the contraction coefficient is clearly shown by the increase of the "adiabatic" discharge coefficient $C_{\mathrm{a}}$. Except for the ignoring of contraction, the assumptions on which the theoretical "adiabatic" rate of flow is computed corresponds very closely to reality; and if the downstream tap is so placed as to give the static pressure of the jet in the vena contracta, the value obtained for $C_{\mathrm{a}}$ is nearly identical with the contraction coefficient. The curves marked $C_{\mathrm{a}}$, in Figures 5 and 6, therefore, show approximately how the section of the vena contracta increases relatively to the area of the orifice as the percentage differential increases and the difference of behavior between air and water becomes more and more pronounced.

Turning, now, to the consideration of the pipe tap arrangement, we find a different state of affairs. The assumption that the frictional resistances are negligible, and that changes of static pressure represent changes in speed, is nearly true for the region included between the throat taps; but when extended to the whole region between the pipe taps it becomes totally false, and the bodily transfer of the algebra developed for throat taps to the case of pipe taps, while perfectly legitimate and justifiable on the score of expediency, does not represent any physical reality.

The differential between the pipe taps is merely the over-all loss of static pressure between the two taps, due to dissipative resistance. With a liquid, and supposing the diameter of the pipe to be the same at both taps, there is, on the whole, no acceleration at all and no appreciable change of kinetic energy. And in the case of a gas there is only the-usually quite insignificant-increase of linear speed due to the fact that the density falls with the pressure, and that the product of speed and density must remain constant if the flow is to be steady. The orifice plate interposed between the two taps acts merely as an obstruction which introduces a large resistance and so concentrates a pressure drop great enough for convenient measurement within a short length of pipe-101/2 pipe diameters if the taps are in the standard positions.

When the diameter ratio is very small, the kinetic energy of the jet is all dissipated, there is no restoration of pressure, and it is appropriate to regard the orifice as a device for forcibly accelerating the fluid. But when the diameter ratio is large and there is a considerable restoration of pressure, the differential between the pipe taps represents dissipative or frictional resistance and not kinetic resistance to acceleration, except in the sense that if there had been no acceleration anywhere there would have been no increase 
of kinetic energy to be dissipated. Hence, it is more natural and in closer accordance with the physical facts to regard an orifice plate of large diameter ratio merely as a ridge projecting inward from the wall of the pipe and introduced for the sake of increasing the resistance of the pipe to flow along it.

There is thus a gradual change of the nature of the phenomena which occur between the orifice and a point eight pipe diameters downstream, as $\beta$ increases. The discharge coefficient is not susceptible of the same simple interpretation for pipe as for throat or flange taps, and a more complicated and quite different form of equation is required to represent the manner in which it depends upon the diameter ratio and pressure ratio.

\section{SPECIMENS OF THE EXPERIMENTAL RESULTS}

Several matters which deserve mention may best be elucidated by comparing the values of $C_{1}$ obtained from the observations on particular orifices with the values given by the empirical equation. For this purpose, data for four of the orifices and for throat taps are presented in Tables 19 to 22, which are all arranged in the same way.

The values of $C_{1}$ determined by the observations are listed in column 4 , in the order of increasing values of $x$ as shown in column 3 .

For each orifice a curve

$$
C_{1}=f(x)(\beta \text { constant })
$$

was drawn to represent equation (30) with the given $\beta$; and for each of the observed values of $x$ in column 3 the value of $C_{1}$ was read off. This value, denoted by $C_{1}$ (calc.), was then subtracted from the observed value $C_{1}$ (obs.), and the difference

$$
C_{1} \text { (obs.) }-C_{1} \text { (calc.) }=\delta
$$

listed in column 5 , is the amount by which each observed point is above the curve, or the excess of the observed over the computed value of $C_{1}$. The combined errors of drawing the curve and reading from it may sometimes have amounted to \pm 5 in the last figure given, but the values of $\delta$ are quite accurate enough for our present purpose.

Each table is divided into two parts, of which the first contains the values of $C_{1}$ (obs.) and $\delta$ for $x<0.02$ and the second all the remaining values. The mean values of $\delta$ for the two parts are shown separately, and the general mean is given at the foot of column 5 . 
Table 19.-Plate No. 1-6 (Foxboro Company)

[ $D=5.785$ ins.; $d=0.6265$ ins.; $\beta=0.1083$; throat taps]

\begin{tabular}{|c|c|c|c|c|c|c|}
\hline Flow nozzle used & $\begin{array}{c}\text { Initial } \\
\text { pressure } \\
p_{1} \\
\text { lbs./in.2 }\end{array}$ & $\begin{array}{l}\frac{p_{1}-p_{2}}{p_{1}} \\
\quad=x\end{array}$ & $\begin{array}{c}C_{1} \\
\text { (obs.) }\end{array}$ & $\begin{array}{c}C_{1} \text { (obs.) } \\
-C_{1} \text { (calc.) } \\
=\delta\end{array}$ & $\delta-0.0018$ & $\delta-0.0009$ \\
\hline 1 & 2 & 3 & 4 & 5 & 6 & 7 \\
\hline \multirow[t]{2}{*}{$\begin{array}{l}\text { D-1.. } \\
\text { D-1.. }\end{array}$} & \multirow[t]{2}{*}{$\begin{array}{r}207.9 \\
86.7\end{array}$} & \multirow[t]{2}{*}{$\begin{array}{r}0.0151 \\
.0180\end{array}$} & \multirow[t]{2}{*}{$\begin{array}{r}0.5814 \\
.6185\end{array}$} & $\begin{array}{r}-0.0140 \\
+.0234\end{array}$ & $\begin{array}{r}-0.0158 \\
+.0216\end{array}$ & \multirow[t]{2}{*}{ - } \\
\hline & & & & +.0047 & \pm .0187 & \\
\hline \multirow[t]{2}{*}{ 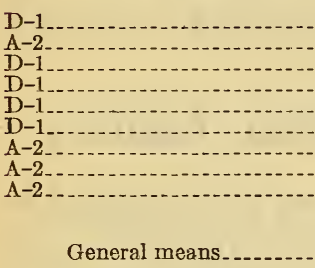 } & \multirow[t]{2}{*}{$\begin{array}{r}139.1 \\
22.6 \\
16.1 \\
89.3 \\
18.4 \\
20.7 \\
24.2 \\
39.6 \\
64.7\end{array}$} & \multirow[t]{2}{*}{$\begin{array}{l}.0522 \\
.0594 \\
.0864 \\
.1052 \\
.1718 \\
.2877 \\
.3842 \\
(.6100) \\
(.7340)\end{array}$} & \multirow[t]{2}{*}{$\begin{array}{l}.5764 \\
.5826 \\
.5963 \\
.5998 \\
.5806 \\
.5586 \\
.5312 \\
.4862) \\
(.4638)\end{array}$} & $\begin{array}{l}-.0144 \\
-.0073 \\
+.0100 \\
+.0122 \\
+.0066 \\
+.0041 \\
-.0046 \\
(+.0022) \\
(+.0153)\end{array}$ & $\begin{array}{r}-.0162 \\
-.0091 \\
+.0082 \\
+.0104 \\
+.0048 \\
+.0023 \\
-.0064 \\
-\end{array}$ & $\begin{array}{r}-0.0153 \\
-.0082 \\
+.0091 \\
+.0113 \\
+.0057 \\
+.0032 \\
-.0055 \\
\hdashline-. .-. .-\end{array}$ \\
\hline & & & & $\begin{array}{l}+.0009 \\
+.0018\end{array}$ & $\begin{array}{l} \pm .0095 \\
\pm .0098\end{array}$ & \pm .0083 \\
\hline
\end{tabular}

We may first examine Table 19, which refers to the smallest of all the orifices tested. The observations are spread over a very wide range of $x$, but we shall ignore the last two values of $C_{1}$ because the values of $x$ at which they were obtained are outside the range for which the empirical equation was developed and over which we regard it as safely applicable.

The general mean at the foot of column 5 shows that, on the average, the values of $C_{1}$ found for this orifice were higher than the computed values by about 0.0018 or 0.3 per cent.

Column 6 gives the departures of the individual values of $\delta$ from their general mean. The mean of these departures, taken without regard to sign, is \pm 0.0098 , and this figure may be regarded as a rough measure of the internal inconsistencies of the series.

Column 7 contains the corresponding values for $x>0.02$.

Judged by the criterion of internal consistency, this series is one of our worst, and if there had been none better our results would not have been worth much.

Table 20 contains similar, but more numerous, data for an orifice of diameter ratio $\beta=0.2778$. The last value of $C_{1}$ is disregarded for reasons stated above. The general mean at the foot of column 5 shows that, on the average, the values of $C_{1}$ for this orifice were lower than the values from equation (30) by about 0.0024 or 0.5 per cent.

The mean departure from the general mean is \pm 0.0041 (foot of zolumn 6), so that this series is much more consistent with itself than the series in Table 19. 
Bean, Buckingham,
Murphy $\quad$ Discharge Coefficients of Orifices

TABLE 20.-Plate No. 5-8 (Bureau of Standards)

[ $D=7.634$ ins.; $d=2.121$ ins.; $\beta=0.2778$; throat taps]

\begin{tabular}{|c|c|c|c|c|c|c|}
\hline Flow nozzle used & $\begin{array}{l}\text { Initial } \\
\text { pressure } \\
p_{1} \\
\text { lb./in. }{ }^{2}\end{array}$ & $\begin{array}{l}\frac{p_{1}-p_{2}}{p_{1}} \\
=x\end{array}$ & $\begin{array}{c}C_{1} \\
\text { (obs.) }\end{array}$ & $\begin{array}{c}C_{1} \text { (obs.) } \\
-C_{1} \text { (calc.) } \\
=\delta\end{array}$ & $\delta+0.0024$ & $\delta+0.0027$ \\
\hline 1 & 2 & 3 & 4 & 5 & 6 & 7 \\
\hline $\begin{array}{l}\mathrm{B}-2 \\
\mathrm{~A}-\mathrm{2} \\
\mathrm{A}-2 \\
\mathrm{~A}-\mathrm{2}\end{array}$ & $\begin{array}{r}222.7 \\
112.0 \\
89.2 \\
49.1\end{array}$ & $\begin{array}{r}0.0057 \\
.0059 \\
.0088 \\
.0093\end{array}$ & $\begin{array}{r}0.5947 \\
.5936 \\
.5896 \\
.5889\end{array}$ & $\begin{array}{r}-0.0025 \\
-.0037 \\
-.0074 \\
-.0080\end{array}$ & $\begin{array}{r}-0.0002 \\
-.0013 \\
-.0050 \\
-.0056\end{array}$ & $\cdots$ \\
\hline \multirow[t]{2}{*}{ 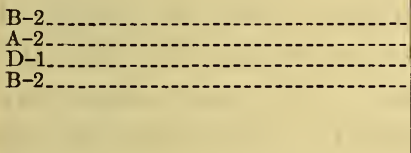 } & \multirow[t]{2}{*}{$\begin{array}{r}128.4 \\
50.9 \\
15.0 \\
142.3\end{array}$} & \multirow[t]{2}{*}{$\begin{array}{l}.0106 \\
.0113 \\
.0117 \\
.0150\end{array}$} & \multirow[t]{2}{*}{$\begin{array}{l}.5961 \\
.6002 \\
.6034 \\
.5920\end{array}$} & $\begin{array}{l}-.0006 \\
+.0036 \\
+.0068 \\
-.0042\end{array}$ & $\begin{array}{l}+.0018 \\
+.0060 \\
+.0092 \\
-.0018\end{array}$ & \multirow[t]{2}{*}{ 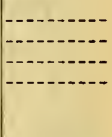 } \\
\hline & & & & -.0020 & \pm .0039 & \\
\hline 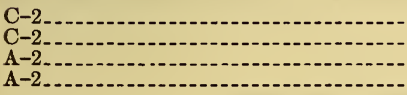 & $\begin{array}{l}90.9 \\
48.9 \\
16.0 \\
16.6\end{array}$ & $\begin{array}{l}.0624 \\
.0757 \\
.0771 \\
.1136\end{array}$ & $\begin{array}{l}.5845 \\
.5810 \\
.5926 \\
.5833\end{array}$ & $\begin{array}{l}-.0055 \\
-.0073 \\
+.0046 \\
+.0003\end{array}$ & $\begin{array}{l}-.0031 \\
-.0049 \\
+.0070 \\
+.0027\end{array}$ & $\begin{array}{r}-0.0028 \\
-.0046 \\
+.0073 \\
+.0030\end{array}$ \\
\hline  & $\begin{array}{l}47.8 \\
18.5 \\
20.6 \\
48.0\end{array}$ & $\begin{array}{l}.1722 \\
.1977 \\
.2664 \\
.2742\end{array}$ & $\begin{array}{l}.5642 \\
.5673 \\
.5601 \\
.5455\end{array}$ & $\begin{array}{l}-.0098 \\
-.0026 \\
+.0018 \\
-.0114\end{array}$ & $\begin{array}{l}-.0074 \\
-.0002 \\
+.0042 \\
-.0090\end{array}$ & $\begin{array}{l}-.0071 \\
+.0001 \\
+.0045 \\
-.0087\end{array}$ \\
\hline \multirow[t]{2}{*}{  } & \multirow[t]{2}{*}{$\begin{array}{l}21.6 \\
23.5 \\
26.8 \\
37.3\end{array}$} & \multirow[t]{2}{*}{$\begin{array}{l}.3208 \\
.3732 \\
.4438 \\
(.5510)\end{array}$} & \multirow[t]{2}{*}{$\begin{array}{c}.5482 \\
.5386 \\
.5240 \\
(.4923)\end{array}$} & $\begin{array}{c}-.0002 \\
+.0002 \\
+.0007 \\
(-.0061)\end{array}$ & $\begin{array}{l}+.0022 \\
+.0026 \\
+.0031\end{array}$ & $\begin{array}{l}+.0025 \\
+.0029 \\
+.0034\end{array}$ \\
\hline & & & & $\begin{array}{l}-.0027 \\
-.0024\end{array}$ & $\begin{array}{l} \pm .0042 \\
\pm .0041\end{array}$ & $\begin{array}{l} \pm .0043 \\
.\end{array}$ \\
\hline
\end{tabular}

TABLE 21.-Plate No. 5-6 (Bureau of Standards)

[ $D=5.785$ ins.; $d=1.997$ ins.; $\beta=0.3452$; throat taps]

\begin{tabular}{|c|c|c|c|c|c|}
\hline Flow nozzle used & $\begin{array}{l}\text { Initial } \\
\text { pressure } \\
p_{1} \\
\text { lbs./in. }{ }^{2}\end{array}$ & $\begin{array}{l}\frac{p_{1}-p_{2}}{p_{1}} \\
=x\end{array}$ & $C_{1}$ (obs.) & $\begin{array}{c}C_{1} \text { (obs.) } \\
-C_{1} \text { (calc.) } \\
=\delta\end{array}$ & $\delta-0.0009$ \\
\hline 1 & 2 & 3 & 4 & 5 & 6 \\
\hline 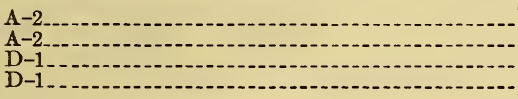 & $\begin{array}{r}213.8 \\
209.5 \\
15.0 \\
49.9\end{array}$ & $\begin{array}{l}0.0016 \\
.0026 \\
.0036 \\
.0043\end{array}$ & $\begin{array}{r}0.5864 \\
.5985 \\
.6159 \\
.6008\end{array}$ & $\begin{array}{r}-0.0117 \\
-.0021 \\
+.0181 \\
+.0032\end{array}$ & $\begin{array}{r}-0.0126 \\
-.0030 \\
+.0172 \\
+.0023\end{array}$ \\
\hline \multirow[t]{2}{*}{$\begin{array}{l}\text { B-2 } \\
\text { B-2 } \\
\text { D-1 } \\
\text { A-2 }\end{array}$} & \multirow[t]{2}{*}{$\begin{array}{r}213.9 \\
219.5 \\
15.0 \\
88.9\end{array}$} & \multirow[t]{2}{*}{$\begin{array}{l}.0073 \\
.0074 \\
.0090 \\
.0108\end{array}$} & \multirow[t]{2}{*}{$\begin{array}{l}.5892 \\
.5952 \\
.6062 \\
.5978\end{array}$} & $\begin{array}{l}-.0082 \\
-.0022 \\
+.0091 \\
+.0008\end{array}$ & $\begin{array}{l}-.0091 \\
-.0031 \\
+.0082 \\
-.0001\end{array}$ \\
\hline & & & & +.0009 & \pm .0069 \\
\hline  & $\begin{array}{r}132.1 \\
16.6 \\
49.2 \\
17.4 \\
84.2\end{array}$ & $\begin{array}{l}.0225 \\
.0250 \\
.0251 \\
.0298 \\
.0401\end{array}$ & $\begin{array}{l}.6326) \\
.5968 \\
.5947 \\
.5968 \\
.5940\end{array}$ & $\begin{array}{l}+(+0371) \\
+.0015 \\
+.0006 \\
+.0022 \\
+.0006\end{array}$ & $\begin{array}{l}+.0006 \\
+.0015 \\
+.0013 \\
-.0003\end{array}$ \\
\hline $\begin{array}{l}\mathrm{D}-1 \\
\mathrm{~A}-2 \\
\mathrm{~A}-2 \\
\mathrm{~A}-2\end{array}$ & $\begin{array}{l}19.8 \\
45.6 \\
21.3 \\
23.6 \\
87.5\end{array}$ & $\begin{array}{l}.0484 \\
.0641 \\
.0665 \\
.0780 \\
.0871\end{array}$ & $\begin{array}{l}.5888 \\
.5920 \\
.5917 \\
.5903 \\
.5872\end{array}$ & $\begin{array}{l}+.0035 \\
+.0017 \\
+.0018 \\
+.0019 \\
+.0006\end{array}$ & $\begin{array}{l}-.0044 \\
+.0008 \\
+.0009 \\
+.0010 \\
-.0003\end{array}$ \\
\hline 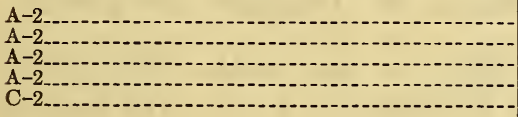 & $\begin{array}{l}28.3 \\
30.1 \\
32.7 \\
34.9 \\
49.3\end{array}$ & $\begin{array}{l}.0923 \\
.0961 \\
.1015 \\
.1051 \\
.1158\end{array}$ & $\begin{array}{l}.5855 \\
.5853 \\
.5867 \\
.5874 \\
.5859\end{array}$ & $\begin{array}{l}-.0009 \\
-.0006 \\
+.0016 \\
+.0022 \\
+.0018\end{array}$ & $\begin{array}{l}-.0018 \\
-.0015 \\
+.0007 \\
+.0013 \\
+.0009\end{array}$ \\
\hline \multirow[t]{2}{*}{ 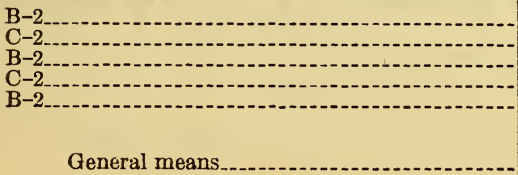 } & \multirow[t]{2}{*}{$\begin{array}{l}50.0 \\
49.5 \\
27.3 \\
47.2 \\
30.4\end{array}$} & \multirow[t]{2}{*}{$\begin{array}{l}.1316 \\
.1752 \\
.2382 \\
.2428 \\
.2578\end{array}$} & \multirow[t]{2}{*}{$\begin{array}{l}.5831 \\
.5744 \\
.5642 \\
.5647 \\
.5608\end{array}$} & $\begin{array}{l}+.0024 \\
+.0002 \\
+.0007 \\
+.0020 \\
+.0007\end{array}$ & $\begin{array}{l}+.0015 \\
-.0007 \\
-.0002 \\
+.0011 \\
-.0002\end{array}$ \\
\hline & & & & $\begin{array}{r}+.0009 \\
+.0009\end{array}$ & $\begin{array}{l} \pm .0011 \\
\pm .0028\end{array}$ \\
\hline
\end{tabular}


Table 21 contains the data for an orifice of diameter ratio $\beta=0.3452$. One of the values of $C_{1}$ is far out of line with the others and gives a very large $\delta$. We regard this large departure from the mean $(+0.0371)$ as representing a mistake rather than an error, and we omit it from the average. In a few other similar cases we have likewise had no scruples in ignoring isolated points which departed from the general run by several times the average departure of the rest of the points.

The general mean at the foot of column 5 shows that the values of $C_{1}$ for this orifice averaged about 0.0009 , or something less than 0.2 per cent, higher than the computed values. The mean departure from the mean $\delta$ is \pm 0.0028 (foot of column 6 ). This series is one of the very best.

\section{Table 22.-Plate No. 11-6 (Foxboro Company)}

[ $D=5.785$ ins.; $d=3.500$ ins.; $\beta=0.6050$; throat taps]

\begin{tabular}{|c|c|c|c|c|c|c|c|}
\hline & Flow nozzle used & $\begin{array}{c}\text { Initial } \\
\text { pressure } \\
p_{1} \\
\text { lbs./in.2 }\end{array}$ & $\begin{array}{l}\frac{p_{1}-p_{2}}{p_{1}} \\
=x\end{array}$ & $\begin{array}{c}C_{1} \\
\text { (obs.) }\end{array}$ & $\begin{array}{c}C_{1} \text { (obs.) } \\
-C_{1} \text { (calc.) } \\
=\delta\end{array}$ & $\delta-0.0026$ & $\delta-0.0013$ \\
\hline & 1 & 2 & 3 & 4 & 5 & 6 & 7 \\
\hline \multirow[t]{2}{*}{$\begin{array}{l}\text { A-2. } \\
\text { C-1- } \\
\text { A-2-2 }\end{array}$} & & \multirow[t]{4}{*}{$\begin{array}{l}49.4 \\
88.6 \\
15.1 \\
48.8\end{array}$} & \multirow[t]{2}{*}{$\begin{array}{r}0.0015 \\
.0061 \\
.0090 \\
.0196\end{array}$} & \multirow[t]{2}{*}{$\begin{array}{r}0.6148 \\
.6088 \\
.6135 \\
.6075\end{array}$} & $\begin{array}{r}+0.0059 \\
+.0005 \\
+.0066 \\
+.0010\end{array}$ & $\begin{array}{r}+0.0033 \\
-.0021 \\
+.0001 \\
-.0016\end{array}$ & \multirow[t]{2}{*}{ 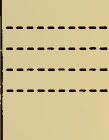 } \\
\hline & & & & & +.0035 & \pm .0027 & \\
\hline \multirow[t]{2}{*}{$\begin{array}{l}\text { B-2- } \\
\text { C-2- } \\
\text { C-2. }\end{array}$} & & & \multirow[t]{2}{*}{$\begin{array}{l}.0810 \\
.1110 \\
.1262\end{array}$} & \multirow[t]{2}{*}{$\begin{array}{r}.5980 \\
.5925 \\
.5926\end{array}$} & $\begin{array}{r}+.0007 \\
+.0002 \\
+.0030\end{array}$ & $\begin{array}{r}-.0019 \\
-.0024 \\
+.0004\end{array}$ & $\begin{array}{r}-0.0006 \\
-.0011 \\
+.0017\end{array}$ \\
\hline & General means & & & & $\begin{array}{l}+.0013 \\
+.0026\end{array}$ & $\begin{array}{l} \pm .0016 \\
\pm .0022\end{array}$ & \pm .0011 \\
\hline
\end{tabular}

Table 22 contains the data for an orifice of diameter ratio $\beta=0.605$. The observations cover only a short range of $x$ because it was impossible to reach high differentials with so large an orifice. They are so few in number that averages have little significance, but, judged by the criterion already employed, this is one of the good series. The values of $C_{1}$ are, on the whole, about 0.0026 , or 0.5 per cent, higher than the computed values.

\section{COMMENTS ON THE DATA IN TABLES 19 TO 22}

For convenience of comparison, some of the mean values from Tables 19 to 22 are brought together in Table 23, which may now be examined. 
TABLE 23.-Summary of values from Tables 19 to 22

\begin{tabular}{|c|c|c|c|c|c|}
\hline & & \multicolumn{4}{|c|}{ Table- } \\
\hline & 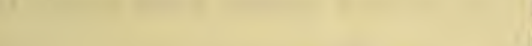 & 19 & 20 & 21 & 22 \\
\hline $\begin{array}{l}1 \\
2 \\
3 \\
4\end{array}$ & $\begin{array}{l}\text { Serial number of plate } \\
\text { Diameter ratio, } \beta \\
\text { Number of points for } x<0.02- \\
\text { Number of points for } x>0.02\end{array}$ & $\begin{array}{l}0.1-6 \\
2 \\
7\end{array}$ & $8_{11}^{0.2778}$ & $\begin{aligned} 0.3452 \\
8 \\
19\end{aligned}$ & $\begin{array}{l}11-6 \\
0.6050 \\
4 \\
3\end{array}$ \\
\hline $\begin{array}{l}5 \\
6 \\
7 \\
8\end{array}$ & 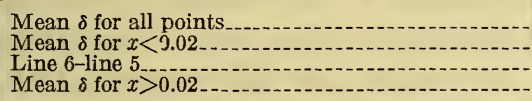 & $\begin{array}{r}+.0018 \\
+.0047 \\
+.0029 \\
+.0009\end{array}$ & $\begin{array}{l}-.0024 \\
-.0020 \\
\pm .0004 \\
-.0027\end{array}$ & $\begin{array}{r}+.0009 \\
+.0009 \\
+.0000 \\
+.0009\end{array}$ & $\begin{array}{r}+.0026 \\
+.0035 \\
+.0009 \\
+.0013\end{array}$ \\
\hline $\begin{array}{r}9 \\
10 \\
11 \\
12\end{array}$ & $\begin{array}{l}\text { Line 8-line 5- } \\
\text { Mean scattering for all points } \\
\text { Mean scattering for } x<0.02 \\
\text { Mean scattering for } x>0.02-\end{array}$ & $\begin{array}{l}-.0009 \\
\pm .0098 \\
\pm .0187 \\
\pm .0095\end{array}$ & $\begin{array}{l}-.0003 \\
\pm .0041 \\
\pm .0039 \\
\pm .0042\end{array}$ & $\begin{array}{l}.0000 \\
\pm .0028 \\
\pm .0069 \\
\pm .0011\end{array}$ & $\begin{array}{l}-.0013 \\
\pm .0022 \\
\pm .0027 \\
\pm .0016\end{array}$ \\
\hline
\end{tabular}

\section{MEAN VALUES OF $\delta$}

For each orifice let the curve $C_{1}=f(x)$ be constructed from equation (30) with the appropriate value of $\beta$. Let this curve be raised by the amount shown in line 5 of Table 23, and let the new curve be called "the adjusted curve" for the orifice in question. If points representing the observed values of $C_{1}$ are also plotted, they will obviously be, on the average, as much above as below the adjusted curve.

Line 7 shows the average amount by which the observed points are above the adjusted curve for those experiments in which $x<$ 0.02 ; that is, in which the downstream static pressure was more than 98 per cent of the upstream pressure. For plate No. 5-6, the best of the series here presented, the mean point for $x<0.02$ lies on the adjusted curve, while for the other three plates it lies higher; but this does not indicate a general rule. For when all the orifices are taken into account the differences corresponding to those in line 7 come out negative about as often as positive, and the mean point for $x<0.02$ is sometimes above and sometimes below the adjusted curve, with no marked preponderance of either direction.

For $x>0.02$ the mean departure of the obselved points from the adjusted curve is, of course, of the opposite sign to that for $x<0.02$, as is illustrated by a comparison of lines 9 and 7 .

\section{SCATTERING OF OBSERVED POINTS}

The average distance of a series of points from the adjusted curve, taken without regard to sign, may be called their "mean scattering." As remarked in section 21 , this quantity, shown in line 10 , may be taken as a rough measure of the "badness" of the series.

If, as before, we treat the two groups of points separately (lines 11 and 12), we find that in three of the four cases the mean scattering $14830^{\circ}-29-4$ 
was much greater for $x<0.02$ than for $x>0.02$, though in the fourth case the two were sensibly equal. This does illustrate a rule to which there were few exceptions. In nearly all series which included several points near $x=0$ - that is, near $r=1$-these points were much more scattered than points farther out.

\section{DISCUSSION OF THE ACCIDENTAL ERRORS}

The greater scattering of the values of $C_{1}$ obtained from experiments at low values of $x$ might naturally, at first sight, be attributed to the greater percentage errors in reading low differentials; but this explanation is fallacious, for, in the first place, the absolute static pressures varied in the ratio of 15 to 1 and a low value of $x$ did not always mean a low absolute value of the differential.

But there is a more striking piece of evidence. Each reading of the differential between the throat taps was accompanied by readings between the flange and between the pipe taps, all within a short space of time and as nearly as possible under the same working conditions. The accidental errors of the three readings can not have been systematically related, but the three values of $C_{1}$ varied together, a high value of $C_{1}$ for throat taps being accompanied by high values for the other two combinations, and vice versa.

This parallelism was, of course, not perfect, because the accidental errors of reading the differential gauge were not entirely inappreciable. But for the orifices of the lower diameter ratios the resulting accidental errors in $C_{1}$ were of the order of only 0.1 or 0.2 per cent; and the agreement of the three sets of values of $C_{1}$, as regards their variations from one experiment to another, proved conclusively that these simultaneous variations were not due to errors of the readings at the orifice but to some other cause which affected all three values of $C_{1}$ in the same way.

Three possible explanations suggest themselves-the discharge coefficient may depend on the absolute static pressure, to which no attention has hitherto been given; or the discharge coefficients of the flow nozzles may have been incorrectly determined; or the observations at the flow nozzle may have been affected by large errors. (a) If the discharge coefficient of an orifice depended on the absolute static pressure at which the experiment was made, this influence would be revealed by intercomparing all the values of $C_{1}$ obtained with the same flow nozzle, and the value of $\delta$ would vary systematically with the initial pressure $p_{1}$.

Particular series may be picked out where this appears to be the case, especially at low values of $x$; but in general the hypothesis is not substantiated, and the whole mass of observations indicates that within the range of static pressures covered in these experiments the discharge coefficient of an orifice depends only on the ratio of the two 
pressures and is sensibly independent of their absolute values. It would, indeed, be very surprising if any effect of the absolute pressure were observed with a gas so nearly ideal as air.

(b) Each of the orifices referred to in Tables 19 to 22 was tested with two or more flow nozzles, and the same was true of nearly all the orifices. If the discharge coefficients of the nozzles had been incorrectly determined relatively to one another, the values of $\delta$ would have varied with changes from one nozzle to another, some nozzles giving systematically high values of $C_{1}$ and others systematically low values.

Series of values of $C_{1}$ for particular orifices may be found. which seem to show evidence of this, but here, again, the idea is not confirmed by the aggregate of all the experiments and there is, on the whole, no evidence of errors in the discharge coefficients of the flow nozzles which are at all comparable in magnitude with those required to account for the actual variations in $\delta$.

(c) Of the observations made at the flow nozzle, the only one subject to errors of any importance is the reading of the differential by means of the central impact tube; but this was read each time one of the differentials at the orifice upstream was read, and there can have been no systematic connection between the errors of reading the differential gauges at the orifice and at the nozzle. Furthermore, there is no reason to suppose that the errors at the nozzle were of a different order of magnitude from those at the orifice, which have already been shown to be relatively small. It therefore appears that this third explanation of the large accidental errors in $C_{1}$ can not be accepted as adequate.

(d) The true cause seems to have been the lack of complete steadiness in the rate of flow, due to the impossibility of holding the speed of the compressors perfectly constant or, ultimately, to variations of voltage in the power supply to the motors. There was a large capacity between even the 8-inch orifice station and the flow nozzle, and when the air supply varied there must evidently have been a time lag between the orifices and the nozzle, so that observations made simultaneously at both places did not, in reality, correspond to precisely equal rates of flow.

Any such time lag would be greater the lower the rate of discharge, and its effects on the value of $C_{1}$ computed by assuming the flow to be perfectly uniform all along the line would therefore be more likely to be large at low than at high rates of flow. With any one orifice, low rates of flow occur at low values of $x$. Hence, the effects of variations of compressor speed in producing variations of $\delta$ should, on the whole, be more pronounced at low values of $x$, and, in general, this is just what happened, as was remarked in section 22 .

Furthermore, at any given pressure ratio, the absolute rate of flow is lower for small than for large orifices. Hence, if the errors 
now in question are really due to the time lag, they will be most marked for the smaller orifices, and this, also, is what was actually found, as is illustrated by Tables 19 to 22 , or by the summary in lines 10,11 , and 12 of Table 23.

For any given diameter ratio the orifices are smallest for the 4-inch plates and, other things being equal, the scattering might be expected to be, on the whole, greatest for the 4-inch plates which were, moreover, farthest upstream and separated from the flow nozzle by a somewhat greater capacity than the others. This expectation is also confirmed by an examination of the whole collection of values of $C_{1}$.

The voltage, compressor speed, and air supply were, of course, more unsteady at some times than at others, and the statements above are true only on the whole and not in every individual case. But it seems fair to conclude that the greater part of the unexpectedly large accidental errors of the experiments was due to the lack of a perfectly steady power supply, and that even if all our measurements had been absolutely accurate, unavoidable errors would still have been present in the results. The only mitigation of the effects of these accidental errors lies in the multiplication of experiments, by which they are, to a considerable extent, averaged out.

It seems useless to attempt any further quantitative discussion of the accuracy of our results, and the reader must be left to form his own estimate from the specimens given in Tables 19 to 22 and from the remarks which have been presented in this and the two preceding sections.

\section{THE EFFECTS OF VISCOSITY}

Within the range of working conditions covered by our experiments, the discharge coefficients of square-edged orifices are not appreciably affected by changes in the viscosity of the fluid. The experiments were therefore not adapted to investigating such effects and did not add anything to the experimental information concerning them which has already been published by Hodgson and Daugherty. ${ }^{12}$ Nevertheless, the subject is of such importance that it will be discussed briefly here, rather than relegated entirely to an appendix, as would otherwise be more appropriate. It will be treated somewhat further in Appendix C.

Let us suppose that a liquid of low viscosity, such as water, is flowing through an orifice, and that the discharge coefficient is determined from measurements of the differential and rate of discharge. Let the liquici then be replaced, successively, by others of greater and greater viscosity, and in each case let the discharge coefficient

12 J. L. Hodgson, The Orifice as a Basis of Flow Measurement; Inst. Civ. Eng., Selected Engineering Papers, No. 31; 1925. R. L. Daugherty; Bulletin No. 130, Goulds Pumps (Inc.), Seneca Falls, N. Y.; 1926. 
of the orifice be determined at the same volume rate of flow as in the first experiment. Sooner or later the discbarge coefficient will begin to increase with the viscosity, the point where this increase first becomes evident depending on the precision of the experiments.

The first effect of increased viscosity is to retard the motion of the liquid over the upstream face of the plate toward the orifice and around the edge. The surface film creeps around the corner more slowly, and the centrifugal force urging it toward the axis of the jet is diminished. Hence, there is less tendency to contraction, the cross section of the vena contracta becomes larger, and the discharge coefficient increases.

But this action can, at most, go only so far as entirely to eliminate contraction; and meanwhile, as the viscosity increases, its retarding effect reaches farther and farther from the edge of the orifice into the jet, so that a higher and higher differential is needed to maintain the given rate of discharge. If the viscosity were increased indefinitely, the differential would evidently also have to be raised indefinitely, and the discharge coefficient would fall toward zero.

The combined result of these two opposing tendencies is that, as the viscosity is progressively increased from low values while the rate of discharge is held constant, the discharge coefficient of the orifice first increases, then passes through a maximum, and thereafter decreases.

The foregoing is an elementary physical interpretation of the observed facts as described by Hodgson and Daugherty in the papers referred to above.

In the absence of viscosity, the only forces called into play in the formation of a jet would be the inertia reactions of the liquid against acceleration, which are proportional to the density; but since no real liquid is entirely free from viscosity, viscous forces are also necessarily developed. The degree to which they modify the motion of the liquid evidently depends, not on their absolute magnitude, which is proportional to the viscosity, but on their relative magnitude in comparison with the inertia forces. Hence, in the present connection, the important characteristic property of the liquid is not simply its viscosity $\mu$ but the ratio of viscosity to density or

$$
\frac{\mu}{\rho}=\nu
$$

which is known as the "kinematic viscosity."

With a given orifice and a given liquid, the viscous resistances increase with the speed of flow, but the kinetic energy and the accompanying inertia reactions increase with the square of the speed. Hence, the influence of viscosity is greater at low than at high speeds, and lowering the rate of discharge has qualitatively the same effect on the discharge coefficient as increasing the kinematic viscosity. 
Let us suppose, finally, that without altering either the liquid or the mean linear speed of the jet, experiments are made upon smaller and smaller orifices which are, together with the adjacent parts of the pipe, all geometrically similar to one another or of the same "shape," in the general sense of the term. Reducing the linear dimensions of the apparatus without reducing the linear speed of flow through it increases the transverse gradients of speed, to which the viscous forces are proportional, and the influence of viscosity is therefore greater on small than on large orifices; or reducing the size of the orifice has qualitatively the same effect as increasing the kinematic viscosity of the liquid.

The foregoing conclusions are all consistent with the proposition that for orifices of any one shape the discharge coefficient is determined by the value of the single quantity

$$
R=\frac{d S}{\nu}=\frac{d S \rho}{\mu}
$$

in which $S$ is the mean linear speed through the orifice, computed from the known diameter $d$ and the observed volume rate of discharge, and $R$ is known as the "Reynolds number."

The proof of this proposition may be edeferred to Appendix C, but an important inference may be drawn at once; namely, that for all orifices of any one shape there is a general relation

$$
C=f(R)
$$

which holds for all liquids, all sizes, and all rates of discharge. According to the reasoning advanced above concerning the effects of varying

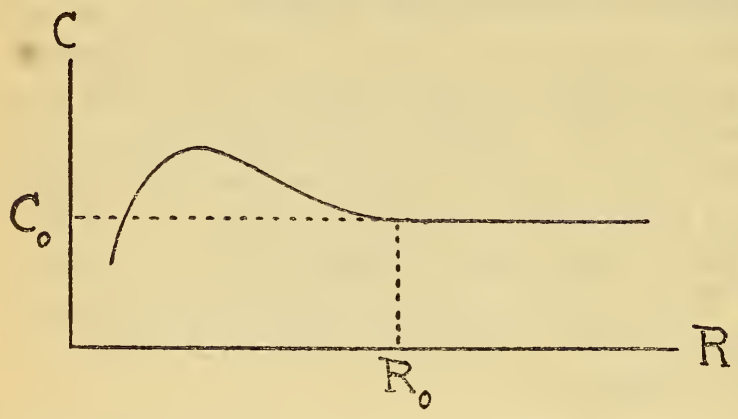

Fig. 9.-Variation of discharge coefficient with Reynolds number $\nu, S$, and $d$ separately, the curve representing equation (49) should be qualitatively of the form illustrated in Figure 9, and the experiments of both Hodgson and Daugherty have, in fact, given curves of this form. They show that for all large values of $R$ the discharge coefficient of an orifice has the same sensibly constant value $\mathrm{C}_{0}$, and that it is not measurably affected by variations of the kinematic viscosity or the rate of discharge unless these are such as to reduce $R$ below some limiting value $R_{0}$.

The foregoing statements have referred specifically only to liquids, but they are equally applicable to gases when the percentage differen- 
tial is small, so that the density is nearly constant; and in Hodgson's experiments the points obtained for air and for various mixtures of water and glycerine all lay indiscriminately along the same smooth curve of the form represented in Figure 9.

The precise form of the curve and the values of $C_{0}$ and $R_{0}$ depend on the "shape" of the orifice; this term being understood in the most general sense as referring not only to diameter ratio, sharpness of edge, and relative positions of the pressure taps, but to any and all other geometrical peculiarities of the orifice itself or of the channel in which it is installed, which influence the nature of the fluid motion between the two cross sections where the taps are situated. Our present interest is not, however, in the whole curve but only in the horizontal portion of it. It is safer to avoid the effects of viscosity than to attempt to make allowance for them, and what is needed is a simple criterion which will show, in any particular case which may occur in practice, whether the effects of viscosity on the discharge coefficient will be negligible or, if not, how the working conditions may be modified to make them so.

The meaning to be assigned to the term "negligible" obviously depends on the precision of the experiments, so that the value of $R_{\mathrm{o}}$ is somewhat indefinite at best. Furthermore, the information hitherto published, though drawn from a large number of laborious and painstaking observations, is meager and somewhat conflicting, so that only very rough estimates of the value of $R_{\mathrm{o}}$ are possible. Nevertheless, such data as are available indicate that for air at ordinary temperatures and for orifice diameter ratios between 0.2 and 0.6 the Reynolds number $R$ will be high enough to make the effects of viscosity negligible in all commercial measurements whenever the relation

$$
d^{2} p h>10
$$

is satisfied, $d$ being the diameter of the orifice in inches, $p$ the absolute static pressure in pounds per square inch, and $h$ the differential in inches of water.

Since the process of arriving at the numerical value in (50) involves the use of the density and viscosity of air, the estimate would be different for another gas and, moreover, the value is not independent of the diameter ratio of the orifice. But in the present state of our knowledge it seems useless to attempt further refinements, and we can do no better than to regard the inequality (50) as probably a safe criterion in the commercial metering - of natural or other gases which are not widely different from air as regards specific gravity and viscosity.

The condition expressed by (50) is evidently amply satisfied in the great majority of commercial measurements of gas by orifice meters, 
for with an orifice of as small diameter as 0.8 inch and an absolute pressure as low as $15 \mathrm{lbs}$./in. ${ }^{2}$ the differential

$$
h=\frac{10}{0.8^{2} \times 15}=1 \mathrm{inch}
$$

will still be high enough. But in the employment of smaller orifices for the measurement of very low rates of discharge the condition might be violated; and until the subject has been further investigated it seems well to accept (50) as a warning to adopt some other method of metering in these cases, unless the orifice can be standardized under the same working conditions as are to prevail when it is used as a meter.

\section{GEOMETRICAL SIMILARITY AND THE INFLUENCE OF PIPE DIAMETER}

The values of $C_{1}$ obtained for the 4 -inch plates were, on the average, about 1.5 per cent higher than those found for 6 and 8 inch plates of the same diameter ratio, and this result agrees, qualitatively, with the experience of other experimenters.

Other things being equal, reducing the diameter of the orifice lowers the Reynolds number and will ultimately increase the discharge coefficient, as explained in section 24, and some of the high values obtained with small apparatus have doubtless been due to the disturbing action of viscosity. But many experiments, including our own, have shown a dependence of discharge coefficient on pipe diameter, even when the Reynolds number was much too high to admit of this explanation of the observations.

On the other hand, the theory of dimensions ${ }^{13}$ predicts that so long as the effects of viscosity are negligible a mere change of scale will not alter the discharge coefficient, and the validity of the theory has been confirmed experimentally in so many applications to hydro and aerodynamics that deductions from it are no longer open to any reasonable doubt.

The obvious and necessary conclusion is that when, for example, an 8-inch and a 4-inch plate of the same diameter ratio and with similarly situated pressure taps are found to have different discharge coefficients, the change of size has not altered the linear dimensions of all the essential features of the apparatus in the same ratio, but has been accompanied by more or less change of "shape," in the general sense of the term. The two installations are not quite geometrically similar, and the difference of discharge coefficients is caused by this departure from similarity and not directly by the change of absolute size.

13 Seo Appendix C. 
It is easy to see how this might come about. The most obvious elements of shape are diameter ratio, sharpness of edge, and relative location of pressure taps. To secure an adequate degree of similarity as regards diameter ratio and positions of the taps is a simple matter, because small changes in these elements of shape have very little effect on the discharge coefficient unless the diameter ratio is large. Similarity of edge is much more difficult to attain, as is shown by the considerable differences of behavior exhibited even by carefully made orifices of the same size, installed in identically the same way.

But these three are not the only important elements of shape. For example, it is well known that the introduction of elbows or other pipe fittings, upstream from the orifice, may change the discharge coefficient by several per cent unless the intervening length of straight pipe is sufficient to allow the disturbances produced at the fittings to die out, or unless they are suppressed by means of honeycombs or straightening vanes.

In order that two orifices of different size may be of the same "shape," in the general sense required for the application of dimensional reasoning, all geometrical features of the channel which influence the nature of the fluid motion between the two cross sections where the pressure taps are situated must be reproduced to scale when the size is altered; and in many experimental investigations this condition has not been satisfied.

One point, which becomes of increasing importance as smaller and smaller pipes are employed, is internal roughness. Experiments by Stanton ${ }^{14}$ on pipes which were artificially roughened by internal screw threads showed that the roughening caused a considerable modification of the distribution of velocity over the cross section, the speed being diminished near the wall and increased near the axis, for any given average speed. Such an alteration in the distribution of velocity in the stream approaching an orifice would evidently diminish the contraction of the jet and raise the discharge coefficient of the orifice.

But with pipes of any given quality and in equally good condition, the smaller sizes are extremely likely to be relatively, though not absolutely, rougher than the larger ones, so that substituting a small for a large pipe has the same effect on the "shape" of the apparatus as making the large pipe absolutely rougher. It is therefore to be expected that, as a general rule, when ordinary commercial steel pipe is used, the discharge coefficients of orifices of any given diameter ratio will tum out to be highest for the smallest pipes. This is usually found to be the case; but the effect is not due to the change of absolute diameter, except insofar as this is unavoidably accompanied by a change of relative roughness. 
In our own experiments each orifice station was preceded by an uninterrupted run of uniform straight pipe at least 120 diameters long, which appears sufficient to eliminate the effects of disturbances produced still farther upstream. But the departure from geometrical similarity which consisted in the greater relative roughness of the 4-inch pipe remained, and it seems probable that the higher discharge coefficients found for the 4 -inch plates were due to this.

Other departures from geometrical similarity may also produce an illusory impression that the discharge coefficient of an orifice depends directly on its absolute diameter. For example, in the investigation by Spitzglass ${ }^{15}$, orifices were tested in seven sizes of pipe, from 2 to 12 inches in diameter, and the results showed a systematic increase of the discharge coefficient for any given diameter ratio as the diameter of the pipe was decreased; but the run of straight pipe ahead of the orifice was the same for all sizes-namely, 12 feet-instead of some fixed number of pipe diameters. Hence, the condition of geometrical similarity was vary far from satisfied, and no information was obtained regarding the effect of changing the absolute size by itself, but only when accompanied by a simultaneous progressive change in the shape of essential parts of the apparatus. There is no reason to doubt the correctness of the conclusions drawn concerning the effect of changing the pipe diameter in this particular form of installation. But the quantitative result can not be accepted as of general applicability, for it would quite possibly have been different if the entrance length had been 6 or 30 feet instead of 12 .

From the published accounts of other investigations in which orifices have been tested in pipes of various sizes, it is often impossible to form any opinion of the degree of geometrical similarity between large and small installations, or of the nature of the departures from similarity, so that it would be useless to attempt any physical interpretation of the results obtained. As a general rule, such experiments have shown higher discharge coefficients for small than for large pipes, as happened in our own work. This is probably usually due, at least in part, to roughness, as explained above; but it may also be due to the manner of preparing the orifices. For any slight rounding off of the entrance corner-for instance, by a light finishing touch with fine emery cloth-raises the discharge coefficient, and any given degree of absolute rounding affects a small orifice more than a large one.

The only general conclusions that can safely be drawn are as follows:

(a) So long as the Reynolds number is large enough that viscosity may be ignored, there is no reason to suppose that a uniform change of scale of all the essential parts of the apparatus influences the discharge coefficient at all.

16 J. M. Spitzglass, Trans. Am. Soc. Mech. Eng., 44, p. 912; 1922. 
(b) Changes of pipe diameter are, in practice, nearly always accompanied by changes of shape which are such as to make the discharge coefficient of an orifice of given diameter ratio higher in small than in large pipes.

(c) The magnitude of this change with pipe diameter depends on the particular form of apparatus used, and the results of one experimenter may differ from those of another by more than the errors of experiment, because the two observers are not measuring the same thing.

(d) So far as we know, there are no published data on the variation of discharge coefficient with pipe diameter which can be accepted as generally valid.

\section{EQUATIONS FOR USE IN ORIFICE METER COMPUTATIONS}

Equations (20) of Section X, in conjunction with (26) of Section XI, make it possible to compute the rate of flow of air through an orifice of known discharge coefficient from observations of the temperature, static pressure, humidity, and differential. They are suited to the purpose of defining discharge coefficients for which they were developed, but in practical computation various other forms of equation are more convenient under various circumstances. It would be impossible to give a complete list of such forms, but the sort of transformation required may be illustrated.

(a) It is usually desired that the rate of discharge be expressed in terms of volume, measured at some standard density or under some standard conditions.

Let and

$$
\rho_{\mathrm{s}}\left[\mathrm{lb} . / \mathrm{ft}^{3}{ }^{3}\right]=\text { the standard density adopted }
$$

$V\left[\mathrm{ft} .{ }^{3} / \mathrm{min}.\right]=$ the rate of discharge measured at $\rho_{\mathrm{B}}$.

Then the rate in $\mathrm{lb}$./sec. is

$$
M=\frac{1}{60} V \rho_{\mathrm{s}}
$$

and $(20, C)$ assumes the form

$$
V=\frac{31.50}{\rho_{\mathrm{s}}} C^{\prime}{ }_{1} d^{2} \sqrt{\rho_{1} \Delta}
$$

in which $d$ is in ins.; $\Delta$ in lb./ in. ${ }^{2}$; and $\rho_{1}$ in lb./ft. ${ }^{3}$

(b) The differential is usually measured by a liquid manometer, and it is then convenient to have the equation in such form that the manometer reading may be substituted directly, without being first reduced to $\mathrm{lb}$./in. ${ }^{2}$

Let

$\sigma=$ the specific gravity of the liquid at its actual temperature, referred to water at $60^{\circ} \mathrm{F}$.;

$h[$ ins. $]=$ the differential as read. 
With standard gravity

$1 \mathrm{lb} . /$ in. $^{2}=27.706$ inches of water at $60^{\circ} \mathrm{F}$.

so that

$$
\Delta\left[\text { lb./in. }{ }^{2}\right]=\frac{\sigma h}{27.706}
$$

and the factor $\sqrt{\Delta}$ in (52) is to be replaced by

$$
\sqrt{\frac{\sigma h}{27.706}}=0.1900 \sqrt{\sigma h}
$$

The resulting equation is

$$
V=\frac{5.985 \sqrt{\sigma}}{\rho_{\mathrm{B}}} C^{\prime}{ }_{1} d^{2} \sqrt{\rho_{1} h}
$$

(c) The density $\rho_{1}$ must be computed from the pressure, temperature, and humidity, and it is convenient to embody the computation in the equation, rather than perform it separately and then substitute.

For this purpose equation (26) Section XI may be utilized. In all ordinary commercial metering air may be regarded as following Boyle's law; hence, the correction factor $Y$ may be omitted and the equation simplified to the form

$$
\rho=\frac{2.6914 p(1-0.38 w)}{458+t}
$$

in which $w=\pi / p$ is the "vapor fraction"; that is, the partial pressure of the water vapor in the air, expressed as a fraction of the total pressure.

If the value of $\rho_{1}$ given by (57) is substituted in (56), the result may be written

where

$$
V=N C^{\prime}{ }_{1} d^{2} \sqrt{\frac{p_{1} h(1-0.38 w)}{458+t}}
$$

$$
N=\frac{9.819 \sqrt{\sigma}}{\rho_{\mathrm{B}}}
$$

If the standard density is not stated directly but specified by standard conditions, let

$$
\begin{aligned}
p_{\mathrm{B}}\left[\mathrm{lbs} . / \mathrm{in} . .^{2}\right] & =\text { the standard pressure; } \\
t_{\mathrm{B}}\left[{ }^{\circ} \mathrm{F} .\right] & =\text { the standard temperature; }
\end{aligned}
$$

and

Then by (57)

$$
w_{\mathrm{s}}=\text { the standard vapor fraction. }
$$

$$
\rho_{\mathrm{s}}=\frac{2.6914 p_{\mathrm{s}}\left(1-0.38 w_{\mathrm{s}}\right)}{458+t_{\mathrm{s}}}
$$

and (59) takes the alternative form

$$
N=\frac{3.648 \sqrt{\sigma}\left(458+t_{\mathrm{s}}\right)}{p_{\mathrm{s}}\left(1-0.38 w_{\mathrm{s}}\right)} .
$$


The value of the factor $N$ is fixed by the standard density or the standard conditions and the specific gravity $\sigma$ of the manometer liquid. It is independent of the working conditions at the orifice, and is constant except for small variations in $\sqrt{\sigma}$ which may be caused by variations of the temperature of the manometer liquid. If this remains between $32^{\circ}$ and $100^{\circ} \mathrm{F}$., the greatest possible variation of $N$ from its mean value is about one-fourth per cent for water and much less for mercury. Such errors are negligible in commercial metering and $N$ may be regarded as sensibly constant. If it is desired to allow for even small variations, the most natural procedure is to use a constant value of $N$, computed for some fixed temperature of the manometer, and reduce the observed values of $h$ to this temperature before substituting in (58).

(d) The operations by which $(20, c)$ was transformed into (58) might equally well have been carried out on $(20, a, b, d)$. The results can be obtained from (58) by substituting $C^{\prime}{ }_{2}, p_{2}$ for $C^{\prime}{ }_{1}$, $p_{1}$, or by utilizing the equations

$$
C_{1}=C^{\prime}{ }_{1} \sqrt{1-\beta^{4}} ; C_{2}=C^{\prime}{ }_{2} \sqrt{1-\beta^{4}}
$$

The value of $N$ is the same in all four cases and is to be found from (59) or (61).

\section{NUMERICAL EXAMPLES}

To illustrate the computation of $N$, let the standard conditions adopted for fixing the standard density be $60^{\circ} \mathrm{F}$., $14.65 \mathrm{lb} . / \mathrm{in} .{ }^{2}$, and 50 per cent saturation; and let the manometer liquid be carbon tetrachloride of specific gravity $\sigma=1.58$.

As a preliminary to substitution in (61) it is necessary to find the value of $W_{\mathrm{s}}$. The pressure of saturated water vapor at $60^{\circ} \mathrm{F}$. is found from the steam tables to be $0.256 \mathrm{lb}$./in. ${ }^{2}$ Hence, for 50 per cent saturation at $60^{\circ} \mathrm{F}$. and $14.65 \mathrm{lbs}$. $/ \mathrm{in}^{2}{ }^{2}$ the value of the vapor fraction is

$$
W_{\mathrm{B}}=\frac{0.256}{2 \times 14.65}=0.00874
$$

whence

$$
1-0.38 W_{\mathrm{s}}=0.9967
$$

Equation (61) now gives for $N$ the value

$$
N=\frac{3.648 \sqrt{1.58}(458+60)}{14.65 \times 0.9967}=162.7
$$

and this is to be substituted in (58) or in whichever of the four equivalent equations may be best suited to the problem in hand.

Since the air must be somewhere between perfectly dry and completely saturated, equation (64) shows that, if the standard tempera- 
ture is $60^{\circ} \mathrm{F}$., the value of $N$ given by (65) can not be in error by more than \pm 0.33 per cent, whatever be the standard vapor fraction. If an uncertainty of this amount in $V$ is regarded as negligible, it is therefore unnecessary to specify any standard humidity and it is sufficient to assume 50 per cent saturation. The uncertainty will be less if a lower standard temperature is adopted, because the saturation pressure of water vapor decreases with the temperature.

To illustrate further, the general equations may be applied to the measurement of air by a particular orifice meter.

Let an orifice of diameter $d=2.50$ ins. be installed in a long, straight pipe of diameter $D=6.90$ ins. and provided with flange taps, the static pressure gauge being connected to the downstream tap.

To avoid useless repetition, it will be supposed that the differential is read in inches of a liquid of specific gravity $\sigma=1.58$, and that the standard conditions for measuring $V$ are those specified above, so that $N$ has the value already computed and given by (65).

Under these circumstances the equation to be used for computing the rate of discharge of air through the orifice is

in which

$$
V=162.7 \times 2.5^{2} \times C^{\prime}{ }_{2} \sqrt{\frac{p_{2} h(1-0.38 w)}{458+t}}
$$

$V\left[\mathrm{ft}^{3} \cdot \mathrm{min}.\right]=$ the rate of discharge measured under the specified standard conditions;

$p_{2}\left[\mathrm{lb} . / \mathrm{in.}^{2}\right]=$ the absolute static pressure at the downstream pressure tap;

$h$ [ins.] $=$ the differential as read on a manometer containing a liquid of specific gravity $\sigma=1.58$, referred to water at $60^{\circ} \mathrm{F}$.;

$t\left[{ }^{\circ} \mathrm{F}.\right]=$ the temperature of the air entering the orifice; $w=$ its vapor fraction; and

$C^{\prime}{ }_{2}=$ the hydraulic discharge coefficient, based on the downstream static pressure and with the approach factor included, for flange taps.

In applying (66) to the case of a particular measurement of flow, the values of $t$ and $h$ are observed directly and that of $p_{2}$ is obtained by allowing for the outside barometric pressure in the usual manner. The value of $w$ will be discussed presently, but we may first specialize further by assuming that the following values have been observed:

$$
p_{2}=25 \mathrm{lb} . / \mathrm{in} .^{2} ; h=45 \text { ins.; } t=80^{\circ} \mathrm{F} \text {. }
$$

When substituted in (66), these values give

$$
V=1470 \quad C^{\prime}{ }_{2} \sqrt{1-0.38 w}
$$

and the value of $w$ is now to be considered. 
The value of $w$ depends on the humidity of the air entering the orifice, and this is seldom known, although a knowledge of the circumstances may show that the air must be nearly dry or nearly saturated. But $w$ is almost always so small that a very rough estimate of its value is all that is needed, and it is sufficient to assume that the air is one-half saturated.

In the present example the pressure of saturated water vapor at $80^{\circ} \mathrm{F}$. is $0.505 \mathrm{lb}$./in. ${ }^{2}$, so that on the assumption of 50 per cent saturation the partial pressure of the water vapor is $\pi=0.2525$. The total pressure of the air entering the orifice is by (54).

$$
p_{1}=p_{2}+\frac{\sigma h}{27.706}
$$

or

Hence

$$
p_{1}=25+\frac{1.58 \times 45}{27.706}=27.57 \mathrm{lb} . \text { in. }^{2}
$$

and

$$
0.38 w=\frac{0.38 \times 0.2525}{27.57}=0.0035
$$

$$
\sqrt{1-0.38 w}=0.9982
$$

Since the actual humidity of the air must be between 0 and 100 per cent of saturation, this value can not be in error by more than \pm 0.18 per cent, and the uncertainty caused by failure to determine the humidity is insignificant.

At higher temperatures or lower static pressures the uncertainty is greater and in extreme cases it might be of some importance, but it is evident that in the great majority of commercial measurements the assumption of 50 per cent saturation is amply accurate, and that in most cases the effect of humidity on the density may be entirely ignored and the factor $\sqrt{1-0.38 w}$ omitted from the general equation (58), of which (66) and (58) are special forms.

Retaining the value given by (72) reduces (68) to the form

$$
V=1467 C^{\prime}{ }_{2}
$$

and it remains only to insert the value of $C^{\prime}{ }_{2}$.

This value must either have been determined by an experimental standardization of the particular orifice, or it must be taken from some standard table. If the edge of the orifice is of the same quality as the average of the orifices used in our experiments, the value of $\mathrm{C}^{\prime}{ }_{2}$ may be found from Table 13, Section XVI. The diameter ratio is

$$
\beta=\frac{d}{D}=\frac{2.50}{6.90}=0.362
$$

and the pressure ratio is (see equation (70))

$$
r=\frac{p_{2}}{p_{1}}=\frac{25.0}{27.57}=0.907
$$


whence by interpolation in the table we have $C_{2}^{\prime}=0.623$ and finally, by . (73).

$$
V=914 \mathrm{ft}^{3} / \mathrm{min} \text {. }
$$

It may be noted here that the limiting value given by the table for $r=1.0$ is $C^{\prime}{ }_{2}=0.605$, which differs from 0.623 by nearly 3 per cent. The change of discharge coefficient with the pressure ratio is therefore by no means negligible in this example.

\section{REMARKS ON METERING OTHER GASES}

For other gases than air, the developments of Section XXVI remain unchanged up to and including equation (56), but from that point onward they must be modified as regards the computation of the density $\rho_{1}$, and also of $\rho_{\mathrm{B}}$, if this is merely specified by stating standard conditions.

If the gas in question obeys Boyle's law as approximately as air does, its specific gravity may be treated as a constant and the modifications needed in the equations are simple and obvious. But if the gas deviates far from Boyle's law as happens with some natural gasses at high pressures, the computation of density is not so simple, for it is to be remembered that $\rho_{1}$ in (56) represents the actual density of the fluid in the pipe ahead of the orifice, and this may differ seriously from the density computed by means of Boyle's law from the density at atmospheric pressure. But since the experiments which gave occasion for this paper were concerned with air only, the computations needed for gases that do not follow Boyle's law need not be discussed further here.

As regards numerical values of the discharge coefficients of orifices, it may be said that the limiting values for $r=1$ will be the same for all gases. ${ }^{16}$ For lower values of $r$-that is, for higher percentage differentials -it is probable that the discharge coefficient will be found to vary slightly with the properties of the gas, especially with its specific heat ratio. It does not, however, seem likely that these variations will be of any importance so long as the pressure ratio is not lower than $r=0.9$. Further experimental data on this subject are to be desired.

\section{SUMMARY OF CONCLUSIONS}

Aside from the tables of discharge coefficients which have been given in Sections XIV, XVI, and XVIII, and constitute the quantitative results of the investigation, the following points may be noted:

(a) The discharge coefficient of an oriffice for air does not depend on or vary with the absolute static pressure.

${ }^{16}$ See, however, Section XXIV. 
(b) The hydraulic discharge coefficient based on either upstream or downstream static pressure is not a constant but varies with the ratio of the two pressures. At low static pressures and high differentials these variations may be of serious importance and ignoring them may lead to errors of several per cent in the computed rate of flow. This difficulty may be avoided by using a discharge coefficient based on the mean of the two static pressures.

(c) Very slight changes in the condition of the edge of an orifice may have an appreciable effect on its discharge coefficient; and to produce duplicate orifice plates which have the same discharge coefficient within \pm 0.5 per cent requires very careful mechanical work, even when the diameter of the orifice is 1 inch or more. The commercial plates loaned to us were quite as good, in this respect, as the plates made at the Bureau of Standardis.

(d) The difficulty of duplication increases as the size of the orifice is reduced, and if a standard table of discharge coefficients is to be relied upon, and the orifices not tested individually, it is advisable to use the largest orifice practicable within the range of diameter ratios covered by the available tables.

(e) The tables given in Sections XIV, XVI, and XVIII represent average results obtained from well-made orifices installed in 6 and 8 inch pipes, with a straight run of at least 120 pipe diameters upstream and 30 downstream. Similar orifices installed in a 4-inch pipe gave higher coefficients; but the experiments were not adequate to the establishment of a general relation between discharge coefficient and pipe diameter, even for this particular mode of installation, and any such relation must be expected to vary with the nature of the installation.

\section{Appendix A. THEORY OF THE FLOW NOZZLE AND THE IMPACT TUBE}

In finding the rate at which a gas is discharged through a flow nozzle under observed conditions of pressure and temperature, the first step is to compute the "theoretical" rate $M_{t}$ which would occur under certain ideally simplified conditions.

With well-made nozzles, suitably designed for the rates to be measured, most of these conditions are nearly satisfied in practice, and in these respects the simplified ideal state of flow through the nozzle is a close approximation to reality. But one of the conditions assumed in the theoretical work is that the speed of the jet is the same near the wall of the nozzle as farther out toward the center of the stream, and since skin friction and retardation at the wall can not be done away with, this condition is not well satisfied in any real jet. 
The result of the departure of the actual from the ideal conditions is to make the true rate of discharge a little less than the theoretical rate, and this fact may be expressed by the equation

$$
M=C M_{t}
$$

in which $C$ is a correction factor or discharge coefficient by which the computed theoretical rate must be multiplied to give the true rate $M$. If the nozzle is to be used in this way as a flow meter, the value of $C$ must, of course, be known to the same percentage accuracy as is required in $M$.

The obvious procedure for finding the value of $C$ is to measure $M$ by some direct method which does not involve any assumptionsby means of a gas holder, for example-and compare the value obtained for $M$ with the value of $M_{t}$ computed from the observed working conditions. If this has been done, the nozzle may be used as a convenient secondary standard, the primary standard being the method or instrument by which $M$ was measured.

There is abundant experimental evidence to show that under ordinary working conditions the values of $C$ for well-made nozzles are always within a few per cent of unity. But when an accuracy of two or three parts per 1,000 is required we are left in the lurch, so far as large nozzles are concerned, because no method of that accuracy has been developed so as to be available for measuring large rates of discharge directly, for the purpose of standardizing large nozzles. As the matter now stands, if large rates of flow are to be measured with an accuracy of 0.5 per cent or better, it is necessary to treat the nozzle as a primary standard, accepted on its own merits.

What is done is, in effect, to assume that the whole difference between $M$ and $M_{t}$ is due to the violation, in practice, of the condition that the speed oi the jet shall be uniform right out to the wall of the nozzle, the other ideal conditions of the theory being sensibly realized. The effect of the falling off of speed near the wall of the nozzle is then determined by exploration with a fine impact tube, and a suitable correction applied to the computed theoretical rate of discharge $M_{t}$. This amounts to determining $C$ by a self-calibration of the nozzle, without reference to any other standard.

To justify this procedure, we have to examine and criticize the assumptions involved in it and satisfy ourselves that they are sufficiently near the truth to make the values obtained for $M$ accurate to much better than "a few per cent." We shall attempt to do this.

The nozzles used in the present investigation were of the converging type, ending in cylindrical throats, and the speed of the jet was always below the speed of sound in the jet. The discussion may therefore be limited to these conditions, and it will not be necessary to consider diverging nozzles or very high speeds. It will also be 
supposed that the approach pipe is straight, round, and coaxial with the nozzle, as it was in our apparatus.

It is sometimes convenient to regard the stream of fluid through the nozzle as composed of a bundle of small filaments, each bounded and separated from the adjacent filaments by a tubular surface with its axis everywhere along the direction of the average motion. If the flow is perfectly steady and along fixed stream lines, this conception of stream tubes is evidently legitimate; but more often the flow is somewhat turbulent and the velocity at any fixed point is not quite steady but subject to small, rapid, irregular, fluctuations in both direction and magnitude.

In this general case the direction of the mean velocity at a point may be defined as the direction of a straight line, such that the mass flow through a small closed curve drawn about the point in any plane containing the line, vanishes when integrated over any appreciable interval of time. Since it is characteristic of turbulence that the fluctuations are too rapid to be followed by our ordinary measuring instruments, an "appreciable" interval of time is to be understood as one during which a large number of fluctuations takes place.

With this definition, a system of curves may be drawn in the stream so as to be, at each point, tangent to the direction of the mean velocity at that point; and the stream may be divided into filaments by tubular surfaces generated by the motion of such curves perpendicularly to themselves. On the whole, no fluid enters or leaves such a filament transversely; the mass flow is sensibly constant at any section of the filament and the same for all sections; and the motion is in some respects analogous to flow along a tubular channel with rigid impervious walls.

The magnitude of the mean velocity at any point, or the mean speed there, may be defined by saying that the constant mass flow along an infinitesimal filament containing the point is equal to the product of the mean speed, the density, and the cross sectional area of the filament at the point.

Having disposed of these preliminaries, we may state the assumptions on which the theoretical equations are based and outline the deduction of the equations, after which we shall discuss the assumptions in some detail.

For the sake of brevity the normal section of the approach pipe just ahead of the point where the stream begins to converge toward the nozzle will be denoted by $A_{o}$, and the normal section of the emerging jet at the mouth of the nozzle will be denoted by $A$. The assumed ideal conditions under which the theoretical equations would be true and $M$ exactly equal to $M_{\mathrm{t}}$ may now be described, as follows:

(a) The static pressure of the fluid is uniform and constant over $A_{0}$. 
(b) The static pressure in the jet is uniform over $\mathrm{A}$ and is equal to the constant pressure of the atmosphere into which the jet is escaping.

(c) The temperature of the fluid is uniform and constant over $A_{0}$ and $A$.

(d) The mean velocity is uniform over $A_{0}$ and $A$ and parallel to the common axis of the pipe and the nozzle.

(e) There is no transmission of heat between the fluid and the nozzle or between different portions of the fluid; that is, the flow from $A_{0}$ to $A$ is adiabatic.

$(f)$ There is no dissipative generation of heat either by the decay of turbulence or by reason of transverse variations of speed, which may occur in the converging stream even though the velocity is uniform and axial at $A_{0}$ and $A$.

(g) The fluid is an ideal gas.

The following notation will be employed:

$D_{0}, D=$ the diameters of the sections $A_{0}$ and $A$, respectively; $\beta=D / D_{0}=$ the "diameter ratio" of the nozzle;

$S_{0}, S=$ the speeds normal to $A_{0}$ and $A$;

$p_{0}, p=$ the static pressures in the gas at $A_{0}$ and $A$;

$\rho_{0}, \rho=$ the densities of the gas at $A_{0}$ and $A$;

$\theta_{0}, \theta=i$ ts absolute thermodynamic temperatures at $A_{0}$ and $A$;

$\epsilon_{0}, \epsilon=$ the values, at $A_{0}$ and $A$, of the internal energy of the gas per unit mass;

$T_{0}, T=$ the values, at $A_{0}$ and $A$, of the kinetic energy of unit mass of gas;

$C_{\mathrm{v}}, C_{\mathrm{p}}=$ the specific heats of the gas at constant volume and constant pressure, respectively;

$\gamma=C_{\mathrm{p}} / C_{\mathrm{v}}=$ the specific heat ratio of the gas;

$R=$ the "gas constant" for unit mass of gas;

$M_{\mathrm{t}}=$ the "theoretical" mass flow or rate of discharge from the nozzle;

$M=$ the actual or true mass flow: $M$ and $M_{\mathrm{t}}$ would be identical if the assumed ideal conditions were realized in practice.

As regards units, quantities of heat and internal energy are to be measured in the same units as kinetic energy and work, and mechanical quantities are to be measured in some set of normal units. For example, if speed is in $\mathrm{ft} . / \mathrm{sec}$., density in lb./ft. ${ }^{3}$, and mass flow in lb./sec., then diameters are to be in feet, pressures in poundals per square foot and quantities of energy in foot poundals $(1 \mathrm{ft} . / \mathrm{lb} .=32.2$ feet poundals, and $1 \mathrm{lb} . /$ in $^{2}=32.2 \times 144$ poundals per square foot.) 
Units of this sort are most convenient in the theoretical work, but more familiar units will be introduced later when the equations are to be used for numerical computation.

The first law of thermodynamics, as applied to the passage of unit mass of gas through the nozzle from $A_{0}$ to $A$, may be expressed by the equation

$$
(T+\epsilon)-\left(T_{\mathrm{o}}+\epsilon_{\mathrm{o}}\right)=\frac{p_{\mathrm{o}}}{\rho_{\mathrm{o}}}-\frac{p}{\rho}+W+Q
$$

in which the first member represents the increase of the total energy of the unit mass, kinetic plus internal, and the terms of the second member have the following meanings:

$p_{0} / \rho_{0}$, or $p_{0} \times$ the specific volume at $A_{0}$, is the work done on the unit mass, as it crosses $A_{o}$, by the gas following it;

$p / \rho$ is the work done by the unit mass, in crossing $A$, on the gas ahead;

$W$ is the work done by outside forces on the unit mass while it is between $A_{0}$ and $A$; and

$Q$ is the heat received from outside sources by the unit mass while it is between $A_{0}$ and $A$.

In the case of a horizontal nozzle with fixed rigid walls, no work is done by the walls or by gravity and $W=0$. Furthermore, in the ideal state of flow now under discussion, $Q=0$ by assumption $(c)$, the flow being adiabatic. Equation (2) may therefore be written in the form

$$
T-T_{\mathrm{o}}=\left(\epsilon_{\mathrm{o}}+\frac{p_{\mathrm{o}}}{\rho_{\mathrm{o}}}\right)-\left(\epsilon+\frac{p}{\rho}\right)
$$

In perfectly steady stream line motion with the speed uniform, as required by assumption ( $d$ ), the kinetic energy per unit mass is simply $S^{2} / 2$. But if turbulence is superimposed on the steady flow, the kinetic energy of the turbulent motion increases the total kinetic energy by an amount $\hbar$ equal to the quantity of heat that would be generated if the turbulence were all instantaneously dissipated without changing the speed $S$. We must therefore write, in general,

$$
T_{\mathrm{o}}=\frac{S_{\mathrm{o}}^{2}}{2}+h_{\mathrm{o}} ; T=\frac{S^{2}}{2}+\hbar
$$

and

$$
T-T_{\mathrm{o}}=\frac{1}{2}\left(S^{2}-S_{\mathrm{o}}^{2}\right)-\left(h_{\mathrm{o}}-h\right)
$$

in which the term $\left(h_{0}-h\right)$ represents the amount by which the kinetic energy of turbulence has decreased from $A_{0}$ to $A$ by dissipation into heat. 
In the ideal case, assumption $(f)$ requires that $\left(h_{0}-h\right)=0$, though it is to be noted that $h_{\mathrm{o}}$ and $h$ are not required to vanish separately; hence we have

$$
T-T_{\mathrm{o}}=\frac{1}{2}\left(S^{2}-S_{\mathrm{o}}^{2}\right)
$$

or by (3)

$$
\frac{1}{2}\left(S^{2}-S^{2}{ }_{0}\right)=\left(\epsilon_{0}+\frac{p_{0}}{\rho_{0}}\right)-\left(\epsilon+\frac{p}{\rho}\right)
$$

Since the rate of discharge is constant, the mass flow is the same at $A$ as at $A_{o}$ and we have

$$
M_{\mathrm{t}}=\frac{\pi}{4} D^{2}{ }_{\mathrm{o}} \rho_{\mathrm{o}} S_{\mathrm{o}}=\frac{\pi}{4} D^{2} \rho S
$$

and after eliminating $S_{0}$ from (7) and solving for $S$, we have

$$
S=\sqrt{2 \frac{\left(\epsilon_{0}+\frac{p_{0}}{\rho_{0}}\right)-\left(\epsilon+\frac{p}{\rho}\right)}{1-\beta^{4}\left(\frac{\rho}{\rho_{0}}\right)^{2}}}
$$

which holds for the flow of any fluid, subject to conditions $(a, \ldots, f)$, because ap to this point no assumption has been made regarding the nature or properties of the fluid.

Since skin friction necessarily retards the flow near the wall of the nozzle, assumption $(d)$, that the speed is uniform over A, implies that there is no skin friction and that the flow is unresisted. By assumptions $(e, f)$ the flow is also adiabatic and free from any internal dissipation; hence the process of expansion and acceleration from $A_{0}$ to $A$ is isentropic, and in order to go on from (9) we must know how the density and internal energy of the fluid in question vary with the pressure during isentropic changes of state.

These relations become very simple if it is stipulated that the fluid shall be an ideal gas, in accordance with assumption $(g)$. An ideal gas is, by definition, one for which the equations

$$
\frac{p}{\rho \theta}=R=\text { constant }, \text { and } C_{v}=\text { constant }
$$

are exactly satisfied. For such a gas it is readily shown, by elementary thermodynamics and with no further assumptions, that

$$
C_{v}=\frac{R}{\gamma-1} \text { and } \epsilon=C_{v} \theta+\text { constant }
$$

and that during isentropic changes of state between any two pressures $p$ and $p_{0}$, the density and temperature change in accordance with the equations

$$
\frac{\rho}{\rho_{0}}=\left(\frac{p}{p_{0}}\right)^{\frac{1}{\gamma}} \text { and } \frac{\theta}{\theta_{0}}=\left(\frac{p}{p_{0}}\right)^{\frac{\gamma-1}{\gamma}}
$$


From $(10,11,12)$ we have

$$
\begin{gathered}
\left(\epsilon_{0}+\frac{p_{0}}{\rho_{0}}\right)-\left(\epsilon+\frac{p}{\rho}\right)=\left(R+C_{v}\right)\left(\theta_{0}-\theta\right)=\frac{\gamma}{\gamma-1} R \theta\left(\frac{\theta_{0}}{\theta}-1\right) \\
=\frac{\gamma}{\gamma-1} \cdot \frac{p}{\rho}\left[\left(\frac{p_{0}}{p}\right)^{\frac{\gamma-1}{\gamma}}-1\right]
\end{gathered}
$$

and after substituting from (13) into (9) and eliminating $\frac{\rho}{\rho_{0}}$ by means of (12) we have

$$
S=B \sqrt{\frac{2 \gamma}{\gamma-1} \cdot \frac{p}{\rho}\left[\left(\frac{p_{0}}{p}\right)^{\frac{\gamma-1}{\gamma}}-1\right]}
$$

where

$$
B=\left[1-\beta^{4}\left(\frac{p}{p_{0}}\right)^{\frac{2}{\gamma}}\right]^{-\frac{1}{2}}
$$

The mass flow may then be found from (8), one form of the result being

$$
\left.M_{\mathrm{t}}=\frac{\pi}{4} D^{2} B \sqrt{\frac{2 \gamma}{\gamma-1} p_{\mathrm{o}} \rho_{\mathrm{o}}\left[\left(\frac{p}{p_{\mathrm{o}}}\right)^{\frac{2}{\gamma}}-\left(\frac{p}{p_{\mathrm{o}}}\right)^{\frac{\gamma+1}{\gamma}}\right.}\right]
$$

Equations $(14,15,16)$ may, of course, be obtained in various alternative forms by utilizing $(11,12,13)$ in different ways, but since the subject is treated in most works on technical thermodynamics the foregoing outline of the reasoning will be sufficient here, and further algebraic details may be dispensed with.

The quantity $B$, defined by (15), is the "speed-of-approach factor" necessitated by the fact that the gas crosses the section $A_{0}$ at the finite speed $S_{0}$, instead of starting from rest, as in the case of an orifice in the wall of a large tank. If $A_{0}$ is very large compared with A, $S^{2}{ }_{o}$ is negligible in comparison with $S^{2}$ and may be omitted from (7). In other words, if $\beta$ is very small, $B$ is sensibly unity and may be omitted from (14) and (16). The greatest value of $\beta$ for any of the nozzles used in this investigation was $5 / 36$; and since $p$ was necessarily always less than $p_{0}$, the greatest possible value of $B$ was less than 1.00019. The correction for speed of approach was thus entirely negligible, even in the worst case, and $B$ could be omitted from $(14,16)$.

The assumptions described above define the ideal conditions under which the actual speed and rate of discharge would have precisely the theoretical values given by $(14,16)$, but the same conditions might have been defined by stating the assumptions somewhat differently. For example, if the fluid were entirely nonconducting and free from viscosity, conditions $(e)$ and $(f)$ would be satisfied automatically, and these two assumptions might, therefore, be replaced by the two other assumptions, that the fluid was noncon- 
ducting and nonviscous. The particular set of assumptions adopted above was chosen, partly because it permits of going as far as equation (9) without imposing any restrictions whatever on the nature of the fluid and partly because it is easier with this choice than with some others to form an estimate of the probable effect of the departures from the ideal conditions which necessarily occur in practice. As they now stand, assumptions $\left(a_{\ldots} \ldots f\right)$, concerning the general nature of the fluid motion, are more or less interdependent, but the final assumption $(g)$ is quite separate from the others, and it will be convenient to dispose of it first.

No real gas satisfies equations (10) exactly, for departures may always be observed if the experiments cover a wide enough range; but all that is really assumed is that the equations are satisfied over the range of pressure from $p_{\mathrm{o}}$ to $p$ and over the accompanying range of temperature due to the cooling by rapid expansion from $p_{\mathrm{o}}$ to $p$; and if $R$ and $C_{\mathrm{v}}$ are sensibly constant over this range of conditions, the use of equations $(10,11,12)$ is justified.

In our work with flow nozzles the initial pressure in the pipe was seldom more than $1 \mathrm{lb}$./in. ${ }^{2}$ above the outside barometric pressure, but during the calibration of two of the smaller nozzles there were a few cases in which the pressure drop was nearly $2.6 \mathrm{lbs} . / \mathrm{in} .{ }^{2}$, so that the pressure fell from 17.3 to $14.7 \mathrm{lbs} . / \mathrm{in} .{ }^{2}$. The simultaneous fall of temperature may be found approximately by means of (12), and for initial temperatures in the vicinity of $70^{\circ}$ or $80^{\circ} \mathrm{F}$. the cooling must have been about $25^{\circ} \mathrm{F}$.

Over this range of conditions the variations of $R$ from its mean value are of the order of \pm 1 in 25,000. The variations of $C_{\mathrm{v}}$ are nearly \pm 1 in 1,300 and those of $\gamma \pm 1$ in 4700 . But a change of this magnitude in $\gamma$ affects the value of $S$ computed from (14) by only about 1 in 200,000 . In view of the foregoing, it seems quite safe to ignore the variations of $R$ and $C_{\mathrm{v}}$ and to accept assumption $(g)$, or equations $(10,11,12)$, as sensibly exact under the given experimental conditions.

We proceed to the consideration of assumptions $(a)$ and $(b)$. In a steady stream of gas fiowing straight along a uniform pipe the static pressure must be uniform over any normal section, for any departure from this condition would result in transverse currents and be inconsistent with flow parallel to the axis. If the flow is turbulent, it is to be presumed that the static pressure at any point is subject to rapid fluctuations; but if the stream has been freed from permanent eddies, cross currents, or whirl, either by straightening devices or by a sufficient preliminary length of straight pipe, the average static pressure must be the same at all points of a cross section. Assumption (a), therefore, corresponds closely to the actual experimental conditions. 
The boundary of a jet of air from a flow nozzle may be made visible by suitable means, and for speeds below that of sound, observation shows that while the boundary gradually loses its sharpness at increasing distances from the end of the nozzle, it starts out as a cylinder and shows no tendency to swell or shrink laterally, as it would necessarily do if the air in the jet were at a different pressure from the surrounding atmosphere. From this it may be concluded that the static pressure is sensibly uniform and equal to the atmospheric back pressure at all points of the exit section $\mathrm{A}$. This agrees with experimental measurements of the static pressure at the center of the mouth of the nozzle, where the pressure, if not uniform, might be expected to differ most from the outside pressure.

It thus appears that assumptions $(a)$ and $(b)$ are, as nearly as we can tell, satisfied in practice and that, in this regard, the ideal state of affairs is a close approximation to reality, though it is impossible to say just how close.

Turning to assumption $(c)$, we find that the first part requires no extended comments, for the temperature in the approach pipe is under experimental control, if necessary, and may without difficulty be made very uniform; but the remaining assumptions are not so readily disposed of, for the assumed conditions are evidently violated in the outer part of the stream close to the wall of the nozzle. Nevertheless, equivalent assumptions sufficient for the validity of (14) may be very nearly true for the central part of the stream at a distance from the wall, and we may consider this possibility.

If the section of the jet at the mouth of the nozzle is explored with a fine impact tube, there is no indication of any systematic variation of the impact pressure with distance from the axis until the tube is moved fairly close to the wall, when the impact pressure begins to fall off rapidly. So far as impact pressure is concerned, and to the limit of accuracy of the apparatus, the jet consists of a uniform core surrounded by a thin nonuniform sheath.

Decreasing the speed of the jet thickens the sheath and diminishes the diameter of the core, and the same effect is produced by increasing the length of the cylindrical throat. Another pertinent fact is that when a steady stream of fluid enters a long, straight pipe from a large space in which the fluid is sensibly at rest the impact pressure is found to be uniform over almost the whole of a cross section near the entrance and does not settle down to its ultimate nonuniform distribution for a long distance.

It takes time for a tangential drag or shearing stress to be propagated from one point to another in a fluid, and the observations cited above show that the uniformity of the core at the mouth of the nozzle is due to the shortness of the time of transit of any given particle of air through the nozzle. The retarding effect of a wall of 
given smoothness penetrates the stream only a certain distance before becoming inappreciable, and beyond this distance-the thickness of the sheath-no effect is produced unless the skin friction is increased by roughening the wall or unless, alternatively, the time available is increased, either by slowing down the jet or by lengthening the nozzle. Those filaments of the stream which make up the uniform core observed at the exit section $\mathrm{A}$ are too far from the wall to have been appreciably retarded by it, even at the end of their course through the nozzle, and the flow along them goes on in the same way as if there were no skin friction at all.

To this conclusion it might be objected that the impact pressure of a stream depends on density as well as speed, and that constancy of impact pressure does not prove that speed and density are separately constant. Any change of speed due to the proximity of the wall of the nozzle must necessarily be a decrease, but a simultaneous increase of density by the right amount would offset this and keep the impact pressure corstant, in spite of the falling off of speed.

In reply, it may be remarked that if the static pressure is constant all the way across the mouth of the nozzle, as it appears to be, an increase of density near the wall would require that the temperature there be lower than farther out in the stream. Now, the air is cooled by its rapid expansion and, in any normal circumstances and in the absence of artificial cooling of the nozzle, it tends to be colder than the nozzle and to be heated by contact with it. Furthermore, the surface layer is most heated by skin friction because it is most rapidly sheared. For both these reasons the air immediately in contact with the wall must be not colder but hotter than the air farther out, and the transverse temperature gradient must be upward toward the wall. Hence, there can be no such compensating increase of density as was postulated above, and we are justified in concluding that the speed at the exit section $\mathrm{A}$ is unretarded by skin friction at least as far out from the axis as the impact pressure remains constant.

The increase of temperature due to the flow of heat from the surface layer toward the axis is also confined to the sheath and is imperceptible inside the core, for at constant static pressure an increase of temperature at any point within the core would lower the density and would have to be accompanied by a simultaneous increase of speed in order to keep the impact pressure constant. The nearer the point in question is to the source of heat at the wall the greater will be the rise of temperature and the greater the increase of speed required to compensate it, whereas the speed can only decrease toward the wall, if it changes at all. Hence, the heating must be negligible inside the core where the impact pressure is constant. 
It may be noted here, as a side remark, that the propagation of a retarding drar and of a rise in temperature into a stream of gas, from a fixed boundary which is kept hotter than the gas, is the result of a single mechanism, so that the two phenomena are not independent but intimately connected. When two parallel streams of gas are flowing past each other they tend to mix, and the mixing tends to equalize both temperature and velocity. In pure stream line motion the mixing is on a molecular scale by diffusion, which tends to equalize not only the mean longitudinal components of the molecular velocities, but also the mean molecular kinetic energies of translation in all directions indiscriminately, to which the absolute temperatures are proportional. If the motion is turbulent, the mixing occurs on a molar instead of on a molecular scale; the colder but faster moving layer is continually having some of its particles replaced by others from the adjacent layer which are hotter but moving forward more slowly. The substitution of turbulent convection for the slower process of mixing by diffusion accelerates both phenomena, but the parallelism of heating and retardation remains and both effects necessarily increase or decrease together.

To return from this parenthesis, the general conclusion is that the expansion and accelaration of the air that escapes from the nozzle within the region of uniform impact pressure revealed by exploration with the impact tube go on in sensibly the same manner as if the wall of the nozzle were perfectly frictionless and nonconducting. And if we now suppose this inner part or core of the stream to be surrounded by a geometrical surface, reaching from $A_{0}$ to $\mathrm{A}$ and so constructed as to be everywhere tangent to the direction of the mean velocity, the air of the core is discharged through this imaginery nozzle in precisely the same way as if the geometrical surface were a rigid, impervious, frictionless, nonconducting, material nozzle, somewhat smaller in diameter than the actual nozzle but of similar though less sharply curved profile. The conditions which were originally assumed to prevail throughout the stream but which are evidently violated near the wall of the nozzle are much more approximately satisfied in this core from which the nonuniform sheath has been excluded; but some further examination of the circumstances is required before it can be admitted that all the conditions necessary to the validity of (14) are satisfied.

It will first be supposed that the diameter ratio $\beta$ is so small that $S^{2}{ }^{2}$ and, a fortiori, its transverse variations, may be neglected. As already noted, this condition was satisfied by even the largest of the nozzles employed in the present investigation.

The different filaments of the core now all start from $A_{0}$ at the same static pressure $p_{0}$ and with the same (negligible) speed $S_{0}$, and they all reach $\mathrm{A}$ at the same static pressure $p$ and with the same 
impact pressure. The question is: Can the flow along each filament be regarded as unresisted, adiabatic, and free from internal dissipation; that is, as isentropic? If so, the speed $S$ attained at A must be the same for all filaments and must have the value given by (14).

The conditions of flow are not quite the same along all the filaments, because the outer ones are longer and more curved than the ones near the axis; and it can not be assumed that there are no transverse gradients of speed and no shearing anywhere in the converging stream, even though there is no skin friction to retard the outer layer. Such shearing will be distributed symmetrically about the axis of the nozzle, but it will be different at different distances from the axis on account of the varying curvature of the filaments.

Let us consider the ring of filaments where this shearing is most rapid, wherever that may be. The resistance to shearing dissipates kinetic energy into heat, lowering the speed and raising the temperature relatively to other filaments where the rate of shear is lower. Hence, where those filaments which have suffered the greatest dissipation arrive at $A$, over which the static pressure is constant, the impact pressure will be less than it is elsewhere; but in practice no such variation is observed, hence it is to be concluded that the effects of this internal dissipation on the speed of flow are insignificant, and that the speed at $\mathrm{A}$ is sensibly uniform throughout the core. Moreover, if this dissipative heating is insignificant, its effects in disturbing the initial uniformity of temperature and causing a flow of heat between adjacent filaments must also be negligible, and the flow along each filament of the core may be regarded as adiabatic.

It remains only to consider the possible effects of the dissipative decay, between $A_{0}$ and $A$, of turbulence initially existing at $A_{0}$. It is a matter of common observation that the natural turbulence of a stream of water or air decreases with the speed of the stream and may even become quite imperceptible while the general forward speed is still considerable; and it is obvious that, in the absence of artificial stirring or of devices introduced with the special purpose of creating turbulence, the kinetic energy of turbulence in any ordinary slow stream is, at all events, not of a higher order of magnitude than the kinetic energy of the general forward motion.

If the latter supplies only a negligible term to the equations for the speed of the jet, as is now supposed and as was true in our experiments, the term representing heat obtained from the dissipation of an equal amount of kinetic energy of turbulence must also be negligible. Moreover, turbulence does not vanish instantaneously but decays slowly, and it seems probable that only a small fraction of the turbulence existing at $A_{o}$ is dissipated during the extremely short time of transit through the nozzle. It therefore seems perfectly safe to 
assume that under such conditions as existed in our experiments the effects of the dissipation of initial turbulence were entirely negligible.

Accepting the foregoing reasoning as valid within the limitations of accuracy of the experimental observations on which it depends, we may now say that the flow along each filament of the core is unresisted, adiabatic, free from dissipation, and therefore isentropic; hence equation (14) is applicable to each filament separately. And since the initial speed and density and the initial and final static pressures are the same for all, the final speeds and temperatures are also the same, and the final speed of the uniform core at the mouth of the nozzle has the value

$$
S=\sqrt{\frac{2 \gamma}{\gamma-1} \frac{p}{\rho}\left[\left(\frac{p_{0}}{p}\right)^{\frac{\gamma-1}{\gamma}}-1\right]}
$$

given by (14) when $\beta$ is small enough that $S^{2}$ is negligible.

The ideal conditions required for the validity of (17) thus appear to be very nearly realized in the core of the jet, and under the circumstances of our experiments it seems probable that if the observations of pressure and temperature were exact, equation (17) would give the true speed of the middle part of the jet within \pm 1 in 1,000 or better. If the uniform core filled the whole section of the mouth of the nozzle, the mass flow might then be found to the same accuracy by (16); but since the nonuniform sheath is of finite thickness, a correction factor must be introduced, and in default of a method for the absolute measurement of mass flow this factor has to be determined by means of impact tube observations. Hitherto, it has been sufficient to assume, as a familiar qualitative result of experiment, that the impact pressure of a stream of fluid increases with both speed and density, but it now becomes necessary to discuss the quantitative interpretation of measurements of impact pressure.

Let the impact tube be placed, pointing directly upstream, in a current of air of speed $S$, static pressure $p$, and density $\rho$; and let $\Delta$ be the observed impact pressure, so that the absolute static pressure of the air in the mouth of the tube is $p+\Delta=p_{0}$. The values of $p$ and $\Delta$ are observed directly, while that of $\rho$ has to be found from an observation of the temperature, together with the value of $p$ and known constants for air. The problem is to find the unknown value of $S$ from the observations of pressure and temperature.

Air approaching from upstream is slowed down and brought sensibly to rest at the mouth of the impact tube, and concurrently with this decrease of kinetic energy the air is compressed and its pressure rises from $p$ to $p+\Delta$. This air may be regarded as flowing along a tubular filament which is initially of very small cross section in the undisturbed stream but which expands laterally as the speed of flow along it decreases, and finally merges into the nearly station- 
ary cap of air at the static pressure $p+\Delta$, which covers the mouth of the tube. The equivalent outflow needed to maintain a steady pressure in the mouth of the tube is provided by a continual slow spilling over the edge, this escaping air falling at once to the pressure $p$ and mixing with the general stream past the tube.

If it be assumed that the flow along this central filament is adiabatic, unresisted, and free from dissipation, the process of deceleration and compression is isentropic and thermodynamically reversible and is an exact reversal of adiabatic isentropic expansion from $p+\Delta$ to $p$, accompanied by acceleration from a negligibly low speed to the final speed $S$. Hence, on the permissible assumption that air acts sensibly like an ideal gas, the air speed required to set up the observed impact pressure will be given by the equation

$$
\left.S=\sqrt{\frac{2 \gamma}{\gamma-1} \frac{p}{\rho}\left[\left(\frac{p+\Delta}{p}\right)^{\frac{\gamma-1}{\gamma}}\right.}-1\right]
$$

which is identical in form with (17) and deduced by the same theoretical reasoning.

Equation (18), or some more convenient mathematical equivalent, is commonly used for finding the value of $S$; but since the equation is deduced from assumptions which are evidently not exactly true, this practice requires justification.

In discussing the discharge of air through a nozzle, reasons were advanced for supposing that the conditions are so nearly uniform across the core of the stream that the flow along any filament is sensibly unaffected by interchange of heat or momentum with adjacent filaments; but in the case now under consideration the conditions are evidently different and are less simple. The central filament which leads to the mouth of the impact tube is not surrounded by other filaments which are just like it and so have no effect on it. On the contrary, the surrounding filaments are, on the whole, moving much faster than the central one and must exert a forward drag on it, something like a negative skin friction. Moreover, the air in the central filament is heated by the rapid compression, and must lose heat laterally. The reasons for regarding (17) as accurate for the case of the jet are therefore not sufficient to make (18) appear reliable for interpreting impact tube observations, and some additional evidence is needed before (18) can be trusted.

The best sort of evidence would be furnished by experiments in which the air speed $S$ was measured by an independent absolute method, but such measurements are difficult, and there is not much evidence of this kind available, even for low speeds. Experiments at the National Physical Laboratory ${ }^{17}$ showed that up to air speeds of

${ }_{17}$ Bramwell, Relf, and Fage; Rep. Adv. Comm. Aeron., p. 35; 1912-13. 
$50 \mathrm{ft}$.-sec. the measured and computed speeds did not differ by more than 1 part in 1,000; and other observers, using various methods for measuring the speed, have also failed to detect any disagreement of measured and computed values greater than the errors of experiment. For higher speeds there are no direct measurements to refer to but there is, fortunately, an important piece of indirect evidence.

Let an impact tube be fixed on the axis of the jet from a flow nozzle a little outside the end of the nozzle, and let it be connected, through a sensitive differential gauge, to a static side hole in the wall of the approach pipe ahead of the nozzle, so that the gauge indicates the excess of the total static pressure in the impact tube over the static pressure of the approaching stream. If the speed of approach is so low that the equivalent impact pressure is below the limit of accuracy of the gauge, the gauge reads sensibly zero, otherwise the reading of the gauge is equal to the impact pressure at the axis of the approaching stream. In any event, the total pressure in the impact tip at the mouth of the nozzle is equal to the total pressure in an impact tip placed in the center of the approaching stream.

This convenient relation, which was pointed out and utilized by Moss $^{18}$ in the paper already cited, appears to hold very accurately.

In addition to the experiments of Moss, experiments by the Bureau of Standards with a 2-inch nozzle on the end of an 8-inch pipe have shown that at air speeds slightly below the speed of sound the relation was certainly accurate to within less than 0.001 of the pressure drop through the nozzle, and there is every reason to suppose that it holds more rather than less accurately at lower speeds. ${ }^{19}$

The air in the central filament which strikes the mouth of the impact tube starts from a low or negligible speed in the approach pipe, expands to atmospheric pressure at the mouth of the nozzle, and is accelerated to a high speed there. It is then decelerated and brought to rest at the mouth of the impact tube, and its pressure rises from atmospheric to the pressure in the tube. The relation described above shows that the final pressure of the air when brought to rest is, as nearly as we can tell, exactly equal to the initial static pressure it would have had in the approach pipe if the pipe had been very large and the speed of approach negligible; and that so far as speed and static pressure are concerned the second half of the process is an exact reversal of the first half.

It follows from this that if (17) does, in fact, give the speed of the jet accurately, from observations of the initial and final static pressures and the initial temperature (needed for computing $\rho$ ), (18) gives the speed of a stream of air to the same degree of accuracy from obser-

\footnotetext{
${ }_{18}$ Trans. Am. Soc. Mech. Eng., 38, p. 761; 1916. See also a recent paper presented at the annual meeting of the society; December, 1927.

${ }_{10}$ Under some very special conditions the relation might be expected to fail, but these conditions would never occur in ordinary practice. See M. Barker; Proc. Roy. Soc., A-101, p. 435; Aug. 1, 1922.
} 
vations of the impact pressure $\Delta$ and of the static pressure and temperature of the undisturbed stream. Hence, if we admit the force of the reasons set forth above for regarding (17) as accurate for the core of a jet, we must accept (18) as confirmed empirically, without any further discussion of the physics of the impact tube.

There is, however, a quite different way of looking at the matter. Let us ignore the arguments hitherto advanced in favor of the accuracy of (17) and start afresh from the experimental fact that when an impact tube is placed in the jet from the mouth of the nozzle the expansion and acceleration through the nozzle are reversed by the compression and deceleration in front of the impact tube.

This is, of course, just what would happen if the whole process of expansion and recompression were completely reversible and isentropic, for on this condition both (17) and (18) are exact, and the experimental relation necessarily follows; but while this condition is sufficient it is not strictly necessary, for it is conceivable that both parts of the process might be irreversible, and yet the departures from the ideal conditions might happen to offset each other in such a way that both equations were always in error by the same amount and the experimental relation still subsisted.

If the conditions of expansion along a core filament to the end of the nozzle were at all like those of the recompression along the central filament ahead of the impact tube, such a compensation of errors might seem possible; but when we consider the dissimilarity of the two processes it seems almost infinitely improbable that there should be any compensation of this sort. There are obvious causes to prevent either process from being exactly reversible and isentropic, but these causes are so different, while their effects, if any, are the same, that the only rational conclusion to be drawn is that the effects are insignificant in both cases; and from this it follows that the ideal conditions for the validity of (17) and (18) are so nearly realized in practice that the departures from them may be ignored and the equations regarded as sensibly exact.

This second method of justifying the use of the theoretical formulas is much simpler than the former one, and it is based on a single well established experimental fact, namely, the existence of the relation pointed out by Moss, which is known to hold to an accuracy of 1 in 1,000 at worst. Most readers will probably find the argument more satisfactory than the earlier one; but in any event it seems safe to assume, in the absence of convincing experimental proof to the contrary, that, so far as the equations themselves are concerned and aside from errors in the measurements of pressure and temperature, the equations will give the true values of the speeds in question to an accuracy of 1 part in 1,000 or better, and they will henceforth be accepted without further discussion of their accuracy. 
The employment of the impact tube in calibrating a nozzle so as to determine the value of its discharge coefficient $C=M / M_{\mathrm{t}}$ will be considered in Appendix B. At present we have only to supplement the theoretical discussion of the flow nozzle by showing how the theoretical mass flow $\dot{M}_{\mathrm{t}}$ may be computed in practice from the observations of pressure, temperature, and humidity.

Direct substitution of $S$ from (17) into (8) gives us

$$
\left.M_{\mathrm{t}}=\frac{\pi}{4} D^{2} \sqrt{\frac{2 \gamma}{\gamma-1} p \rho\left[\left(\frac{p_{\mathrm{o}}}{p}\right)^{\frac{\gamma-1}{\gamma}}-1\right.}\right]
$$

and by (12) we have

$$
p_{\rho}=p_{\mathrm{o}} \rho_{\mathrm{o}} \frac{p}{p_{\mathrm{o}}} \cdot \frac{\rho}{\rho_{\mathrm{o}}}=p_{\mathrm{o}} \rho_{\mathrm{o}}\left(\frac{p}{p_{\mathrm{o}}}\right)^{\frac{\gamma+1}{\gamma}}
$$

whence by (19)

$$
M_{\mathrm{t}}=\frac{\pi}{4} D^{2} \sqrt{\frac{2 \gamma}{\gamma-1} p_{\mathrm{o}} \rho_{\mathrm{o}}\left[\left(\frac{p}{p_{\mathrm{o}}}\right)^{\frac{2}{\gamma}}-\left(\frac{p}{p_{\mathrm{o}}}\right)^{\frac{\gamma+1}{\gamma}}\right]}
$$

which is the form into which (16) degenerates when $\beta$ is small, as it was in the present experiments.

For air in the vicinity of atmospheric pressure and temperature the specific heat ratio is very nearly $\gamma=1.40$, so that (21) reduces to

$$
M_{\mathrm{t}}=2.078 D^{2} \sqrt{p_{\mathrm{o}} \rho_{\mathrm{o}}\left[\left(\frac{p}{p_{\mathrm{o}}}\right)^{\frac{1.0}{\gamma^{2}}}-\left(\frac{p}{p_{\mathrm{o}}}\right)^{\frac{17^{2}}{2}}\right]}
$$

Hitherto, all equations have been given in terms of normal units, so that in (22), if $M_{\mathrm{t}}$ is expressed in lb./sec. and $\rho_{0}$ in lb./ft. ${ }^{3}, D$ must be measured in feet and $p_{0}$ and $p$ in poundals/ft. ${ }^{2}$. If we now express $D$ in inches and $p_{0}$ and $p$ in $\mathrm{lb} . /$ in. $^{2}$, the numerical factor

$$
\frac{\sqrt{144 \times 32.174}}{144}=0.47268
$$

must be introduced and (22) becomes, with these new units

$$
M_{\mathrm{t}}=0.98222 D^{2} \sqrt{p_{\mathrm{o}} \rho_{\mathrm{o}}\left[\left(\frac{p}{p_{\mathrm{o}}}\right)^{\frac{10}{7}}-\left(\frac{p}{p_{\mathrm{o}}}\right)^{\frac{1,2}{t^{2}}}\right]}
$$

The diameter $D$ is a known constant for each nozzle and $p_{\mathrm{o}}$ and $p$ are observed directly, but the value of $\rho_{0}$ has to be found from the pressure, temperature, and humidity of the air in the approach pipe. The method of computation and the necessary data on air have already been described in Section XI of the body of the paper, and the result is expressed there by equation (26). Since the range of pressure at the nozzle is small, we may set $Y=1$ and we then have, for our present purpose,

$$
\rho_{0}=2.6914 \frac{p_{0}}{458+t}\left(1-0.38 \frac{\pi}{p_{0}}\right)
$$


in which $t^{\circ} \mathrm{F}$. is the temperature of the approaching air, and $\pi \mathrm{lb} . / \mathrm{in}^{2}{ }^{2}$ is the partial pressure of the water vapor in it. Upon substituting this value of $\rho_{0}$ in (23) we get as the final equation for computing $M_{\mathrm{t}}$

in which:

$$
M_{\mathrm{t}}=1.6114 D^{2} p_{\mathrm{o}} \sqrt{\frac{1-0.38 \frac{\pi}{p_{0}}}{458+t_{\mathrm{o}}}\left[\left(\frac{p}{p_{\mathrm{o}}}\right)^{\frac{1,0}{\gamma^{2}}}-\left(\frac{p}{p_{\mathrm{o}}}\right)^{\frac{1,2}{2}}\right]}
$$

$M_{\mathrm{t}}[\mathrm{lb} . / \mathrm{sec}]=$. the theoretical rate of discharge;

$D$ [ins.] = the throat diameter of the nozzle;

$p_{0}\left[\mathrm{lb} . / \mathrm{in} .{ }^{2}\right]=$ the static pressure in the discharge trunk;

$p\left[\mathrm{lb} . / \mathrm{in} .{ }^{2}\right]=$ the pressure of the outside atmosphere;

$\pi\left[\mathrm{lb} . / \mathrm{in} .{ }^{2}\right]=$ the partial pressure of the water vapor in the air in the trunk; and

$t\left[^{\circ} \mathrm{F}.\right]=$ the temperature of the air in the trunk.

\section{Appendix B. DISCHARGE COEFFICIENTS OF THE NOZZLES}

It has been shown in Appendix A that the theoretical equations $(12,17)$ may be regarded as giving the actual values of the density and speed, without appreciable error, for all points of the section A within the uniform core of the jet, and these equations lead to the expressions $(19,21,22,23,25)$ for the "theoretical" rate of discharge which would occur if the core filled the whole throat of the nozzle. But since, in reality, the speed is lower in the immediate vicinity of the wall than farther away, the actual rate of discharge is less than the theoretical rate, and the next problem is to find how the theoretical rate must be corrected to allow for the actual departure from uniformity of conditions near the boundary of the jet.

The only experimental method available for investigating the state of affairs in the variable region consists in observing the impact pressure in a fine impact tube set at various distances from the axis of the jet, and we have now to consider how the results of such observations may be interpreted and utilized.

The walls of the pipe and nozzle formed a surface of revolution, and after the approaching stream had been straightened by passing through the honeycombs, conditions in the jet appeared to be nearly symmetrical about the axis of the nozzle. The arithmetical mean of readings of the impact pressure at a given radius but in several uniformly spaced azimuths was therefore taken to represent the reading that would have been obtained everywhere at that radius if the flow had been completely symmetrical, and we proceed to consider the properties of a symmetrical jet.

In accordance with the notation employed in Appendix A, let $\rho_{\mathrm{r}}, S_{\mathrm{r}}$, etc., denote the density, speed, etc., in the exit section A at the radius $r$, and let $a$ be the radius of this section. 
The mass flow through a ring shaped element of $A$, of radius $r$ and width $d r$, is

$$
d M=2 \pi r d r \rho_{\mathrm{r}} S_{\mathrm{r}}
$$

whereas if the density and speed at this radius had the theoretical values given by $(12,17)$ the mass flow would be

$$
d M_{\mathrm{t}}=2 \pi r d r \rho S
$$

For this element of the area, the ratio of actual to theoretical flow is $\rho_{\mathrm{r}} S_{\mathrm{r} /} / \rho S$, and the discharge coefficient of the nozzle is the average value of this ratio for the whole area of the section. We therefore have the equation

$$
C=\frac{1}{\pi a^{2}} \int_{0}^{a} 2 \pi r \frac{\rho_{\mathrm{r}} S_{\mathrm{r}}}{\rho S} d r=\int_{0}^{1} \frac{\rho_{\mathrm{r}} S_{\mathrm{r}}}{\rho S} d\left(\frac{r}{a}\right)^{2}
$$

or if we abbreviate by setting

$$
\left(\frac{r}{a}\right)^{2}=x \text { and } \frac{\rho_{\mathrm{r}} S_{\mathrm{r}}}{\rho S}=y
$$

we have

$$
C=\int_{0}^{1} y d x
$$

If the values of $y$ can be determined and the curve

$$
y=f(x)
$$

drawn, the value of $C$ may then be found graphically by measuring the area inclosed by the curve, the axes, and the ordinate at $x=1$. If $A B C$ in Figure 10 represents the curve, the value of the discharge coefficient is given by

$$
C=\text { area } \overline{\mathrm{OABCDO}}=1-\text { area } \overline{\mathrm{BECB}}
$$

This procedure can not be followed strictly, because there is no practicable way of determining the required values of $y$ according to the definition in (29). But approximate values may be obtained from measurements of impact pressure, and under the conditions prevailing in our ex- $\mathrm{O}$ periments the approximation is close



Fig. 10 enough that the foregoing graphical method may be followed without serious error. 
It was shown in Appendix A that, for an impact tube in a uniform stream of air, equation (18) may be relied on as a sensibly accurate relation connecting the observed impact pressure with the speed, density, and static pressure of the undisturbed stream. With $\gamma=1.40$, as for air, the equation is

$$
S=\sqrt{7 \frac{p}{\rho}\left[\left(\frac{p+\Delta}{p}\right)^{\frac{2}{7}}-1\right]}
$$

and after developing $(1+\Delta / p)^{\frac{3}{7}}$ by the binomial theorem, this may be reduced to

$$
S=Q \sqrt{\frac{2 \Delta}{\rho}}
$$

in which

$$
Q=\left[1-\frac{5}{14} \frac{\Delta}{p}+\frac{10}{49}\left(\frac{\Delta}{p}\right)^{2}-\frac{95}{686}\left(\frac{\Delta}{p}\right)^{3}+\frac{247}{2401}\left(\frac{\Delta}{p}\right)^{4}-\cdot-\text { etc. }\right]^{\frac{1}{2}}
$$

Equations $(34,35)$ are usually more convenient than (33) for numerical computation, and they are more suitable to our present purpose.

If the speed of the stream in which the impact tube is placed varies transversely, as it does near the boundary of the jet from a nozzle, and if the observed value of $\Delta$ is substituted in $(34,35)$, the resulting value of $S$ is the speed of a uniform stream, of the given density and static pressure, which would set up the pressure actually observed in the impact tube. This fictitious uniform speed is some sort of average of the speeds upstream from the mouth of the tube and is between the highest and lowest of them; but it is not necessarily equal to the speed that would exist at the present position of the geometrical center of the mouth if the impact tube were removed. And when the impact pressure has been measured with the geometrical center of the tip at a known distance from the axis of the nozzle, and the corresponding uniform speed has been computed from $(34,35)$, some uncertainty remains as to the radius at which the speed of the jet really has this value.

The uncertainty diminishes with the diameter of the impact tip, and the obvious remedy for it is to make the tip very fine; but the possibilities in this direction are limited, both by mechanical difficulties and by the fact that (33) ultimately ceases to hold, even for a uniform stream. ${ }^{20}$ The tip used in all our final calibrations had a diameter of about 0.02 inch, and this, though small, was not entirely negligible, as will be noted later.

The task of interpreting the results of an impact tube calibration is further complicated by the necessity of traversing the tip in a plane that clears the end of the nozzle instead of exactly in the plane A where the cylindrical throat of the nozzle terminates. It

${ }^{20}$ See M. Barker, Proc. Roy. Soc., A 101, p. 435, Aug. 1, 1922. 
did not appear that there was any appreciable spreading of the free jet in the short distance between these planes; but when the impact tube was moved entirely outside the jet, so that its tip faced the flat end of the nozzle, with a clearance of a few thousandths of an inch, there was still a considerable excess pressure in the tube. This can not have been due to direct impact of the jet, and whatever its cause it was spurious as an indication of impact pressure.

We shall start, however, by ignoring the difficulties just mentioned and shall assume that values of $\Delta_{r}$ have been obtained with a tip of negligible diameter in the plane $\mathrm{A}$. The effects of the actual departures from these ideal experimental conditions will be considered subsequently.

For a point at the radius $r$ (34) takes the particular form

$$
S_{\mathrm{r}}=Q_{\mathrm{r}} \sqrt{\frac{2 \Delta_{\mathrm{r}}}{\rho_{\mathrm{r}}}}
$$

in which $Q_{\mathrm{r}}$ is defined by (35) with $\Delta_{\mathrm{r}} / p_{\mathrm{r}}$ in place of $\Delta / p$; and from $(34,36)$ we have, as a new expression for $y$,

$$
y=\frac{\rho_{\mathrm{r}} S_{\mathrm{r}}}{\rho S}=\frac{Q_{\mathrm{r}}}{Q} \sqrt{\frac{\rho_{\mathrm{r}} \Delta_{\mathrm{r}}}{\rho \Delta}}
$$

Moreover, it may be shown that under the conditions of our experiments both $Q_{\mathrm{r}} / Q$ and $\rho_{\mathrm{r}} / \rho$ were so nearly unity that the simpler equation

$$
y=\sqrt{\frac{\Delta_{\mathrm{r}}}{\Delta}}
$$

was an adequate substitute for (37).

Before proceeding to justify this simplification it will be convenient to put equation (30) into a slightly different form. Let $r_{\mathrm{c}}$ denote the radius of the uniform core; let

$$
\left(\frac{r_{e}}{a}\right)^{2}=w
$$

and let (30) be written in the form

$$
C=\int_{0}^{w} y d x+\int_{w}^{1} y d x
$$

Within the core $\Delta_{\mathrm{r}}=\Delta$ and $\rho_{\mathrm{r}} S_{\mathrm{r}}=\rho S$. Hence, for $x \equiv w, y=1$, whether defined by the exact equation (37) or by the approximate equation (38). Equation (40) may now be put into the form

$$
C=w+(1-w) \bar{y}
$$

in which $(1-w) \bar{y}$ represents the area $\overline{\mathrm{BCDFB}}$ of Figure 10 and $\bar{y}$ is the mean ordinate of the part of the curve between $\mathrm{B}$ and $\mathrm{C}$, which refers to the variable region near the boundary. Any error in the 
location of the curve $y=f(x)$ due to using (38) instead of (37) can affect only this outer part of the curve.

We return to the consideration of $\rho_{\mathrm{r}} / \rho$. In normal operation the mouth of the nozzle is kept somewhat warmer than the cold core of the expanded jet by the flow of heat through the metal from the entrance end which is in contact with the warmer air entering it; and since the temperature of the surface film of air is largely, if not completely, controlled by that of the metal in contact with it, the temperature of the air at the boundary of the jet as it leaves the throat will be somewhere between the initial temperature $\theta_{0}$ and the temperature $\theta$ reached by isentropic expansion in the core.

The greatest conceivable effect of this sort would be to prevent the surface film from cooling at all and make the expansion along the wall isothermal; and since the static pressure is sensibly uniform all over A, the final density at the boundary would then be

$$
\rho_{\mathrm{a}}=\rho_{\mathrm{o}} \frac{p}{p_{\mathrm{o}}}
$$

The final density in the core, as given by (12) with $\gamma=1.40$, is

$$
\rho=\rho_{\mathrm{o}}\left(\frac{p}{p_{\mathrm{o}}}\right)^{\frac{s}{5}}
$$

so that in the ideal extreme case we have

$$
\sqrt{\frac{\rho_{\mathrm{a}}}{\rho}}=\left(\frac{p}{p_{\mathrm{o}}}\right)^{\frac{1}{7}}<1
$$

At any intermediate radius between $r=r_{\mathrm{c}}$ and $r=a$ the value of $\sqrt{\rho_{\mathrm{r}} / \rho}$ will always be between unity and the extreme lowest value given by (44); and if $d \bar{y}$ denotes the amount by which the mean ordinate $\bar{y}$ is overestimated when the variation of density is ignored, an outside limit for this error is given by

$$
\frac{d \bar{y}}{\bar{y}}<1-\sqrt{\frac{\rho_{\mathrm{a}}}{\rho}}=1-\left(\frac{p}{p_{0}}\right)^{\frac{2}{\gamma}}
$$

The resulting positive error in $C$ is then, by $(41,45)$

$$
d C=(1-w) d \bar{y}<(1-w)\left[1-\left(\frac{p}{p_{0}}\right)^{\frac{1}{7}}\right] \bar{y}
$$

and since $\bar{y}$ is always less than unity, an outside value for the error in $C$ is given by

$$
d C<(1-w)\left[1-\left(\frac{p}{p_{0}}\right)^{\frac{1}{7}}\right]
$$


The effect of setting $Q_{r}=Q$ may be treated in a somewhat similar manner. Equation (35) shows that $Q<1$, and that as $\Delta_{r}$ decreases toward the boundary of the jet $Q_{r}$ increases, its limiting value being $Q_{a}=1$, if $\Delta_{a}=0$. Ignoring this variation and setting $Q_{r}=Q$ for all values of $r$ results in an underestimate of $\bar{y}$ and of $C$, and outside limits for these negative errors are given by

$$
-\frac{d^{\prime} \bar{y}}{2}<1-Q
$$

and

$$
-d^{\prime} C<(1-w)(1-Q)
$$

For numerical values we turn to the experimental data. The greatest pressure drop at which any of the nozzles was calibrated was $\Delta=2.6 \mathrm{lb}$./in. ${ }^{2}$, and at this rate of flow the observed radius of the uniform core gave $w=0.95$ for the smallest nozzle. With these values, we find from $(47)$ and from $(35,49)$

$$
d C<0.0012 ;-d^{\prime} C<0.0015
$$

This same nozzle running at $\Delta=0.6 \mathrm{lb} . / \mathrm{in} .^{2}$ gave $w=0.93$, whence

$$
d C<0.0006 ;-d^{\prime} C<0.0005
$$

At any given pressure drop the larger nozzles gave higher values of $w$ and therefore lower values of $d C$ and $-d^{\prime} C$.

It thus appears that the greatest conceivable errors in $C$ which could be caused by setting $Q_{\mathrm{r}}=Q$ in (37) are of the same order of magnitude as those caused by setting $\rho_{\mathrm{r}}=\rho$, but of opposite sign, and that both kinds of error are separately very small. The approximation involved in passing from (37) to (38) is therefore amply close and (38) may be used without further scruple.

This point having been established, the first step in finding the discharge coefficient of a nozzle when running at a constant pressure drop $\Delta$, from the values of $\Delta_{r}$ observed during the calibration, was to plot the values of $\sqrt{\Delta_{\mathrm{r}} / \Delta}$ against those of $(r / a)^{2}$ and to draw, as nearly as possible through the resulting points, a smooth curve

$$
\sqrt{\frac{\Delta_{\mathrm{r}}}{\Delta}}=f\left(\frac{r^{2}}{a^{2}}\right)
$$

such as is represented qualitatively by $\mathrm{ABC}$ in Figure 10. This was an approximation to the curve that would have been obtained from perfectly accurate observations, made in the ideal manner with an impact tip of negligible diameter, traversed exactly in the plane of the section $\mathrm{A}$. The area $\overline{\mathrm{BECB}}$ was therefore measured, and a 
provisional approximate value of the discharge coefficient of the nozzle was found from the relation

$$
C=1-\text { area } \overline{\mathrm{BECB}}
$$

Figure 11 shows three sample curves drawn from observations on a nozzle of 3.262 inches diameter with the impact tip of 0.02-inch diameter. The positions of the plotted points are subject to the errors of measuring the impact pressure and of setting the tip at the intended radius, the former being halved and the latter doubled. The uncertainty of setting was estimated to be about \pm 0.003 inch, and this corresponds in Figure 11 to a horizontal displacement of nearly four of the smallest scale divisions, so that the abscissa of a point representing a single observation might be in error by this amount. Accidental errors were, however, partly eliminated in



FIG. 11

averaging a number of observations taken in different azimuths at the same nominal radius, and the smoothness of the curves indicates that the remaining accidental errors were small.

But assuming that these errors are very small and that the curves are a sensibly accurate representation of the facts, it is evident that they differ systematically from what might be expected of an ideal calibration; for there can be no doubt that the air adheres to the nozzle, or that the speed of the stream, so long as it is still inside the nozzle, is entirely inappreciable at the wall $;^{21}$ and curves obtained from accurate observations made in the ideal manner would all meet at the point $(x=1, y=0)$ represented by $D$ in Figures 10 and 11. It is the ideal curves that are needed in order that the graphical method described above may give accurate values of $C$, so we must attempt to interpret the departures of the observed from the ideal curves and apply corrections for them.

\footnotetext{
${ }^{21}$ In this connection see Stanton, Marshall, and Bryant, Report Adv. Comm. Aeron. (Great Britian),
} $1919-20,1$, p. 51 . 
In a perfect nozzle the plane end would meet the cylindrical throat at a right angle. and the section $\mathrm{A}$ would be in the plane of the end face instead of a little inside, as it is in any real nozzle because the corner can not be made perfect, even if it is not intentionally rounded off or chamfered to prevent damage in handling.

If the end of the impact tip were ground perfectly flat and set so as, when moved out radially, to slide over the end of the nozzle, making perfect contact, with no clearance, the observations of impact pressure would be made in the plane of $A$, and the excess pressure in the impact tube would vanish as soon as the tip had been moved entirely outside the jet.

If $b$ denotes the radius of the tip, let

$$
\left.\begin{array}{c}
a-b=r_{\mathrm{I}} ;\left(\frac{a-b}{a}\right)^{2}=x_{\mathrm{I}} \\
a+b=r_{\mathrm{II}} ;\left(\frac{a+b}{a}\right)^{2}=x_{\mathrm{II}}
\end{array}\right\}
$$

As long as $x \equiv x_{I}$, the whole mouth of the tip is exposed to the impact of the jet; when $x_{I}<x<x_{I I}$, the mouth is only partly exposed, the outer part being covered; and when $x=x_{I I}$ the mouth is completely closed. As the tip is moved out through the boundary of the jet, the excess pressure in it must vanish when $r=r_{\text {II }}$, and curves obtained in the way described would all meet at the point $\left(x=x_{I I}\right.$, $y=0)$.

In the case of Figure 11, $a=1.631$ inches and $b=0.01$ inch, so that $x_{1}=0.988$ and $x_{I I}=1.012$. The lines marked $I$ and $I I$ are drawn -at these abscissas. Points on or to the left of $I$ represent observations with the tip entirely inside the jet; points between $I$ and $I I$ represent observations with the tip partly outside the geometrical prolongation of the throat of the nozzle; and for points to the right of $I I$-for example, points on line $I I I$ - the tip was entirely outside this prolongation.

The condition that the tip should make a perfect fit with the end face of the nozzle was, of course, not satisfied, and the effect of the clearance is very evident from the form of the outer part of the curves. A free jet from a nozzle always entrains the outside air and sets up a circulation in the vicinity. In some way which can not be specified this circulation caused an excess pressure in the slit between the edge of the tip and the end of the nozzle and gave a spurious reading which was not due to the impact of the jet.

This induced circulation is maintained by viscosity, and the effects of viscosity are proportional to the first power of the speed, whereas true impact pressure is proportional to the second power. It is therefore to be expected that the pressure due to the circulation will increase less rapidly with the speed of the jet than does the impact 
pressure and will be relatively less pronounced at high than at low speeds. This means that in Figure 11 the observed points on line III should be lower as the value of $\Delta$ is higher, as they are, in fact. On the other hand, the absolute values of $\Delta_{r}$ for these points should increase with $\Delta$, and this expectation is also confirmed, though it is not at once evident from the figure.

For very low jet speeds it is conceivable that the effects of the induced circulation might even extend inside the prolongation of the throat of the nozzle; but, in general, it is to be expected that when the tip is entirely within this prolongation it will be free from such effects. Accordingly, we find that the observed points to the left of line $I$ lie on curves which might, without violence, be made to pass through the point $D^{\prime}$; and except for the lowest speed this is true also of the points at $x=0.999$, where the tip was nearly half outside the prolongation of the throat.

The question now is, how ought the observed curves to be corrected so as to give values of $C$ which are unaffected by the induced circulation and by the size of the tip? A precise answer is impossible, but our actual procedure was as follows:

It was first assumed that if the clearance had been reduced to zero the curves would all have met at the point $D^{\prime}$. The distance of $D^{\prime}$ from $D$ is

$$
D D^{\prime}=2 \frac{b}{a}+\left(\frac{b}{a}\right)^{2}
$$

and if $b / a$ were negligible, the two points would be sensibly coincident. The foregoing assumption means, therefore, that if the effects of induced circulation were eliminated and the diameter of the tip were negligible the curves would meet at $D$. This was accordingly taken to be one point on each corrected curve.

It was then further assumed that as long as the tip was entirely within the prolongation of the throat of the nozzle the effective center of the tip was at its geometrical center. In other words, it was assumed that so long as $r \sum a-b$ the speed computed from the observed $\Delta_{\mathrm{r}}$ by $(34,35)$ was the true speed at the radius $r$. This means that in Figure 11 the curves were taken to be correct, out as far as the line $I$.

Each curve was then corrected by drawing a straight line from the point where it cut the line $I$ to the point $D$. The area between this line and the curve as first drawn was measured, and its value was subtracted from the earlier, approximate value of $C$ to give a final corrected value.

With respect to the second of the two assumptions, it may be remarked that when the tip was barely inside the jet, with its geometrical center at $r=a-b$, it was in a region of rapidly varying speed, 
and that it is probable that its effective center was slightly displaced toward the axis of the nozzle. If so, the point where the curve cuts line $I$ is too high and failure to allow for this makes the correction too small. On the other hand, the curve is doubtless convex throughout, and treating the last part as a straight line makes the correction to $C$ too large. The compromise adopted, for want of anything better, gives only a rough estimate of the correction, but the whole value was insignificant in most cases.

The curves given in Figure 11, which have been used for illustration, are fairly typical of the numerous others, though the turnup at the end was often less pronounced and the curves sometimes came closer to the point corresponding to $D$. Consistency in this regard was not to be expected, because the clearance was not always the same, even for the same nozzle, but varied irregularly with the azimuth in which the slide carrying the impact tube was set.

The corrections to $C$ obtained from the curves for any one nozzle running at various rates did not differ greatly and an average value was used for each nozzle at all values of $\Delta$. These average values were as given in Table 24 .

\section{TABLE 24}

\begin{tabular}{|c|c|c|c|}
\hline Nozzle & $\begin{array}{l}\text { Correc- } \\
\text { tion (to } \\
\text { be sub- } \\
\text { tracted) }\end{array}$ & Nozzle & $\begin{array}{l}\text { Correc- } \\
\text { tion (to } \\
\text { be sub- } \\
\text { tracted) }\end{array}$ \\
\hline $\begin{array}{l}\mathrm{D}-1 \\
\mathrm{~A}-1 \\
\mathrm{~A}-2 \\
\mathrm{~A}-3\end{array}$ & $\begin{array}{r}0.0032 \\
.0018 \\
.0016 \\
.0019\end{array}$ & $\begin{array}{l}\mathrm{A}-4 . \\
\mathrm{B}-2_{-} \\
\mathrm{C}-1_{-} \\
\mathrm{C}-2_{-}\end{array}$ & $\begin{array}{r}0.0013 \\
.0013 \\
.0011 \\
.0011\end{array}$ \\
\hline
\end{tabular}

In view of the smallness of these corrections, it seems very unlikely that errors in the method of estimating them, described above, can in any case have affected the final value of $C$ by as much as \pm 0.001 .

Figure 12 shows the calibration curves giving the values of the discharge coefficient $C$ in terms of the pressure drop through the nozzle in inches of water. The separate points representing the different calibration runs are put in so that the reader may form his own opinion of the consistency of the observations on each nozzle. No curve is given for nozzle B-1, which was used in only one of the orifice tests recorded in this paper.

Nozzles D-1 and A-2 were calibrated at higher differentials, and in each case three more points were obtained, which would be far off the sheet to the right but are entirely consistent with the curves as shown. The highest nozzle differential in any of the orifice tests was about 27 inches of water, so that Figure 12 gives the parts of the curves actually needed in reducing the observations on the orifices. 
With the exception of the six points for $\mathrm{D}-1$ and $\mathrm{A}-2$, mentioned above, the points given represent all the calibrations that were made with the exploring tip of 0.02 inch diameter. In the earlier stages of the work a number of calibrations with several exploring tips of larger diameter were carried out and gave points which were considerably more scattered than those shown in the figure, probably because of

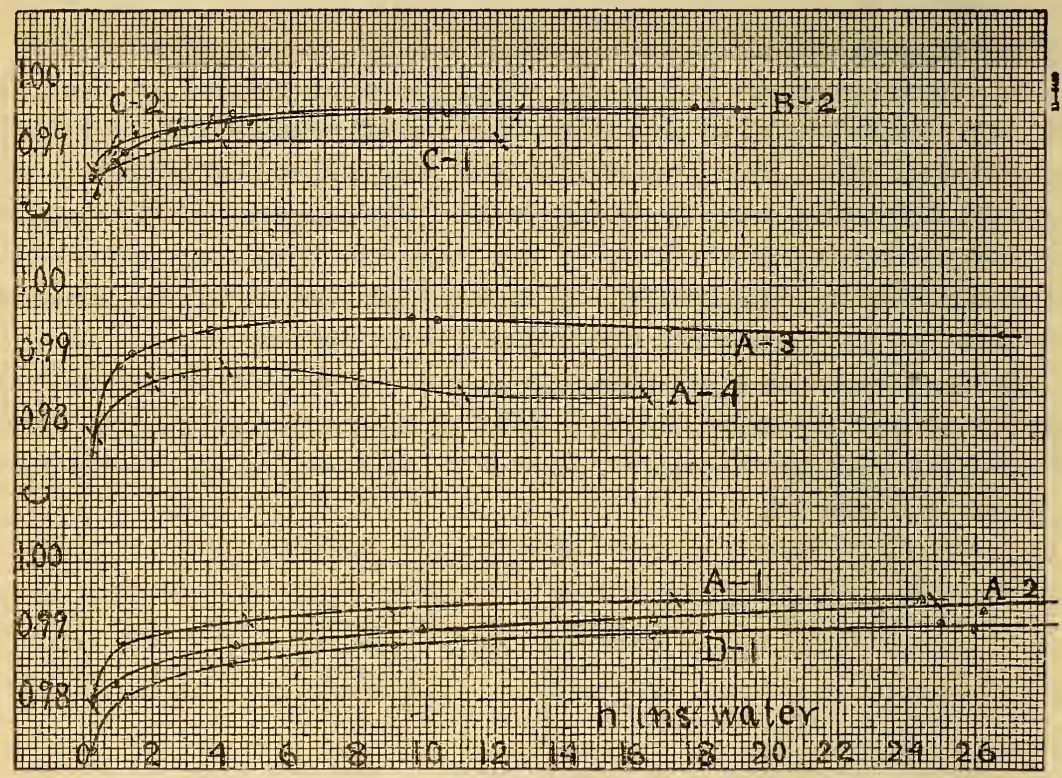

Fig. 12.-Discharge coefficients of flow nozzles

lack of experience in the manipulations. All these earlier observations were discarded.

\section{TABLE 25}

\begin{tabular}{|c|c|c|c|c|}
\hline \multirow[b]{2}{*}{ Nozzle } & \multirow{2}{*}{$\begin{array}{c}\text { Diameter } \\
\text { inches }\end{array}$} & \multirow[b]{2}{*}{$\begin{array}{l}\text { Times } \\
\text { used }\end{array}$} & \multicolumn{2}{|c|}{$\begin{array}{c}\text { Differential at } \\
\text { nozzle }\end{array}$} \\
\hline & & & $\begin{array}{c}\text { Greatest } \\
h \text { (max.) } \\
\text { inches } \\
\text { water }\end{array}$ & $\begin{array}{l}\text { Least } \\
h \text { (min.) } \\
\text { inches } \\
\text { water }\end{array}$ \\
\hline 1 & 2 & 3 & 4 & 5 \\
\hline 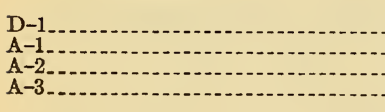 & $\begin{array}{l}\text { 1. } 764 \\
\text { 3. } 255 \\
\text { 3. } 265 \\
\text { 3. } 272\end{array}$ & $\begin{array}{r}57 \\
5 \\
154 \\
7\end{array}$ & $\begin{array}{l}27 \\
13 \\
18 \\
26\end{array}$ & $\begin{array}{l}0.25 \\
1.12 \\
.16 \\
.26\end{array}$ \\
\hline $\begin{array}{l}\mathrm{A}-4- \\
\mathrm{B}-2-1 \\
\mathrm{C}-2-1\end{array}$ & $\begin{array}{l}\text { 3. } 258 \\
4.521 \\
5.006 \\
5.003\end{array}$ & $\begin{array}{l}1 \\
62 \\
16 \\
63\end{array}$ & $\begin{array}{l}17 \\
17 \\
12 \\
12\end{array}$ & $\begin{array}{l}17.21 \\
4.1 \\
2.7\end{array}$ \\
\hline
\end{tabular}


The nozzles were not all employed to the same extent nor over the same range of differentials. In Table 25 column 3 gives the number of orifice tests in which each nozzle was used, each such test including observations on three orifices in series. Columns 4 and 5 give approximate values of the greatest and least differentials at the nozzles in the orifice tests. The lowest differentials were measured on an inclined water manometer.

Upon examination of Figure 12 it appears that $(a)$ so far as can be judged, the points which determine each curve are consistent among themselves within about \pm 0.001 in the values of $C$; and $(b)$ the best determined curves are those for the four nozzles (D-1, A-2, B-2, C-2) which were employed in most of the orifice experiments (336 out of 363).

Whether the different curves are consistent with one another is a question which could not be answered with certainty except by running two or more nozzles in series. We had no facilities for this, but in a great many cases two or more nozzles were used in testing a given orifice. If the discharge coefficients of the nozzles had not been consistent among themselves, the discharge coefficients of the orifice would have shown systematic variations, according to the flow nozzle used; but no such systematic variations were found.

It seems to us probable that the absolute accuracy of the nozzle coefficients read from the curves which are represented on a small scale in Figure 12 was considerably better than \pm 0.3 per cent; and we think that under favorable conditions of steadiness in the supply of air or gas, and with sufficient care in calibration by means of a fine impact tube nozzles of this character and of these sizes or larger may be made reliable as primary standard flow meters to within \pm 0.1 per cent.

\section{Appendix C. SIMILAR ORIFICES}

If a stream of fluid is forced along a pipe line at a fixed rate of discharge, any alteration of the line, such as the introduction of a valve or an elbow into what was previously a straight run of uniform pipe, modifies the motion for an appreciable distance ahead of the place where the change is made, and on the downstream side, eddies or whirls which may be set up are carried along for a considerable distance before dying out. Thus, the distribution of velocity and pressure at any fixed cross section depends on the nature of the line for some distance in both directions, and the discharge coefficient of an orifice installed in the line is influenced by the shape of the nearer parts of the piping, although changes of shape or disturbances set up at sufficiently distant points have no appreciable effect at the orifice. 
In treating the discharge coefficient of an orifice as a definite quantity it is therefore implied, and is always to be understood, that the nature of the line in which the orifice is installed is specified out to a sufficient distance in both directions that changes at still greater distances have no further appreciable effect on the discharge coefficient.

It is not necessary that the pipe be either straight or uniform, although that is the simplest shape to describe. What is required is merely that all peculiarities of shape be specified in sufficient detail that, aside from possible mechanical difficulties of construction, they could be reproduced, either on the same scale or on a different one, within such tolerances that the variations still permitted would not change the discharge coefficient by more than the accidental error of an experimental determination of its value.

It is also to be noted that the part of the line that requires specification may be limited to a comparatively short section by installing honeycombs or cellular grids a few pipe diameters before the upstream and after the downstream pressure tap. Such devices tend to protect the intervening region from disturbances which may originate farther away from the orifice, so that the nature of the rest of the line is no longer of any importance. If this plan is adopted, the design and location of the grids must evidently be included in the specification.

To avoid circumlocution, the term. "orifice" may be used to connote all these important features of the piping as well as the orifice plate itself, and on this understanding any two "orifices of the same shape" are geometrically similar in all essential respects. If they are also of the same size, they are mere duplicates, and under any given working conditions their discharge coefficients are equal. If they differ in size, their discharge coefficients will be equal under similar working conditions, if the term "similar" is suitably defined, and we have next to consider what meaning is to be assigned to "similar" in this connection.

For any given fluid the working conditions may be defined by the initial pressure and temperature and the rate of discharge; but since an orifice may be tested with various fluids, a general definition of the "working conditions" must include some reference to the properties of the fluid.

To simplify matters, it will first be supposed that the fluid is a liquid, so that its properties are sensibly independent of pressure, and compressibility does not come into the problem.

The discharge coefficient of a particular orifice for a given liquid at a given temperature may vary with the rate of discharge-that is, with the linear speed through the orifice-and if the properties of the liquid are varied, either by altering the temperature or by substituting a different liquid, it may again be found that the discharge coefficient has changed. For present purposes the most obviously important 
properties of the liquid are its density and viscosity. Sufficiently precise experiments would doubtless reveal the effects of altering other properties, but under ordinary circumstances these effects are inappreciable and, in practice, the values of density and viscosity may be regarded as constituting a complete characterization of the liquid with respect to flow along pipes or through orifices.

It follows from the foregoing that there is some relation connecting the discharge coefficient $C$ with the speed of flow $S$, the density of the liquid $\rho$, and its viscosity $\mu$. In other words, there is some equation

$$
C=f(S, \rho, \mu)
$$

which holds for this orifice and shows how its discharge coefficient depends on the working conditions specified by the values of $S, \rho$, and $\mu$.

The mathematical form of the functional symbol or operator $f$ remains entirely unknown until determined by experiment; but it is certain that some such equation exists, because changes of $S, \rho$, and $\mu$ do sometimes affect the value of $C$, and the list of variables is complete because, so long as the orifice remains unchanged there is nothing else of importance that can be varied independently.

For an orifice of another shape or size the operator $f$ may be of somewhat different form, and an equation which should hold generally for all orifices would evidently have to contain a sufficient number of geometrical quantities to account for all possible variations of shape and size; but if the problem is limited to orifices of any one shape, the only additional independent variable needed is a single linear dimension such as the orifice diameter $d$, and there is some equation

$$
C=F(S, \rho, \mu, d)
$$

which holds generally for all orifices of the given shape.

The form of $F$ depends on the shape and can be determined only by experiment, but it is subject to an important restriction which simplifies the experimental problem very much. This is the familiar condition that all the terms of the equation must be of the same dimensions. Now, the discharge coefficient $C$ is dimensionless, or of zero dimensions, for it is a pure ratio, and its value is independent of the unit by which the actual and theoretical rates of discharge are measured. Hence, all the terms in the second member of (55) must also be of zero dimensions, and in order that this may certainly be true, regardless of the still unknown form of the operator $F$, it is necessary and sufficient that all the operands or quantities operated on should be of zero dimensions. 
The quantities $S, \rho, \mu, d$ do not satisfy this condition, and they can, therefore, not appear separately but only in combinations, each of which, taken as a whole, is of zero dimensions. The expression

$$
\frac{d S \rho}{\mu}=R
$$

satisfies this requirement, as is evident upon substitution from the dimensional equations $[d]=[\mathrm{l}],[S]=\left[\mathrm{It}^{-1}\right],[\rho]=\left[\mathrm{ml}^{-3}\right]$, and $[\mu]=\left[\mathrm{ml}^{-1} \mathrm{t}^{-1}\right]$, and there is no other such combination. Hence, equation (55) is restricted to the more specific form

$$
C=\varphi\left(\frac{d S \rho}{\mu}\right)=\varphi(R)
$$

The form of $\varphi$ still remains to be found from experiment, but there is now only one independent variable $R$, instead of the four in (55); and when the experiments have been made, the results can be represented within the experimental errors by a plane curve.

The statement made above, that $R$ is the only dimensionless combination of $S, \rho, \mu, d$, is, of course, to be understood as meaning that there is no other combination which is independent of $R$. Such expressions as $R^{3}$ or $\log R$ are also of zero dimensions, but their values are fixed by that of $R$ and can not be varied independently of it. So long as the form of $\varphi$ remains indeterminate, equation (57) is merely a statement that the value of $C$ is fixed by that of $R$; and the introduction into the second member of any number of additional quantities, each one of which was itself completely determined by $R$, would not change the meaning of the equation in any way.

On the other hand, it is entirely permissible to replace $R$ by any other quantity which is determined by $R$. In other words, in representing the results of experiment by a plane curve with $C$ as ordinate, we may use any convenient function of $R$ as the abscissa in place of $R$ itself.

For example, the mass flow $M$ is connected with the density, the diameter of the orifice, and the mean linear speed through it, by the equation

so that

$$
M=\frac{\pi}{4} d^{2} \rho S
$$

$$
\frac{M}{d \mu}=\frac{\pi d S \rho}{4 \mu}
$$

Hence, the quantity

$$
\frac{M}{d \mu}=R^{\prime}=\frac{\pi}{4} R
$$

may serve in place of $R$, and equation (57) is equivalent to an equation

$$
C=\psi\left(R^{\prime}\right)
$$


Since the diameter ratio $\beta$ is one element of "the given shape," the pipe diameter $D$ is fixed by $d$ and the quantity

$$
\frac{M}{D \mu}=R^{\prime \prime}=\frac{\pi}{4} \beta R
$$

is another possible substitute for $R$. Or if $S_{0}$ denotes the mean linear speed along the pipe, the quantity

$$
\frac{D S_{\circ} \rho}{\mu}=R^{\prime \prime \prime}=\beta R
$$

may also serve as an independent variable; that is, as an abscissa against which observed values of $C$ may be plotted as ordinates.

In discussions of the loss of head in pipes the quantity $R^{\prime \prime \prime}$ defined by (63) is commonly called "the Reynolds number," though other expressions derived from it might equally well receive that name, and the same term is often used of the analogous quantities which occur in the investigation of other problems in fluid motion, such as the forces on airplanes. In the case of an orifice it may be applied to any one of the quantities defined by (56), (60), (62), and (63) or to any other quantity which is fixed by them.

In any event, the conclusion reached by the argument from dimensions may be expressed by the statement that, for orifices of any one shape, the discharge coefficient for liquids is a function of the Reynolds number only. The values of $C$ for all orifices of the specified shape, whatever the absolute size of the orifice or the nature of the liquid or the rate of discharge, may be represented by a single curve which pertains to and is fixed by the particular shape in question; and when the curve has been determined by experiment. the value of $C$ under any future conditions may be found by computing the value of the Reynolds number for these conditions and reading the value of $C$ from the curve.

If the Reynolds number has the same value in two different experiments on orifices of the given shape, the discharge coefficients will be equal, and the phrase "similar working conditions," which was used earlier, is to be interpreted as meaning "conditions under which the Reynolds number has the same value." This state of affairs-geometrically similar orifices operating under similar working conditions or at the same Reynolds number-is often described by saying that the phenomena are "dynamically similar," and the equality of the discharge coefficients of geometrically similar orifices at equal values of the Reynolds number is a particular result of what is commonly known as the "principle of dynamical similarity."

The foregoing discussion has referred only to liquids, and in order to extend it to gases the additional property of compressibility must be taken into account. This presents no great difficulty, but without any further development of the dimensional reasoning it is sufficiently $14830^{\circ}-29-T$ 
obvious that if the fall of pressure at the orifice is only a small fraction of the absolute static pressure the change of density can have only an insignificant effect, and the gas will behave sensibly like a liquid. If the curve $C=\varphi(R)$ has been determined for orifices of a particular shape by experimenting on liquids, the same curve is therefore applicable to gases, provided that the percentage differential is very small. Hodgson's experimental results are in entire agreement with this statement.

Since the purpose here has been merely to present the idea of the Reynolds number and to emphasize its importance for the benefit of readers who are not already familiar with the subject, ${ }^{22}$ it is unnecessary to enter upon a detailed discussion of the experimental data which have been published or of the forms of the curves for orifices of different diameter ratios. The data have been examined, and the conclusion drawn from them regarding the effects of viscosity in commercial orifice meter practice has been stated in section 24 of the body of the paper.

Washington, August 22, 1928.

${ }_{22}$ For further discussion of the dimensional method see E. Buckingham, Model experiments and the forms of empirical equations, Trans. Am. Soc. Mech. Eng., 3\%, p. 262; 1915. 